\title{
FARM IMPLEMENTS FOR SMALL-SCALE FARMERS IN TANZANIA
}

Björn Mothander

Finn Kjærby

Kjell Havnevik

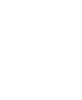




\section{FARM IMPLEMENTS FOR SMALL-SCALE FARMERS IN TANZANIA}

Björn Mothander Finn Kjærby

Kjell Havnevik

Scandinavian Institute of African Studies, Uppsala 1989 
ISBN 91-7106-290-4

(C) The authors and Nordiska afrikainstitutet, 1989

Printed in Sweden by

Motala Grafiska, Motala 1989 


\section{TABLE OF CONTENTS}

List of Abbreviations $\quad 7$

Preface 9

Introduction 13

Chapter 1

TYPES OF FARM IMPLEMENTS USED IN TANZANIA 22

1.1 Introduction 22

1.2 Description of Common Factory-Made

Hand Implements Used in Tanzania 26

1.3 Description of Factory-Made Ox-Drawn
Implements Used in Tanzania

1.3.1 The Ox-Plough 43

1.3.2 The Ox-Drawn Ridger 47

1.3.3 The Ox-Drawn Cultivator 51

1.3.4 Harrows and Planters 53

1.4 Village Visits 56

1.4.1 Introduction and Methodology 56

1.4.2 Main Conclusions from Village Visits 57

1.4.3 The Impact of the Farm Implements
Shortage on Productivity

1.4.4 Summary of Household Tool Inventory
and Requirements and the General

1.5 Ox-Mechanization 70 Supply Situation $\quad 60$

\section{Chapter 2}

INTRODUCTION AND DEVELOPMENT OF NEW

FARM IMPLEMENTS

2.1 Approaches to Technology Introduction

2.2 Selective Priorities for Implements and

Designs to Improve Likelihood of Adoption 77

2.3 New Hand Implements for Cultivation 79

2.4 Ox-Drawn Equipment 80

2.5 Simple Post-Harvesting Equipment 83

2. 6 Research, Testing and Extension 86

2.6.1 Introduction 86

2.6.2 CAMERTEC, Arusha 88

2.6.3 CAMERTEC's Potential Role in the Introduction and Extention of the Improved Farm Implements

2.6.4 Uyole Agricultural Centre, Mbeya 101

$\begin{array}{ll}2.6 .5 & \text { The Regional Oxenization Project, } \\ \text { Iringa } & 103\end{array}$

2.6.6 Kilimo Extension Service, Ox-Training Centres and the Shinyanga RIDEP Extension Approach 


\subsection{Conclusion}

\section{Chapter 3}

DEMAND ESTIMATES 110

3.1 Hand Implements 110

3.2 The Demand for Ox-Ploughs

3.3 The Supply and Requirements for Plough Spare Parts

3.4 The Potential for Ox-Ploughing in the Next Decade

3.5 The Demand for Ridgers, Cultivators and Harrows

3.6 The Demand for Ox-Carts

3.6.1 Background

3.6.2 The Present Demand for Ox-Carts

3.6.3 Some Notes on the Relationship between Design and Demand for ox-Carts

\section{Chapter 4}

LOCAL PRODUCTION AND REPAIR FACILITIES FOR

FARM IMPLEMENTS AND OX-CARTS

4.1 Blacksmiths

4.2 Support Programmes

4.3 Conclusion

4.4 Outline of Raw Material Support Programme 144

4.5 Ox-Cart Manufacturing

4.6 Support for Local Manufacturing of Ox-Carts

\section{Chapter 5}

INDUSTRIAL PRODUCTION OF FARM IMPLEMENTS

5.1 Small-Scale Industrial Production

5.1.1 Production Units within the SIDO Industrial Estates

5.1.2 MAFOTCO, Moshi

5.1.3 Themi Farm Implements and Engineering Co Ltd

5.1.4 Other Small-Scale Industrial Units

5.2 Medium-Scale Production

5.2.1 The MEIDA "capacity-identifying" Exercise

5.2.2 Cotex Metals and Machinery Ltd

5.2.3 Manufacture of Post-Harvesting Equipment

5.3 Large-Scale Production

5.3.1 Ubungo Farm Implements Company (UFI)

5.3.2 Zana za Kilimo Ltd, Mbeya (ZZK)

5.3.4 Mangula Mechanical and Machine Tools Company (MMT) 


\section{Chapter 6}

DISTRIBUTION OF FARM IMPLEMENTS IN TANZANIA 186

6.1 The Distribution System 186

6.2 Distortions in the RTC Distribution System 188

6.3 Stock Position in October $1983 \quad 191$

6.4 The Tanganyika Farmers' Association (TFA) 194

6.5 Credit and Prices 196

6.6 Future Distribution System 198

List of References 201

\section{Appendix 1}

Agricultural Policy of Tanzania 205

\section{Appendix 2}

Rapid Rural Appraisal Survey Methodology

\section{Appendix 3}

Some Notes on the Costs of Importation

\section{List of Tables}

Table 1.1 Basic Rural Household Tool Inventory

Table 1.2 List of Imported or Domestically Manufactured Common Types of FactoryMade Farm Implements Used in Tanzania

Table 1.3 Overview of Farmers Interviews

Table 3.1 NIDC demand figures, hand implements, 1973

Table 3.2 TISCO demand figures, hand implements, 1980

Table 3.3 UFI supply, hand implements 1979-1983

Table 3.4 RTC requirements, hand implements $1983 / 84$

Table 3.5 Annual demand estimate for hand implements 1984

Table 3.6 The Regional Plough Population for Different Periods, as Given by Different Surveys and Estimates

Table 3.7 The Present Demand for Ox-Ploughs (1984/85)

Table 3.8 Regional Ox-Cart Population 1975-1983 and Estimated Demand for Ox-Carts $1984-1986$

Table 4.1 UFI Regional Distribution of Raw Materials for SIDO; June 1983-August 1983

Table 4.2 The Production of Ox-Carts, Wheel Barrows, Hand-Carts and Harrows from 8 Public and Private Manufacturers for the Years 1980-1983

Table 6.1 RTC Stock Position, Central Regional Godowns, October 1983 



\section{LISTOFABBREVIATIONS}

AATP

ACCO

ADP

AISCO

BIT

CAMARTEC

CaM

CFW

DADO

DANIDA

DMO

DPO

DSM

EEC

FAO

FRG

FSC

I BRD

IDA

IFAD

K i limo

Maji

MEID A

NAC
NBC
NDC
N IDC
NMC
NORAD
Oxfam
OTC

Arusha Appropriate Technology Project

Arusha Cutlery Company

Agricultural Development Project, Iringa Region

Agricultural and Industrial Supplies Company

Board of Internal Trade

Centre for Agricultural Mechanization and Rural Technology, Arusha

Chama cha Mapinduzi

Common Facilities Workshop at SIDO estates

District Agricultural Development Officer

Danish International Development Authority

District Mechanization Officer

District Planning Officer

Dar es Salaam

European Economic Community

United Nations Food and Agriculture Organisation Federal Republic of Germany

Farmer Service Centers

International Bank for Reconstruction and

Development (World Bank)

International Development Association

International Fund for Agricultural Development

Ministry of Agriculture

Ministry of Water

Metal Engineering Industries Development

Association

National Allocation Committee

National Bank of Commerce

National Development Corporation

National Industrial Development Corporation

(an Indian consultancy organisation)

National Milling Corporation

The Norwegian Aid Agency

A Private British Aid Organisation

Ox Training Centre

Peoples Republic of China 


\begin{tabular}{|c|c|}
\hline RADO & Regional Agricultural Development Officer \\
\hline RCW & Rural.Craft Workshop \\
\hline $\mathrm{R}$ and $\mathrm{D}$ & Research and Development \\
\hline KDD & Regional Development Director (presently \\
\hline$R / E$ & $\begin{array}{l}\text { Regional Executive Director) } \\
\text { Round eyed }\end{array}$ \\
\hline RIDEP & Regional Integrated Development Plan/Project \\
\hline RMO & Regional Mechanization Officer \\
\hline $\mathrm{RPO}$ & Regional Planning Officer \\
\hline RTC & Regional Trading Corporation \\
\hline SAP & Structural Adjustment Programme \\
\hline SEK & Swedish kronor \\
\hline SIDA & Swedish International Development Authority \\
\hline SIDO & Small Industries Development Organisation \\
\hline Shs & Tanzanian shillings \\
\hline TAMIU & Tanzania Agricultural Machinery Testing Unit \\
\hline TCA & Tanzania Cotton Authority \\
\hline TDFL & Tanganyika Development and Finance Company Ltd \\
\hline TFA & Tanganyika Farmers' Association \\
\hline TIB & Tanzania Investment Bank \\
\hline TISCO & $\begin{array}{l}\text { Tanzania Industrial Studies and Consulting } \\
\text { Organisation }\end{array}$ \\
\hline TRDB & Tanzania Rural Development Bank \\
\hline TShs & Tanzanian shillings \\
\hline TWICO & Tanzania Wood Industries Company \\
\hline UAC & Uyole Agricultural College (Mbeya) \\
\hline UFI & Ubungo Farm Implements \\
\hline UK & United Kingdom \\
\hline UNIDO & $\begin{array}{l}\text { United Nations Industrial Development } \\
\text { Organisation }\end{array}$ \\
\hline URT & United Republic of Tanzania \\
\hline USAID & United States Aid Agency \\
\hline USD & United States Dollars \\
\hline $\mathrm{ZZK}$ & Zana za Kilimo Ltd (Mbeya) \\
\hline m & million \\
\hline th & thousand \\
\hline $1 \mathrm{~b}$ & pound \\
\hline
\end{tabular}




\section{PREFACE}

In 1982, the Tanzanian Government approached the Swedish Government with a request for support to the Tanzanian agricultural implements industry. There was a general consensus that this was an area where donor support would be useful.

Numerous studies had been undertaken on the agrictural implements situation in the country. However, these studies were either theoretical in nature or concerned with specialized aspects. In particular there was a lack of knowledge of the peasants' own perception of requirements of implements. With the aim of assisting the Tanzanian Government to obtain more information on the actual situation in this sub-sector of the economy, and as a basis for Swedish support, SIDA decided to commission a study to look into the types of implements in use, their usage, the demand for different types, the distribution system and the production and importation of farm implements.

During the early 1980's Tanzania had undergone a complete "re-planning" exercise, which resulted in the Structural Adjustment Programme of June, 1982. The renewed emphasis on the agricultural sector revealed that there were knowledge gaps as to the constraints and potentialities of this sector. In particular it was found that the lack of empirical data gave rise to a number of very different opinions, e.g. on the size of the national demand for various farm implements.

Part of the work carried out by the study group consisted of a compilation of previous studies and planning documents of relevance. A 1 ist of the most important reports is given in the 1 ist of references. However, many of these studies complain about the scarcity of actual field data to support assumptions made. It was therefore felt that the investigation, although its basic purpose was to propose a workable strategy for SIDA support (and not a study with scientific aspira- 
tions), would have to be based on actual field data. One of the ways to achieve this was to include in the team people with adequate experience of peasant conditions in Tanzania. The other way was to include a field assessment of matters of importance. These field trips, although extensive, did not allow the forming of any scientifically based conclusions, but were rather a way of contrasting study findings and previous experiences of the team members with conditions in various parts of the country. We would like to use the term "rapid rural appraisal" methodology for the field work. More details on the methodology are found in Appendix 2.

The result of the work of the study group was a description of the agricultural implements sub-sector, based on a grassroot perspective but yet attempting to give a comprehensive picture. The data obtained refer to the mid-1983 situation.

It was later acknowledged that this descriptive material turned out to be of interest also to people concerned with agricultural and industrial development in general. For this reason, and in order to make the material more readily available, the Scandinavian Institute of African Studies decided to publish the parts of the study as a research report with financial support from SIDA.

One important part of the original report was the recommendations concerning the strategy to follow in supporting the farm implements sub-sector of industry. This part has been deleted in the present research report which mainly presents the descriptive parts of the investigation.

In editing the material for this research report we have tried to emphasize three aspects. Firstly, to provide insights into the practical functioning of a central part, the farm implements sector, of a rural economy. Secondly, we hope to demonstrate some elements of the basic development process, viz. the prerequisities for, and the conditions under which, farmers will be prepared to adopt changes in technology. Finally, we try to offer an illustration of the character of the 
planning process in developing countries. The relevance of planning which is not based on actual knowledge of real conditions, but rather on assumptions and unrealistic hopes, we believe is an important impediment to progress.

The material presented on farm implements in this report may also be of interest from the perspective that it was collected at a time, the second half of 1983, when

Tanzania was experiencing its peak crisis. Thus the report may shed light on the issue of or relative importance of problems related to production, distribution and suitability of farm implements for the agricultural stagnation in Tanzania during this period.

Björn Mothander

Finn Kjærby

Kjell Havnevik 



\section{INTRODUCTION}

\section{$\underline{\text { Tools for tillage }}$}

The hoe is the most important tool in peasant agriculture in Africa. It is, indeed, so central that it is often used as a symbol of agriculture.

The concept of the hoe, however, signifies a wide array of tools of different sizes and designs, used for a variety of purposes. But the individual peasant has a profound knowledge of which type of hoe is the most suitable for the conditions of his or her field, and will be most reluctant to buy any other hoe. One of the questions asked in this study is whether manufacturers of hoes, and national planners, have the means or even the ambition to allow this basic knowledge of the peasant to influence their products and plans. One fundamental idea of this investigation is that in order to meet the peasant need for hoes, knowledge of much more than production techniques is required.

Hoe tillage, and the traditions concerned with this form av cultivation, sets very definite $1 \mathrm{imits}$ to the area that can be cultivated by one family. The progressive farmer may therefore be looking for means of expanding his productive capacity. His ultimate ambition is sometimes to become the owner of a tractor. Given the constraints of many African economies, this ambition cannot be satisfied for more than a small number of farmers.

The intermediate solution is plough cultivation. In Tanzania, which is the focus of this book, the oxplough represents an important step in development and the spread of ox-plough cultivation could have a significant impact in large areas of the country. However, there are also areas where cattle are not found for various reasons, or at least are not used for traction, and in those areas other efforts than supplying farmers with ploughs will be required. 
In order to sustain agricultural production, the supply of hoes to the peasant is crucial. To stimulate agricultural development, the supply of ploughs is just as important. The supply of improved implements must, however, form part of a process of adapting to technological changes. One other concept of this study is that this adaptation process must be based on the peasant's existing, and in most cases relevent, body of knowledge and the degree of his control over production resources.

The impact of farm implements

Although food production presupposes the availability of farm implements, these are far from the only or the most critical, inputs in food production. Unless the farmer has seeds, fertilizers for certain crops, and arable land, he will not be able to produce. Nor will his surplus production reach deficit areas without a properly functioning distribution and transportation system. Improved farm implements is one, but certainly not the only, condition for increased agricultural production. Soil and climatic conditions, seeds, the settlement pattern, food preferences, pesticides and relative producer prices must also be taken into account and a 11 these together will determine the composition of agricultural production. Improving farm implements often means changing the farming technique, which in turn may call for more than just an improved implement. A case in point is ox-ploughing, which will be discussed in detail further on in this report. Oxploughing certainly makes cultivation of a larger area possible, compared to hand cultivation. But labour constraints place a limit on the area which can be weeded, and if weeding is not mechanised, which requires a different implement, ox-ploughing will not result in higher yields.

To the majority of farmers in Tanzania there is presently no alternative to hand cultivation. Hand tools will remain of critical importance for a long period to come. In this report we intend to analyse the requirements in respect of such tools, the demand for them and the supply to farmers. We have attempted to look at the 
types of hand tools available, their supply to the farmers, the national demand for the most important hand tools, their production in the country and the alternative costs for importing them.

The use of animals in cultivation has the potential of increasing the production of one farmer significantly. Ox-ploughing did not start in Tanzania until the $1930 \mathrm{~s}$ but its importance is increasing. We will discuss below this form of production. We believe relatively small investments can have important effects in the medium term.

The next step in agro-mechanisation, the use of tractor-drawn implements, requries a complex pattern of inputs, management and service infrastructure, several of which presuppose their own distribution systems, This type of implement is excluded from this study. Our view is that this type of farming willonly be a viable alternative in some restricted areas in Tanzania for many years to come given the weakness in the present transportation system, the difficulty of maintenance and repair, and the unreliable supply of fuel. Investments in production of tractor-drawn implements locally would, in our view, thus be a misallocation of resources.

\section{National policies}

What are, then, the national Tanzanian policies pertaining to the farm implements sub-sector? We will review those policies and contrast them to the discussion above.

The National Food Strategy 1982 includes some objectives relevant to our study. The Strategy announces that steps will be taken to improve supply mainly through the planned establishment of Farm Service Centres. The Strategy further envisages a big push for oxenization both in the short and long run, subject however to cultural and environmental constraints. A more diversified use of oxen is seen to be the key strategy to revolutionize agriculture. 
The Structural Adjustment Programme for Tanzania (SAP) was formulated in June, 1982. In 1983 it was the most important document for development planning in Tanzania, in spite of the fact that the financing of the Programme had not been agreed with the most important prospective financiers thereof, the IMF and IBRD/IDA. The merit of the SAP, but also its weakness in the absence of financing, was its comprehensive approach to the national development process.

The SAP does not give much guidance in terms of policies for the supply of farm implements. It states:

"Only a few regions and districts are relatively well serviced with well stocked specialised or other sales outlets for agricultural inputs, but the rest lack such outlets. Thus, it is essential to ensure that a range of inputs (primarily fertilizers, pesticides, tools, sprayers and animal-drawn equipment) are available to farmers under one roof, whereever possible on a cash basis, in all areas.

Existing institutions (including the Agricultural and Industrial Supplies Company, Cooperatives, Crop Authorities, Tanzania Seed Company, Tanzania Fertilizer Company, Tanganyika Farmers' Association, IRDB, Ubungo Farm Implements and Regional Trading Companies) will be assisted to widen the range of inputs on sale and expand the number of sales outlets. In addition, a network of Farm Service Centers will be established gradually extending to every district. The Ministry of Agriculture in collaboration with the institutions identified above will prepare a detailed, fully costed programme". 1

As a follow-up, the Ministry of Agriculture formulated the Agricultural Policy of Tanzania, which is dated March 31st, 1983. The policy states that the dominant mode of agriculture in Tanzania is individual peasant production. But,

"Farming in the villages needs modernization; in the majority of cases it is still carried on according to traditional practices, without taking advantage of 
modern knowledge or modern tools. The jembe, the panga, and the shoka - all hands tools - still dominate production methods now". 1

The policy goes on to state:

"Increasing the output and the efficiency of agricultural production in the villages is central to increased national output". 2

The policy is strongly oriented towards the introduction of mechanized agriculture. A shift from hand tools to animal-drawn implements, and from those to tractordrawn equipment is foreseen. The immediate objective is said to be achievement of national food

self-sufficiency as well as agricultural production for the industrial sector and increased earnings from export crops. But the major task is "to move the peasant farmers from reliance on handtools to the use of animal and mechanically assisted implements".

The policy expresses strong support for research, testing and extension activities. Imports shall only be made of evaluated and tested equipment and local production will be stepped up to meet growing demand for improved hand tools and animal-drawn implements.

It is clearly stated that ox-ploughing shall be spread, that new ox-implements shall be introduced and the use of ox and donkey carts encouraged. Repair facilities in villages shall be promoted.

An important point concerns distribution of farm inputs. The Ministry of Agriculture is envisaged to have an important supervisory and coordinating role in this system, On regional level co-operative unions will play a dominant role and will supply the primary co-operative societies and village shops. We will describe below the functioning of the distribution system in

1. APT, $\mathrm{p} 8$

2. APT, $\mathrm{p} 11$ 
1983, and what plans are afoot to change the system. A lot of uncertainty is still attached to the implementation of these principles.

We would like to end this brief summary of the Agricultural Policy with a quote, which we believe puts the Policy and the work undertaken within this study, in its proper perspective:

"But it is still possible to improve the quantity and quality of our output, provided that all activity by the Government and by every public employee is based on the recognition of one simple truth: it is the farmers and especially the peasants, of Tanzania who produce agricultural goods, and the women among them who do a very large proportion of the work".

In Appendix 1 we have collected the statements in the Agricultural Policy which we consider are of importance to this study.

There is a difference of emphasis between our concepts and the Agricultural Policy. Whereas we want to stress development on the basis of available resources and techniques, the Agricultural Policy sees the shifting to more modern techniques as the priority. However, if the time element is introduced, there may not be such a great difference of approach. It will surely be a long time before comprehensive animal traction or ox-mechanization is introduced on a large scale, and even longer before tractor mechanization is implemented. We want to emphasize our view, however, that tractor mechanization should be seen as a policy for the future, but it should not be allowed to draw resources away from the immediate strengthening of the spread and development of other agricultural techniques, in particular ox-utilization.

\section{The purpose of this study}

Considering the priorities of the above planning documents, there is, in our opinion, a need to collect factual, descriptive information, to assess the plans and their goals, whether they are realistic and under 
what conditions and time-frames they could be achieved, The objective of this study is to contribute to this important and continuous exercise.

\section{$\underline{\text { Sub-sector Organisation and Co-ordination }}$}

Several ministries in the Tanzanian government structure are directly concerned with matters pertaining to farm implements. The Ministry of Agriculture (Kilimo) is responsible for promoting agricultural production in the country. Planning measures undertaken in Kilimo will have consequences on matters affecting crop production and the choice between various crops. (E.g., the impact of producer prices.) Above we have reviewed the Agricultural Policy for Tanzania which provides a comprehensive policy frame-work. Apart from planning, extension services is an important area for Kilimo involvement. There are particularly two sections concerned with the farm implements discussed in this report; the Mechanization section (the ox-mechnization unit) and the Farm input section. In the Agricultural Policy it is also mentioned that Kilimo would have a role in the distribution of farm implements.

Distribution is otherwise a matter for the Ministry of Trade. Under this Ministry the Board of Internal Trade (BIT) is responsible for the national distribution set-up, co-ordinating the Regional Trading Companies (RTCs), which we discuss in Chapter 6. BIT is also responsible for the Agricultural and Industrial Supplies Company (AISCO).

It has been decided that the co-operatives will have an important role in the villages in the future.

Co-operatives (and village governments) are organised by the Prime Minister's Office (PMO). PMO is also chairing the National Allocation Committee (NAC), which decides the regional allocations for farm implements, among other things. The secretariat is provided by BIT,

The legislation on confinement and price determination has, as we show in Chapter 6, a profound impact on the 
farm implements sub-sector, both in terms of manufacturing and distribution. This legislation is handled by the Ministry of Trade.

The Ministry of Industries (Viwanda) plans industrial development in Tanzania, and is responsible for coordinating manufacturing activities. Under Viwanda falls, e.g., NDC and SIDO, which are parastatal organizations. MEIDA is not a parastatal but an association of mechanical industries. MEIDA liaises, however, closely with Viwanda.

Apart from these ministries with a functional responsibility in the sector, the Ministry of Planning and Economic Development is over-all responsible for planning of new industries. The Ministry of Finance also has an important role, both in Einancing government activities, as well as in supervising all parastatals (through the Commissioner for Public Investments).

Under the Ministry of Finance, the Bank of Tanzania has a crucial role when it comes to determining how to use foreign exchange. The Bank of Tanzania provides the secretariat for the Foreign Exchange Allocation

Committee. Given the present shortage of foreign exchange, this comtnittee, in which concerned ministries are represented, is virtually deciding what industrial activity is to be allowed in the country. Donor preferences will of course influence those decisions by the Committee which concern the use of import support funds.

Regional authorities (which are under the PMO) also have an important role in planning, supervising and coordinating activities in the sub-sector.

The research institutions belong to several ministries; CAMARTEC reports to Viwanda, Uyole Agricultural College to Kilimo and the Faculty of Agriculture to the Ministry of Education,

There are also a number of other institutions with less direct impact in the sub-sector, e.g., TIRDO (Tanzania 
Industrial Research and Development Organisation), TEMDO (Tanzania Engineering and Manufacturing Design Organisation), TBS (Tanzania Bureau of Standards, which has facilities for materials testing, among other things) and TISCO (Tanzania Industrial Studies and Consulting Organisation which is a comtnercially operating consulting company) all under Viwanda, TARO (Tanzania Agricultural Researach Organisation) and TALIRO (Tanzania Livestock Reserach Organisation) under Kilimo. Most of the research institutions are described in Chapter 2 and in Phillips and Zachariah (1980). We have restricted our analysis to those organizations which we believe have a significant role to play.

Obviously, such a large number of institutions may create confusion and duplicate efforts. For this purpose some co-ordinating initiatives are taken.

We have mentioned the National Allocation Committee, in which PMO, Viwanda, Kilimo and the Ministry of Trade (through BIT) are represented. This committee co-ordinates and allocates distribution volumes. It is, however, not the task of this committee to co-ordinate the distribution set-up, this is handled at Cabinet level.

There is also a technical committee chaired by the Minister for Industries, which decides on how to allocate production to various units.

Small-scale industry matters are discussed in a separate committee in which Viwanda, SIDO, TRDB and NBC participate.

In research and design matters there is a proliferation of institutions, which is difficult to understand. This does not appear to have yielded any benefits to the sub-sector. The various research organisations should keep themselves better informed about the work of the others. 


\section{CHAPTERONE}

TYPES OF FARM IMPLEMENTS USED IN TANZANIA

\subsection{Introduction}

Manual cultivation methods have been the traditional practice in Tanzania and some $85 \%$ of the country's cultivated acreage is estimated by the Ministry of Agriculture (Kilimo) to be cultivated with hand tools on smallholdings below 2 hectares $(5$ acres $)$.

There is a fairly wide range of hand tool types used in Tanzania and marked area-specificity in the use of different types. This diversity is related to a number of factors, including cultural preferences, the need for crop-specific tools, the nature of soil conditions and farming systems, and the availability or shortage over time in different areas of the range of locally and imported factory-made tools, on the one hand, and indigenous blacksmith-made tools on the other.

The principal farm implement used in Tanzania is the hoe. However, the study team was soon to be confronted with the finding, that a hoe is not just a hoe. Quite apart from the numerous variations in material, shape, curvature, quality, size and weight of different hoes be they factory-made local or imported ones, or be they indigenous blacksmith-made ones - a basic distinction is made between the Round Eyed (R/E) hoe and the tanged hoes.

The tanged hoe has a spike protruding straight up from the upper edge of the hoe blade. Some skill and time is required for fitting this type of hoe to a handle which is shaped thicker at the lower fitting end. The tang has to be heated and burned through the handle, sometimes made easier by drilling a hole if a drill is 
available. The tanged hoe was the original type of hoe used all over the country because rural blacksmiths only possessed tools and skills for producing tanged hoes. 1 The advantage of the tanged hoe is that the angle between the hoe blade and handle can be set to suit individual preferences. This angle tends to be sharper or less than 90 degrees. The large tanged hoe tends to be associated with upland farming in the hilly areas of the Southern Highlands.

The Round-Eyed ( $R / E$ ) hoe has a forged eye through which the handle is fitted, set at right-angles to the blade. The hoe is forged in one piece but in some new designs which are not yet used in Tanzania the eye is welded to the blade. Through growing imports during and after the colonial period the R/E hoe has steadily been replacing the tanged hoe in most regions of Tanzania, in some regions (with flat topography) by preference, in others by insufficient supplies of the preferred tanged hoe. The large 3 lb R/E hoe is now by far the most common farm implement used in Tanzania.

On the whole the tools commonly available to the household do not determine the crops grown, whereas the cultivation of certain crops or the existence of particular farming systems often tends to be associated with certain specialized implements or characteristic tool inventories. Thus, small specialized weeding hoes are often found in connection with rice and finger millet growing or in areas with intensive, dense mixed cropping patterns. The coffee-banana highland farming systems tend to have tool inventories characterized by a variety of specialized tools. Upland farming systems i n the hilly areas of the Southern Highlands tend to be associated with the use of tanged hoes. Again, areas with a well-established blacksmith tradition, or export crop areas which have been favoured with input credit, tend to have a varied household tool inventory.

1. URT/Min of Culture \& Youth (1976): Jembe ni mali. Kuza ufundi wa jadi, endeleza nchi yetu. Tanzania Publishing House, Dar es Salaam. 
In some areas, $1 \mathrm{ike}$ Lindi and Mtwara, there is apparently a strong cultural preference for small-sized short-handled hoes. These areas have a well established blacksmith tradition and may also have retained the use of small blacksmith-made hoes due to poor communications, a low level of commercialization of agriculture, and low or irregular supplies of imported or factorymade large hoes.

Despite the diversity of tools used in different areas, some general observations can be made with respect to the most basic hand tool inventory for the average rural household in Tanzania. A household would tend to possess about two large digging hoes, an axe (indigenous- or factory-made) and one or two matchets (factory-made) or bill-hooks (indigenous). In addition, the household would possess at least a couple of smallsized weeding hoes, either made by blacksmiths or more often worn down hoes of originally larger size, used especially by women and children. Harvesting knives (indigenous) or sickles are generally not common, partly because bill-hooks or indigenous knives are used instead, partly because they have been "phased out" in those areas where they are needed, due to lack of supply (e.g. Iringa).

There is a lack of general evidence and country-wide surveys to support these observations with the exception of two sources which only recorded hoes, matchets and axes. A rural household survey made in 1969 recorded an average figure of 3.1 hoes per rural household. 1 The Agricultural Census of 1971/72 (Vol. I) provided the following figures.

1. Livingstone, I. (1970): "Results of a Rural Survey; The Ownership of Durable Goods in Tanzania Rural Households and Some Implications for Rural Industry", ERB Paper 70.1, Univ of DSM, quoted in Müller, J. (1977): Promotion of Rural Implement Manufacture in Tanzania. UNIDO, Vienna. 
Table 1.1. Basic Rural Household Tool Inventory

\begin{tabular}{|c|c|c|c|c|}
\hline I t e m & $\begin{array}{l}\text { No of } \\
\text { holdings }\end{array}$ & $\begin{array}{l}\% \text { of } \\
\text { holdings }\end{array}$ & $\begin{array}{l}\text { No. of } \\
\text { it e m s }\end{array}$ & $\begin{array}{l}\text { Items/ } \\
\text { household }\end{array}$ \\
\hline Hoes & $2.36 \mathrm{~m} \mathrm{i} 11$ & 100 & 9.565 & $4.0 / \mathrm{hh}$ \\
\hline Matchets & $1.83 \mathrm{~m} \mathrm{i} 11$ & 77 & 2.798 & $1.5 / \mathrm{hh}$ \\
\hline Axes & $1.83 \mathrm{~m} \mathrm{i} 11$ & 77 & 2.369 & $1.3 / \mathrm{hh}$ \\
\hline
\end{tabular}

Source: The Agricultural Census 1971/72, Vol. I: Peasant Farming.

The so-called Regional Development Director (RDD) survey, made in 1976 by the Study Committee on Farm Implement Requirements, 1 estimated the number of basic hand tools per rural family to be 1.8 hoes, 0.8 matchets and 0.6 axes. These figures are too low and unreliable, since the data were collected by sending questionnaires to Regional Directorates for completion and were not collected through an actual rural household survey.

On the whole, the Agricultural Census figures support our findings on the basic inventory of tools in actual use, based on spot-check recording of household tool inventories in selected regions.

In areas where ox-cultivation is common, the main implements used are the single-furrow mouldboard plough and locally made sledges.

Kilimo estimates that ten per cent of Tanzania's cultivated acreage is ploughed using oxen, based on an annually ploughed acreage of 10 acres per plough. Our study found that the utilization of ploughs was virtuallyuptocapacity, giving some 15-20 acres ploughed twice. Thus, the total acreage rate per plough was 2025 acres in a 11 places visited. It can thus be assumed that some 15-20 per cent of the country's cultivated

1. Ripoti ya kamati ya uchunguzi wa mahitaji ya zana za kilimo, Jan. 15th, 1976. Dar es Salaam 
acreage is ploughed by oxen using about 180,000 ploughs; and this percentage is increasing fairly rapidly at present through increased supply of the ploughs from the Ubungo Farm Implements factory (UFI) and through more intensive use of ploughs.

Ox-carts are still only possessed by a few wealthier households but the rate of adoption has increased rapidly since villagization, and there is now a high unmet demand for good-quality carts.

Despite limited stocks of imported harrows, cultivators and ridges at central RTC stores over recent years, their use is restricted to very few households. However, where such implements have been made available to farmers and properly demonstrated (Iringa, Shinyanga), farmers have started using them. There is virtually no use of animal-drawn planters and irrigation-related ox-equipment, and in fact no such equipment is availab1e. Attempts have recently been made to introduce animal-drawn sugar-cane crushers and oil pressers. A more detailed discussion of ox-cultivation and animal-drawn equipment is provided below.

\subsection{Description of Common Factory-Made Hand Implements Used in Tanzania}

Table 1.2 lists the most common types of factory-made farm implements (imported or domestically manufactured by UFI) used in Tanzania at present. The implements are listed according to type, weight/size, manufacturer, country of origin and recent retail prices (ex. RTC). The table shows that UFI - which is the sole importer and until late 1982 the sole manufacturer of simple farm implements - only produces 3, $21 / 2$ and $21 \mathrm{bs}$ R/E hoes in addition to ox-ploughs, plough shares and grass slashers. All other implements are imported from the U.K., China and India.

Consignments of R/E hoes, ox-ploughs, cultivators and ridgers have also been imported from Zambia and Zimbabwe. The 30,000 hoes ordered from Zambia (Northland Engineering/Ndola) were press-plate welded hoes of poor quality. Of these, 6,000 hoes sent to RTC's could 
not be sold and UFI in 1983 remained with a stock of 24,000 hoes which they were not prepared to sell in the market due to their poor quality. Only 500 ploughs had been received and distributed by December 1983 .

Maximum retail prices, especially those of imported tools, were raised drastically on 29 August 1983, an increase well above the official rate of inflation, which was about 35 per cent during the early 1980 s.

A description as well as illustrations of the most common of the above list of factory-made farm implements is given below (indigenous-or blacksmith-made tools are dealt with in Chapter 4). The description includes brief technical information on production techniques used, material and quality of implements, where they are used in Tanzania and for what tasks, consumer and cultural preferences, and parallel market prices where this applies. The usage pattern of farm implements, with respect to how variations in tools use and household tool inventories are related to the nature of farming systems, household labour force composition, supply of blacksmith-made tools, etc., has been described in original report to SIDA and will not be included in this research report. 
Table 1.2 List of Imported or Domestically Manufactured Common Types of Factory-Made Farm Implements Used in Tanzania

\begin{tabular}{|c|c|c|c|c|c|}
\hline $\begin{array}{l}\text { Type of } \\
\text { tool }\end{array}$ & $\begin{array}{l}\text { Weight } \text { or size } \\
\text { Ibs } \mathrm{Kg}\end{array}$ & $\begin{array}{l}\text { Supplier or } \\
\text { country }\end{array}$ & $\begin{array}{l}\text { Brand name } \\
\text { or } \\
\text { Chapa }\end{array}$ & $\begin{array}{l}\text { Maximum retail price } \\
\text { shs } \\
\text { before } \quad \text { as of } \\
\begin{array}{ll}29.8 .1983 & 29.8 .1983\end{array}\end{array}$ & $\begin{array}{l}\text { Percentage } \\
\text { price cL } \\
\%\end{array}$ \\
\hline $\begin{array}{l}\text { R/E hoe } \\
= \\
= \\
\text { R/E Moonshape }\end{array}$ & $\mid \begin{array}{rr} & 3 \\
2 & 1 / 2 \\
3 & 2 \\
3 & 1 / 2 \\
& 3\end{array}$ & $\begin{array}{l}\text { UFI; China; } \\
\text { Chillington/ } \\
\text { U.K. or } \\
\text { Brazil } \\
\text { UFI; China } \\
\text { ZZK/Mbeya } \\
\text { Chillington/ } \\
\text { U.K. }\end{array}$ & $\begin{array}{l}\text { Kazi, Joqoo } \\
\text { Mamba } \\
\text { Kazi, Joqoo } \\
\text { Maulima } \\
\text { Mamba } \\
\text { ('scooter } \\
\text { or baiozi') }\end{array}$ & $\begin{array}{l}54 / 90 \\
50 / 65 \\
49 / 20 \\
\\
\\
63 / 52\end{array}$ & $\begin{array}{l}18 \\
19 \\
26\end{array}$ \\
\hline Tanged hoe & \begin{tabular}{|ccc} 
& 4 & 1.8 \\
& & \\
3 & $1 / 2$ & 1.6 \\
& 3 & 1.36 \\
2 & $1 / 2$ & 1.13 \\
& & \\
& & \\
3 & prongs & \\
4 & prongs &
\end{tabular} & $\begin{array}{l}\text { Chillington/ } \\
\text { U.K. } \\
- \\
- \\
\text { Chllington/ } \\
\text { U.K.; Jay- } \\
\text { hind/India } \\
\text { Chillington/ } \\
\text { U.K.; China: } \\
\text { India }\end{array}$ & $\begin{array}{l}\text { Runqwe } \\
\text { Ufipa } \\
- \\
\text { Mamba or } \\
\text { Jayhind } \\
\text { Mamba; } \\
\text { Joqoo } \\
\text { Jayhind }\end{array}$ & $\begin{array}{l}83 / 65 \\
78 / 70 \\
68 / 35 \\
\\
61 / 50 \\
85 / 80 \\
45 / 80\end{array}$ & $\begin{array}{l}37 \\
56 \\
42 \\
\\
40 \\
53\end{array}$ \\
\hline $\begin{array}{ll}\text { Matchet, } & \text { curved } \\
\text { Matchet, } & \text { straight: } \\
- & , \text { curved } \\
- & , \text { straight: }\end{array}$ & $\begin{array}{l}16 \text { inches } \\
16 \text { inches } \\
18 \text { inches } \\
18 \text { inches }\end{array}$ & China & $\begin{array}{l}\text { Diamond } \\
- \\
- \\
-\end{array}$ & \begin{tabular}{|cc}
$22 / 70$ & $34 / 25$ \\
$24 / 70$ & $34 / 85$ \\
$24 / 65$ & $35 / 60$ \\
not quoted & $27 / 95$
\end{tabular} & $\begin{array}{l}51 \\
41 \\
44\end{array}$ \\
\hline $\begin{array}{l}\mathrm{R} / \mathrm{E} \text { axe } \\
- \\
-\end{array}$ & \begin{tabular}{|ccc}
3 & $1 / 2$ & 1.6 \\
& $\mathbf{3}$ & 1.36 \\
2 & $1 / 2$ & 1.13
\end{tabular} & China or U.K & $\begin{array}{l}\text { Diamond } \\
- \\
-\end{array}$ & \begin{tabular}{|cl}
$53 / 90$ & $76 / 65$ \\
$54 / 60$ & $76 / 25$ \\
not quoted & in price \\
& circular
\end{tabular} & $\begin{array}{l}42 \\
40\end{array}$ \\
\hline $\begin{array}{l}\text { Sickle } \\
- \\
\text { Shovels }\end{array}$ & $\begin{array}{l}16 \text { inches } \\
20 \text { inches } \\
\text { square mouth } \\
\text { round mouth }\end{array}$ & $\begin{array}{l}\text { China } \\
\text { China } \\
-\end{array}$ & - & $\begin{array}{lr}11 / 85 & 16 / 75 \\
14 / 85 & 20 / 60 \\
71 / 95 & 104 / 55 \\
74 / 00 & 107 / 70\end{array}$ & $\begin{array}{l}41 \\
39 \\
45 \\
46\end{array}$ \\
\hline $\begin{array}{l}\text { Single-F } \\
\text { ox-plough } \\
\text { - plough shares } \\
\text { upset } \\
\text { - plough shares } \\
\text { flat } \\
\text { Trek chain }\end{array}$ & & $\begin{array}{l}\text { UFI; Cossul/ } \\
\text { India } \\
\text { UFI } \\
\text { China }\end{array}$ & $\begin{array}{l}\text { Ngambe or } \\
\text { Cossul }\end{array}$ & $\begin{array}{l}965 / 60 \quad 1329 / 30 \\
\text { about } 60 /-\quad 84 / 60 \\
\text { about } 50 /-74 / 90 \\
\text { about } 55 /- \text { about } 85 /-\end{array}$ & $\begin{array}{l}38 \\
41 \\
50 \\
54\end{array}$ \\
\hline $\begin{array}{l}\text { Ridger } \\
- \\
\text { Cultivator } \\
- \\
\text { Harrows }\end{array}$ & $\begin{array}{l}\text { about } 35 \\
- \\
5 \text {-tined } \\
- \\
\text { spike tool } \\
\text { steel fr } \\
\text { zlgzaq toothed }\end{array}$ & $\begin{array}{l}\text { India } \\
\text { Zambia } \\
\text { India } \\
\text { Zambia } \\
\text { India } \\
\text { Zambia }\end{array}$ & $\begin{array}{l}\text { Cossul } \\
\text { Northland } \\
\text { Cossul } \\
\text { Northl and } \\
\text { Cossul } \\
\text { Northland }\end{array}$ & \begin{tabular}{|cll} 
about & $850 /-$ & $2453 /-$ \\
& - & $2453 /-$ \\
about & $650 /-$ & $2431 /-$ \\
- & $2431 /-$ \\
about & $1100 /-$ & $3323 /-$ \\
& & \\
- & $3323 /-$
\end{tabular} & $\begin{array}{l}190 \\
274 \\
200\end{array}$ \\
\hline
\end{tabular}

Source: Government Price Circular No. 94, contained in UFI letter to RTC's, August 1983 
The Round-Eyed R/E hoe (see also 3.1.), is a straightedged hoe, forged in one piece.

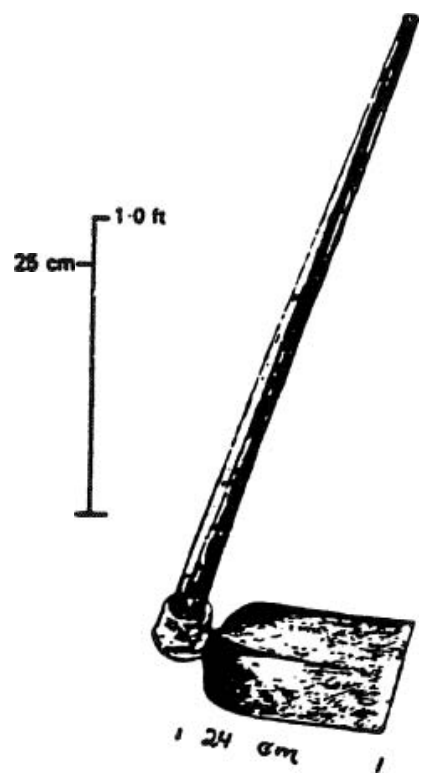

$\mathrm{R} / \mathrm{E}$ Hoe (UFI)

(3Ibs.)
It is most efficiently produced by large-scale manufacturers due to the required forging techniques and the need for tempering (o il heat treatment) to harden the lower cutting part of the blade.

The large 3 lbs R/E digging hoe is by far the most common type of hoe used in Tanzania and it is particularly preferred in the whole of Central and Northern Tanzania, although it is found in most regions. The smaller types of R/E hoes are sold in very limited quantities mainly to the coastline regions. In other regions they are mainly sold when there are shortages of the $31 \mathrm{bs}$ hoe or because the

smaller hoes are preferred by women and children in some areas.

The $31 / 2$ lbs R/E hoe from Zana Za Kilimo (ZzK) Mbeya

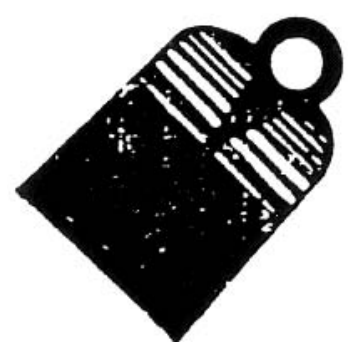

R/E Hoe (ZZK)

(31/2 Ibs.) has so far only been produced in limited quantities and is unpopular in most places, not least in the Southern Highlands (Iringa, Mbeya, Rukwa and Songea) where tanged hoes are preferred. Some Mbyea hoes have been sold in Morogoro, probably when alternative supplies are unavailable, but they are neither selling in

north-central Tanzania nor in Iringa where AISCO has a large non-moving stock which appears unsaleable. The reasons for its lack of popularity are related to its poor quality and its unusual shape and weight. Firstly, it is well-known that a $31 \mathrm{bs}$, not a $31 / 21 \mathrm{bs}, \mathrm{R} / \mathrm{E}$ hoe is the one in demand in Tanzania. Secondly, the eye of 
the ZZK hoe is not attached to the blade with a neck, which led to complaints in, for example, Mwanza. The reason given was that the balance of gravity of the hoe, becomes poorer and that it is inappropriate for ridge-making. Thirdly, on the first batches of hoes sent out, the eyes broke off the blade. Fourthly, the blade is too broad and has an extremely poor rough finish owing to worn forging dies and because the edge is neither properly sharpened nor always properly hardened (tempered or heat-treated). Fifthly, the Mbeya hoe costs over 60/- shs, more than any other R/E digging hoe in the country. Finally, one has to question very strongly why ZZK in Mbeya decided on production of $\mathrm{R} / \mathrm{E}$ hoes when the whole south-western zone demanded - and has been starved of tanged hoes.

The other R/E hoes are supplied by UFI (insufficient supply for the country's requirements); China and the U.K. (Chillington). Throughout the country there is virtually a preference for the Chillingtons (chapa mamba or crocodile brand) and for good reasons. All our evidence shows that the Chillingtons - imported already during the British Colonial period, and now also imported from a licenced factory in Brazil - have a Iifespan much longer than any other brand of digging hoes. The Chinese hoe (chapa jogoo or cock brand) comes second in preference and UFI's hoe (chapa kazi or work brand) comes third. UFI comes third because a good number of their hoes (and plough shares) have not been properly hardened over recent years - some of them not at all - so that they wear down fast or crack easily. Secondly, the quality of forging of some of UFI's hoes has been poor: The front-blade reinforcement ridge leading to the neck and eye is not always forged in the vertical centre of the blade due to problems with UFI's Duplex Rolling Forge Machine. The balance of the hoe is offset and specially-made curved handles have to be fitted by the peasants to try and rectify the balance.

The large tanged Digging Hoes (jembe lenye ulimi, msuka au mkia) (see also 1.1) are still not manufactured by factories in Tanzania although dies were ordered in 1983 for producing tanged hoes at ZzK/Mbeya with support from SIDA. 
The tanged hoe is forged on one whole piece like the R/E hoe and thus lends itself to large-scale mass manufacturing. However, there are plans for local smallscale production of riveted hoes where the tang is riveted to the blade. Traditional rural blacksmith skills only allowed for production of tanyed hoes, forged in one piece or riveted in the case of repairing hoes where the tang or eye had broken off.

Tanged hoes are imported, mainly from Chillington in the U.K. Some tanged hoes weighing $21 / 21$ bs have also been imported from Jayhind, India. The 1 atter are unpopular and sell slowly, mainly because of their poor quality and partly because of the larger types being preferred.

Since the mid 1970's there has been a declining supply of tanged hoes in the country. In 1980-82, the shortage of tanged (and R/E) hoes became particularly acute. The use of the tanged hoe has thus been on the decline. In some areas where it used to be common (e.g. Mbulu Highlands, Songea District) it has largely been replaced by the R/E hoe. As already noted above, the tanged digging hoe tends to be associated with upland farming systems in hilly areas, primarily in Mbeya, Iringa, Rukwa and Ruvuma Regions.

There are basically two types of tanged digging hoes used in the Southern Highlands, with marked area specificity in their occcurrence:

1. The large Rungwe Hoe ( 4 lbs) has a pointed cutting edge and is curved along the horizontal axis. This hoe is preferred by the Wanyakyusa and is found in Rungwe,

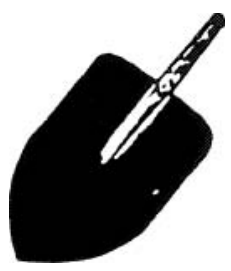

\section{Rungwe Hoe} through the recent RTC confinement system, we did hear
Kyela and Southeastern Mbozi

districts in Mbeya, and in Makete and Southern Iringa (Dabaga Hills) district in Iringa Region. It is fitted with a very long handle (about 2 metres long), often of a particular type of wood. Although black marketing of hand tools is now fairly effectively restricted 
of few cases where Rungwe hoes were selling at $200 /-$ to 250/- shillings in Mbeya.

2. The Ufipa hoes $(31 / 2,3$ and $21 / 2$ lbs) have a slightly curved cutting edge, but with a flat blade

like the R/E hoes. The hoe derives

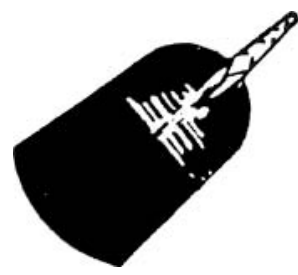

Ufipa Hoe

its name from Ufipa Plateau in

Rukwa Region, where the large sizes are preferred by the Wafipa who have a highly skilled and well-established blacksmith tradition. The hoe is also common in Mbozi and Ileje Districts in Mbeya Region. Songea and Mbinga

districts in Ruvuma prefer the $31 / 2$ lb Ufipa hoes, and so do Ludewa, parts of Iringa, Mufundi and the southern parts of Njombe district in Iringa Region, bordering on Ruvuma Region. The rest of Njombe and Iringa districs prefer the 3 lb Ufipa hoe (and R/E hoes).

The peasants in these areas express their preference for the larger hoes in the following way: 'It is a waste of time and effort to use smaller hoes'. This is understandable when one observes the huge ridges and seed beds built in the Southern Highlands, which require considerable movement and scooping of the light, friable volcanic soils, which are found in most places. It is interesting to note that the large Rungwe hoe is used by the Wanyakyusa in Kyela as well for flat (sesa) cultivation of rice on heavy clay soils.

Here cultural preference seems to override the influence otherwise exerted by the type of cultivation system and soil on the type of tools preferred. One would think that smaller hoes would be more manageable in such a farming system and in such heavy soils.

In Ruvuma Region, the second half of the $1970 \mathrm{~s}$ has seen a change from the checkboard pit and mound cultivation system (e.g. Matengo) with millets and root crops towards flat cultivation of maize. This change has been 
associated with a gradual replacement of the $31 / 2$ lb tanged hoe by the 3 lb $R / E$ hoe. While this seems to be a functional change in the type of tool used to fit a new farming system, the change is also reported to be a result of irregular supplies of tanged hoes.

Digging hoes generally become unusable as large sized dependable tools for primary cultivation, either because of wear (most common) or because of breakage. The abrasiveness of the soil - together with the quality of the blade material, heat treatment and rate of use determines the rate of wear. For example in areas with sandy soils and a high rate of use (e.g. Mwanza, Iringa and parts of Tabora Region), the life span of a Chinese or UFI hoe as a dependable and efficient digging tool is only one year. In Singida and Dodoma, also with sandy soils, but with smaller acreages cultivated per household because of a short cultivation season, a hoe lasts between one and two years. In areas with heavy clay soils or light volcanic soils, e.g. Arusha, Kilimanjaro and Mbeya, a hoe takes 3 to 5 years to wear down to the extent where it can no longer be used for primary tillage (digging and ridge building).

In the latter areas - and in areas with a lot of gravel, stones and stumps - breakage is normally the reason for hoes becoming useless, due to metal fatigue, hitting stones and stumps, or to breakage of the blade when working in sticky or hard clay soils. Part of the cutting edge breaks off when hitting a stump or stone, or a vertical crack occurs in the blade, neither of which can be easily repaired. The hoe blade may also break horizontally above the hardened section, and can then be welded if such facilities are available - which they are not in most rural areas.

As a result of too low a supply of the required hoes over the last five years, the condition of hoes in most areas in 1983 is very poor and far below the acceptable standard required for efficient work rates and proper tillage of the soil, Thus, the drudgery of work and the time spent per acre tilled has increased, while the 
depth of tillage and the thorough working of the soil has declined, possibly affecting yields negatively.

However, we did not find that the shortage of tools had been such that there hade been an acute tool starvation to the extent where the cultivated acreage had declined.

The Moon Shaped or Half Moon R/E hoe ( 3 lbs) is a Chillington weeding hoe which over the last ten years or so has become increasingly popular in Arusha and

Kilimanjaro Regions where it is

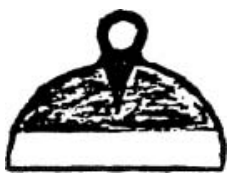

Moon Shaped Hoe calied "Scooter' or Ambassador's hoe (jembe scooter or jembe balozi) because of its high rate of working efficiency. Its broad straight edge and its thin blade, which makes it feel light for its size, make it an excellent weeding hoe when used for light, volcanic soils with broadspaced perennials like coffee, banana and cluster of fodder grass. It is thus associated with the coffee-banana systems of Arusha - Kilimanjaro, and is less common in Mbeya and Kagera, probably due to lack of supply. In the Moshi town market, Half Moon hoes were selling at $80-85 /-$ shs as compared with the official price of $63 / 52$ shs

The Forked Hoe (Rato) is a R/E three or four pronged hoe of which the 3-pronged is the most common, although

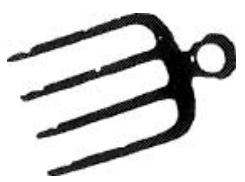

\section{Forked Hoe} (3-4 prongs) not everywhere the most popular. The forked hoe is mainly imported from the U.K. (Chillington) or from China, although a few have been imported from India, The latter are slow moving or not selling at a 11 because they break too easily, while the Chillingtons are the most popular. 
The Forked Hoe (3-pronged) also tends to be associated with the coffee-banana systems of Kilimanjaro, Arusha,

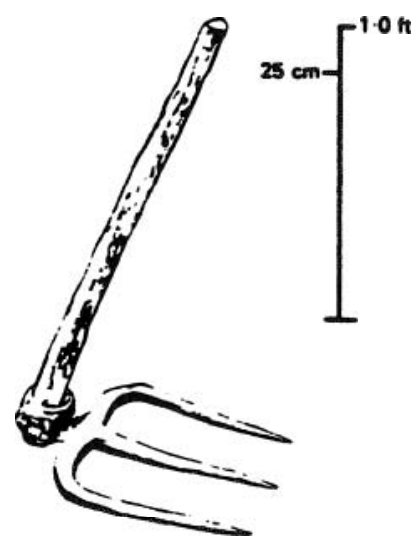

Kagera, Mbeya and Tanga Regions, in some of which it is in high demand and fetches black market prices during supply shortages. It is used for weeding in grass-infested coffee and other perennial tree crops because it does not cut their roots, and also for breaking grass-covered land.

\section{The Forked Hoe}

The forked hoe is also found to a lesser extent in regions like Iringa, Mwanza and Morogoro where it is used for breaking grass-covered virgin land or old fallow land, or breaking heavy clay soils of irrigated land. In Iringa the four-pronged hoe is the most popu$1 \mathrm{ar}$.

With respect to the forked hoes, there has been a problem - at least before the crackdown on "economic saboteurs" - of misplacement of supplies to RTC's. Thus, while there was a serious shortage of forked hoes in Kagera - from where some of the hoes may have been smuggled out of the country - the RTC store in Hanang District, where forked hoes are not used, found itself with a stock of non-moving forked hoes. To try and get rid of them, one case ( 24 pcs) of forked hoes was tied to the sale of one dozen trek chains (for ox-ploughs) as allocated to various village shops. Although there was a crying demand for chains in the district, the result was that neither chains nor the forked hoes were collected by village shops since they could not afford to stock up with forked hoes which nobody wanted. And Kagera was probably too far away for the middlemen to take action on redistributing this misplaced stock. 
The Curved and Straight Matchets (panga) are imported from China in two sizes each: 16 and 18 inches (41 and $46 \mathrm{cms}$ ).

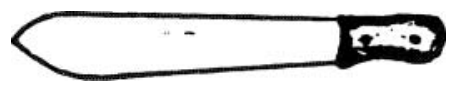

Straight Matchet

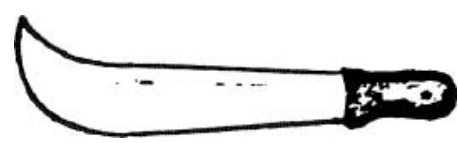

\section{Curved Matchet}

Matchets are fairly simple to produce by punching the blade out of pressed, tempered sheet metal, and they lend themselves to both large- and small-scale production techniques. According to TISCO (1980: Table $7.1 .2 . b)$, the sales of the four varieties are fairly equally distributed, although with a somewhat larger sales of the curved matchets.

Our findings confirmed that there was generally no particular preference as regards the length of matchets, although men might prefer the long ones while women might prefer the short ones.

In some areas, like the coastline regions and areas with use of indigenous bill-hooks (e.g. Singida) there was a preference for curved matchets. Here, they are sharpened along the upper inclined curve for use as bill-hooks. If a sufficient supply of both curved and straight matchets were made available to the consumer, the curved matchets might well take an even higher share of sales. In many areas the sharp pointed tip of the curved matchet is broken off to avoid injury to the user in case it happens to slip during use.

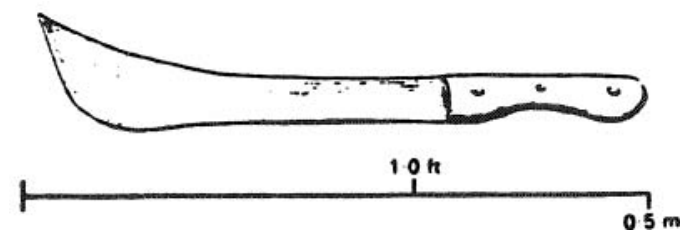


Matchets are used for cutting firewood and bush, for clearing fields of heavy grass and heavy brush wood, and also for a variety of other household tasks.

Matchets are also used in most town households, including in butchers shops, and by the so-called "panga gangs" (burglars or robbers) as a weapon. The first thing to break on a matchet tends to be the handle. A cloth is then wrapped around the iron handle piece or a new handle is fitted made out of wood, old tyres, etc. Matchets have to be sharpened (on stones) regularly and the blade consequently narrows through wear and resharpening.

According to TISCO (1980: 7:2), "1ife expectancy of this tool is 9-12 months when in continuous use". Unless continuous use is taken to infer daily eight-hour use - which would be a rather unusual usage pattern this statement is misleading. In areas with a high rate of use, plenty of bush clearing and lots of hard wood (e.g. coastline and "Miombo" regions and areas with slash and burn cultivation, tobacoo and charcoal production) a matchet would last around three years as a large-sized dependable tool. In other areas with less intensive use, a matchet will last 5 to 8 years.

In a number of areas where indigenous bill-hooks are common (e.g. Southern Singida Region, parts of Mbeya, Ruvuma, etc.) far from a 11 households possess matchets, while in some areas (like Iringa) a household should ideally possess two matchets, one each for the husband and wife. A large proportion of the matchets seen by the study team were in a poor and worn down condition, beyond the state necessary for the tool to be dependable, due to unsufficient supplies reaching the rural areas.

Round-Eye Axes (shoka) of $31 / 2,3,21 / 2$ and 2 pounds were previously imported from the U.K. but now mainly

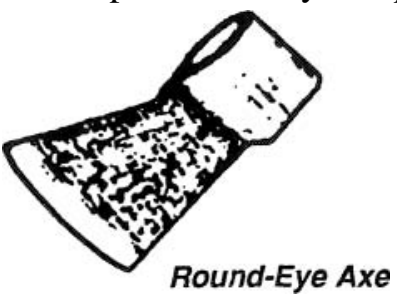

originate from China (Diamond). The three $1 b$ axe is generally the most preferred weight. R/E axes are forged in one piece, require heat treatment and thus lend themselves to large-scale mass production techniques. 


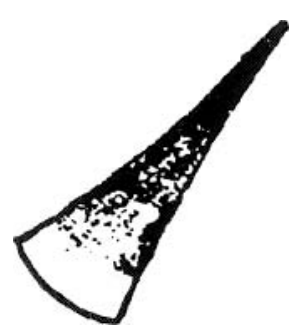

Tanged
Axe
Axes are used for felling trees, clearing heavy bush, destumping fields, cutting and chopping firewood, cutting of poles for house construction, etc. Following hoes and matchets, it is the third most common farm implement in Tanzania, although use of indigenous-made tanged axes is very common in a number of regions (e.g. the southeastern regions, Singida and Meya).

The lifespan of factory-made axes varies a great deal, depending on intensity of use and prevalence of hard wood. As with matchets, axes as a large-sized dependable tool may only last 3-5 years in "Miombo" areas with very intensive use - like those of slash and burn cultivation, tobacco and/or charcoal production - while in deforested areas 1 ike eastern Shinyanga, an axe would last some 15 years ( - in fact we were told that axes were banned there). When used for clearing stumps and cutting firewoood, the axe might hit a stone and breakage of the edge might occur. On the whole, life expectancy of an axe is longer than that of matchets and would tend on average to range between 8-12 years. TISCO $(7: 6)$ mentioned 5 years.

The team found a good number of axes above 12 years of age but they were quite worn down and used mainly by women and children for chopping firewood. For tree felling the husband would borrow a large newer axe if available.

Some villages in Tukuyu had not seen factory-made axes on sale for years and were left to rely on indigenous tanged axes, most of which tend to be of lesser weight and thus less appropriate for the heavier tasks,

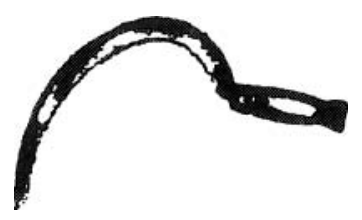

Sickle

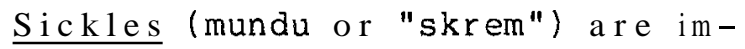
ported from China in lengths of 16 or 20 inches. The cutting edge of the Chinese sickles is serrated, i.e. toothed or notched like a saw edge. 
The imported sickle is on the whole not a common farm tool in Tanzania, largely because a variety of locally indigenous-made harvesting knives, sickles and longhandled bill-hooks, designed with sharp edges for more versatile use, are preferred. Imported sickles are used for harvesting rice, subsistence wheat (Mbulu, Njombe and Ufipa Districts) and finger millet. They are furthermore used for cutting fodder grass and especially thatch grass for roofing material. The imported sickles are mainly supplied to the southern, western and northern highland areas and to Sukumaland and Tabora. Depending on rate of use, a sickle will last some $3-5$ years.

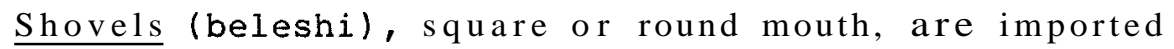
from China. The production technique is fairly simple

and involves punch-

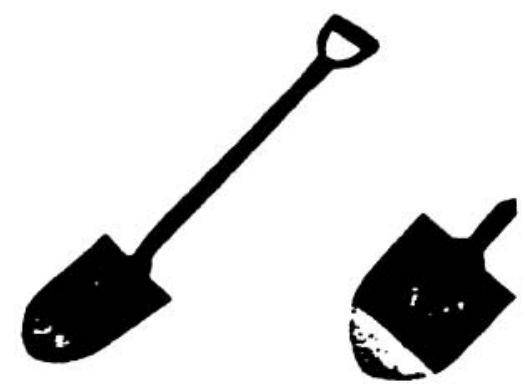

Round Mouth Shovel ing and pressing of sheet metal and the fitting of a lathe-W Qked wooden handle. A smallscale workshop in Arusha (Hans Paul Singh) has recently started batch production of roundmouth shovels - an exact copy of the imported Chinese

one - with indigenously invented self-made machinery. ZKK/Mbeya also has plans to produce shovels. Some spades have recently been imported from Yugoslavia. The spade is a soil digging tool and is not a farm implement but is used as a garden and construction tool in Tanzania

The shovel is an earth-scooping/lifting tool and is still not a common farm implement on smallholdings although they are being more widely used. Apart from their use in road and building construction and as a garden tool, shovels are often associated with wheel barrows in villages and are used for building material 
work, loading and spreading of manure, for digging latrines and for other odd jobs. Borrowing and lending is common.

TISCO (1980: 7:4) mentions instances of blackmarket shovel prices, despite TISCO's demand estimate showing an excess supply. In Iringa where wheelbarrows have become increasingly common in a number of villages, TFA reports a high demand for shovels, the round-mouth ones being preferred. The team was unable to estimate the life span of shovels, since it only encountered two round-mouth shovels during its mission, and omitted to enquire about their age and life expectancy. Nonetheless, we consider it possible to offer a guesstimate of around 5-8 years life expectancy - longer for manure application but shorter for earth work and latrine digging.

Wheel barrows are still possessed only by a fairly limited number of households and are mainly used in the larger semi-urban villages. But the use of wheel barrows - most of them local designs made out of wood with some of the better two-wheeled ones fitted with old car wheel bearings - is evidently becoming increasingly common. They are used for transporting building material, manure, crops, firewood, charcoal and water. Wheelbarrows are often hired or borrowed and there is a growing demand for them.

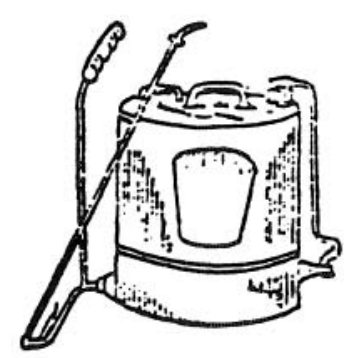

Knapsack Sprayer
In addition to the above-mentioned hand tools, a number of others are imported and which are generally of less importance for peasant farming, perhapswiththe exception of knapsacksprayers which are used in coffee, tobacco, cotton, and previously in the wheat areas of Arusha. TISCO estimated that the annual demand for sprayers was about 75000 . 


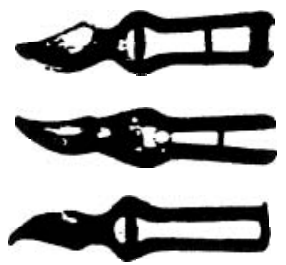

Pruning Shears
Pruning shears (secateurs) for the coffee areas are now being produced by Mocco at the Moshi SIDO Estate. The demand is fairly low. Both sprayers and pruning shears are hired or borrowed a great deal.

Cutter mattocks (jembe-shoka) are used in some rural areas to desturnp fields or to remove unwanted banana

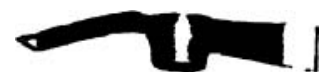

Cutter Mattock (5 lbs.)

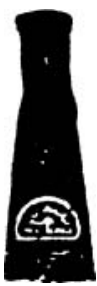

Chimbuo

or

Coffee Digger

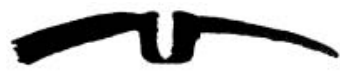

Pick Mattock (4 1/2-5 Ibs.) suckers. For removing banana suckers, a more common implement used, especially in Kilimanjaro, is the indigenous 'chimbuo', a large longhandled chisel type of stabbing implement quoted by UFI a s a 'coffee digger'. Some RTC's, for example the one in deforested Shinyanga, now have large, slow-moving stocks which were sent there by the UFI without firm orders from the RTC. This applies even more to pick-axes or

pick-mattocks (sululu), being a tool for construction work and not a farm implement. The team, during its ruralmission, encountered only one rich ox-farmer who, just having acquired an ox-cart, was in the process of removing large stones from a roadside cattle track along which he was going to use his cart. This farmer had two or three cutter mattocks which he used to destump fields with. Pick-axes are useful for digging latrines in stony ground.

Grass slashers (Eyeko) and rakes are primarily used as garden tools, although a few rakes have found their way to rural areas where they are used in vegetable gardens, and for collecting debris to be burned before 
the rains. The grass slasher is a rare farm implement. Cane knives (for harvesting sugar cane) and sisal

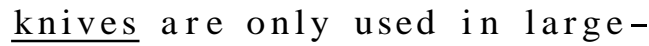

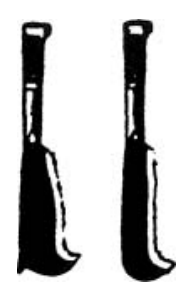

\section{Bill-hooks}

(factory type) scale estate farming. Bill-hooks have not been imported by UFI for some years although bill-hooks might sell well because of their usefulness for clearing bush. Indigenous bill-hooks are very common and are fitted with long handles (up to 1 meter) as compared to the $15-20 \mathrm{~cm}$ handles of the imported type.

The list above largely covers the factory-made hand tools used by peasant farmers in Tanzania, but for one or two important exceptions, i.e. files for sharpening tools (especially matchets) and perhaps also hammers for house construction. We encountered quite a few files possessed both by peasant households and by blacksmiths. There were strong complaints from both quarters on the unavalability of files for a number of years now, and a 11 the files seen were completely worn down and apparently only kept as souvenirs of better days. Files are in demand by rural households and are useful and efficient for both tool sharpening and the occasional on-farm steel repair work. Wood splitting wedges are also popular in a few areas for splitting logs and poles. They are mainly used in forestry activities by lumberers and pit-sawers.

Finally, buckets (ndoo), tins (debe) (both 20 litres), and not least steel drums (pipa or dram) (200 litres) are very common household items. Metal buckets used for carrying water on the head are now possessed by most rural households and are increasingly supplied by indigenous rural and urban tin smiths because the twenty litre tins (debe) have become more difficult to obtain. Factory-made drums or barrels have become increasingly popular, both for beer making and not least for water storage and for ox-drawn water haulage by means of ox-carts or locally made sledges. Comprehen- 
sive ox-mechanization must involve a sufficient supply of steel drums. Needless to say, ox-drawn water haulage by means of drums greatly relieves women, children but quite frequently now - also men, of arduous and time-consuming head porterage.

Simple post-harvesting equipment like hand-operated maize shellers, grinding mills, groundnut shellers, winnowers, threshers and seed dressers are hardly being used on peasant farms so far. OxFAM has recently started a project for introducing hand-operated grinding mills and interest in these is reported to be good in some areas, especially in Iringa, while their adoption is slower in poor areas like Dodoma and Singida.

In the period 1978-80, UFI's national sales of maize shellers and groundnut shellers averaged only about 200 units and 50 units per year respectively and most of the shellers apparently remain unused in RTC stores.

\subsection{Description of Factory-Made Ox-Drawn}

Implements Used in Tanzania

The following section provides a description of the most common ox-drawn factory-made implements found in Tanzania, most of which have been imported or assembled by UFI from semi-finished imported kits. Recently introduced designs like the Themi 'Kabanyola' toolbar and the SIDO Wooden Beam Plough will be described in Chap$\mathrm{te} \mathrm{r} 2.4$.

\subsubsection{The Ox-Plough (plau au jembe la ngombe) most} common in Tanzania is a $1 \mathrm{ight}$ ( $31 \mathrm{~kg}$ ) single-furrow mould-board plough with curved rail beam and furrow depth wheel or drag wheel. It is of Indian design (Cossul), and until recently most of the ploughs sold in the country were imported from Cossul in the form of semi-finished kits which UFI assembled. 


\section{UFI PLOUGH}

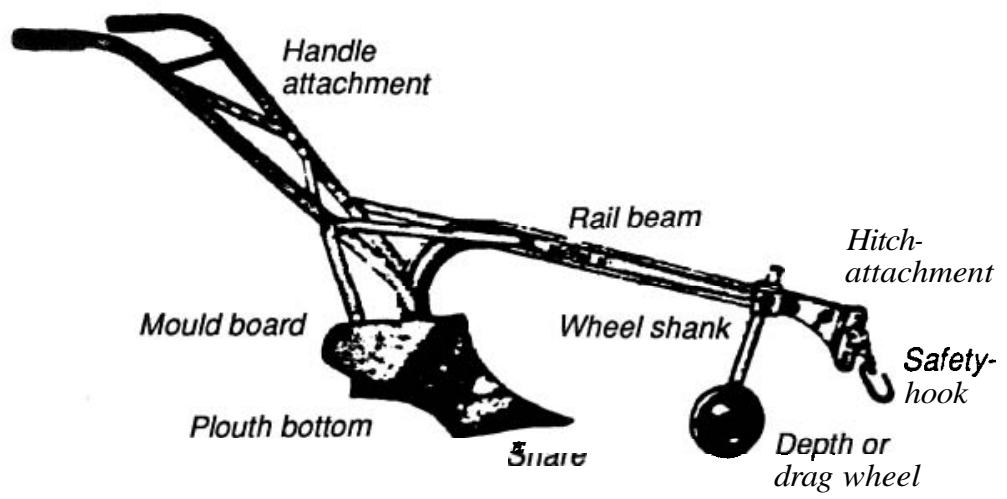

Most of the plough parts are either forged (the beam) or cut from steel bars or sheets and then bent into shape. The wheel is made of cast iron, and the plough parts are bolted together with almost no welded parts. The removal of broken or
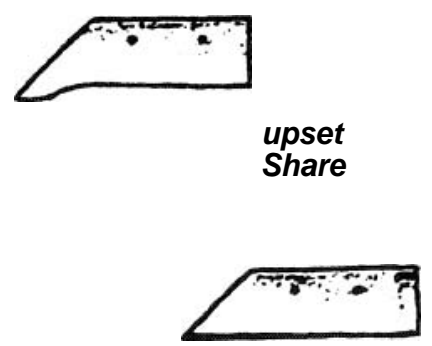

\section{straight Share} worn parts for replacement of new ones is thus easily done by plough owners in the village if they can get the spares - which they normally cannot. However, there are 9 different sizes or types of nut and bolts to hold this plough together and they easily get loose, wear, break or get lost. Apart

from normal strain and metal fatigue, the nuts are not always tightened after each day of work, partly because the spanner, which comes as an accessory with the plough, is of poor quality and difficult to use. There is an urgent need to standardise the nuts and bolts and to use nuts/bolts with a locking device to ensure that they stay tight. A large number of ploughs are in a deplorable condition simply because of the nuts and bolts problem. 
The Cossul or UFI plough has one very important quality: it is light, weighing only 31 kilos. This makes it extremly popular among most peasant households who generally possess small-sized, light and thus weak oxen. It has become increasingly common for young boys and even women (in Tarime and Njombe) to operate the ploughs, and their light weight further eases transport to fields and in some areas lifting of the ploughs when turning.

Most other parts of this Indian plough are, however, of poor quality. The angle of the frog often varies from plough to plough and thus also the approach angle (between share and ground). The approach angle is vital for ensuring proper entry into the soil and working stability of the plough. We saw a number of ploughs where the share fitted very poorly into the mouldboard. Some of the mouldboards do not even comply with the full standard size. Even the size of the standard mouldboard is already at the lower end of what is required for good turning of the turf, which results in poor weed control.

The cast iron wheel breaks easily, and the axel-bushwheel fitting is of poor design and quality. It wears down after just a couple of seasons' work, so that the wheel wobbles and starts to cut through the wheel shanks or holders. The hitch plates are bound to break very soon and with the exception of a few new ploughs seen, local makeshift hitching devices had been fitted, mostly making the safety hook unusable and thus increasing the danger of damaging the plough when hitting a stump.

The landside wears down quickly (after 2-3 seasons), the wheel falls off and the lower end of the beam consequently starts to wear up to the lowest bolt hole. When that happens a new plough has to be bought and this wear may take as 1 ittle as 5-6 years in the sandy soil areas of Singida, Nzega, Mwanza, and Iringa. Thus, the official estimate of an average life-span of ten years of a plough no longer holds, not even in areas with light volcanic soils. 
The reason for this is that the ploughs are of poor quality, that there has been a virtual spare part (and plough) starvation, and that the ploughs are everywhere used to their full capacity, i.e. at a rate of some 20-25 acres per plough per season. This full capacity utilization - which is otherwize a rare feature in presentay Tanzania - is mainly achieved because it has become extremely common for two and even three or four peasant households to cooperate in the use of the ploughs through the pooling of oxen (3-4 oxen are required) and labour (2-3 persons) to form a whole team. Hiring out of ploughs and ox-teams is also common but less so than cooperative pooling of ox/labour work teams.

As noted in the first part of this chapter, Kilimo (Min. of Agriculture) conventionally estimates that $85 \%$ of Tanzania's cultivated acreage is cultivated by hoes, $10 \%$ by ox-ploughs and $5 \%$ by tractors. The tractorploughed acreage has most likely declined somewhat over recent years, due to unusable tractors, lack of spares, shortage of diesel and high - but probably economic charges on hiring tractors, which have made peasant turn to ox-ploughing. According to the Minister for Agriculture, Professor Machunda, it is now government policy to reduce dependency on the hoe from $90 \%$ of cultivated acreage to $70 \%$ by 1990 and down to $50 \%$ by the year 2000 .

According to our survey evidence from eight major plough regions (only Mara, Rukwa and Dodoma were not visited), a rate of 20 acres per plough per season for primary tillage indicates that the peasants have already achieved the 1990 target by applying their own economies of scale, and quite unguided by government policies or targets. In fact, a flooding of the market with good quality ploughs would most likely, at least for the first 6-8 years, involve a further expansion of the ox-ploughed acreage, even without the government or party having to 'educate' peasants on policies or targets. To concentrate efforts on supplying ploughs and other needed inputs is probably more productive than educating the peasants on something they are going to do anyhow. 
In the major ploughing regions there is now a virtual surge for ploughs - still fetching blackmarket prices in some areas, though there is much more limited blackmarket dealing than before the crackdown in March 1983. This regional demand should be satisfied before any attemps are made to introduce ploughs in the coastal, southern and western regions where, on the whole, there are no cattle and no culture and skills in cattle-keeping. A culture of, and skills in, cattlekeeping is a prerequisite for ox-cultivation. It has historically taken traditional cattle-keeping regions decades to adopt ox-ploughing. And the culture and skills of cattle-keeping are acquired by day-to-day growing up with the cattle.

This historical and cultural fact is worth keeping in mind before venturing into new regions with a policy of promoting ox-ploughing. Otherwise, there is a danger that any draught oxen introduced will die of trypanosomiasis (tsetse) or other diseases, or will be slaughtered for a precious beef feast, and the ploughs will rust unused - as has happened, for example, in Lindi and Mtwara upon similar attempts in the 1960 s and early $1970 \mathrm{~s}$.

Attempts at introducing ox-ploughing should not be made i n Kagera, Mtwara, Lindi and Coast Regions. However, it is possible that Songea District in Ruvuma Region will start taking to ox-ploughing within the next decade due to changes in the farming system towards flat cultivation of maize, commercialization of food crop production (maize), the improved road to Njombe, more clearing of bush and in-migration of WaBena and, we have heard, Wasukuma and their cattle herds. Some ox-carts from Mbeya have already been sold in Songea.

1.3.2 The Ox-Drawn Ridger (jembe la matuta) is imported by UFI from Cossul in India. Apart from the ridger bottom, its production and design is somewhat similar to that of the Cossul plough, with a short curved iron rail beam and a furrow depth wheel, but with a different handle assembly, The ridger share is a one-piece upset share and adjustable wings are fitted to the mouldboards. 


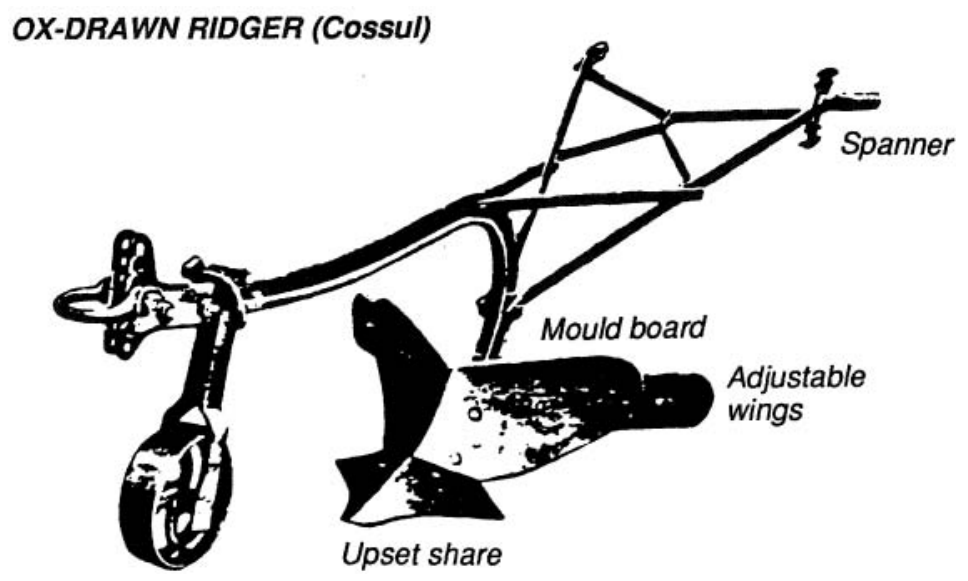

In 1983, UFI ordered 1500 ridgers from Northland/ Zambia under the Tan-Zam barter trade agreement. Of these, only 200 had been received and sent out to the RTC by mid-December, 1983. The team did not get the chance to inspect these ridgers. Despite a delivery agreement, Northland/Ndola is now unable to fullfil the supply schedule and has asked for postponement of delivery until 1985. The company is said to be smaller than UFI.

The ridger is still seldom found on peasant farms and most of those sold by RTC's or TFA are found in Iringa (Njombe), Tabora (Nzega), Shinyanga and Mwanza (Kwimba). The RDD survey at the end of 1975 found 343 ridgers in rural villages. 1 The FAO/Kilimo Survey, conducted between 1976 and 1978 (Dagg, 1978), recorded a total of 757 ridgers in the country, with 340 in i n Shinyanga, 236 in Tabora, 58 in Mbeya and 23 in Singida (Kjærby, 1983a: 82).2 In 1982, UFI supplied 375 ridgers of which 183 went to Iringa (The EEC-funded

1. Ripoti ya Kamati ya uchunguzi wa mahitaji ya zana za kilimo, Jan. 1976 - henceforth referred to as the Regional Survey of 1976, or the RDD Survey.

2. When the team visited Ilongero Ox Training Centre (Kilimo OTC) in Singida in Oct. 1983, it counted 12 unused ridgers rusting there. 
Oxenization Project) and 96 t o Mwanza and Shinyanga each.1 TISCO (1980) estimated that in 1982 and 1986 there would be a demand for 630 and 850 ridgers respectively, based on the assumption that the ratio of ridgers to ploughs found in 1979 would prevail in the future. This method is not reliable.

RTC stocks of ridgers where seen by the team in Mwanza and Shinyanga and they were also reported as slowmoving items of stock by other RTC's. Some of these ridgers lacked essential parts and most of them had never been sent out of central RTC godowns to retail outlets, let alone to villages. Thus they cannot be said to have been made available to the peasants.

Thus, due to low supply, lack of shop display, lack of parts and lack of demonstration on peasant farms and testing of ridgers, the ox-farmers in most villages in Tanzania have never seen ridgers, nor have they had a chance to buy them. This is most unfortunate since the ridger is, without doubt, the single most useful oximplement after the plough. It is a multi-purpose implement, particularly useful for inter-row cultivation (both for the first but even better for the second weeding) for ridge building and for potato and groundnut 1 ifting. Where limited, insufficient demonstration has been done, peasants have complained about too high prices - a criticism which is hardly justifiable. Until August 1983, the Cossul ridgers have been sold at around the same price as the single furrow-ploughs.

However, peasants feel that this (cheap) ridger is too expensive, because its usefulness has not been sufficiently demonstrated to them, because its introduction and use involves a complex of new methods, i.e., row planting with equal spacing, better and more arduous training of oxen and use of halters (with mouth straps or baskets to prevent the oxen from eating the standing

1. UFI Marketing Statistics, 
crop, etc.). Secondly, inter-row cultivation involves a risk of oxen trampling the crops, particularly if they are not trained and properly controlled. Thirdly, for the peasant the investment in a ridger might be more expensive than hiring wage labour to do the job riskfree. Fourthly, a cheap ridger might not be able to compete with the low cost of his own family labour. The relative economics of the two latter points are presently undergoing drastic changes with high unofficial food crop prices and rising rural labour wages.

In Iringa and particuarly in Njombe, where there have been good demonstrations of ridgers since 1982, and where ridgers are lent out to farmers free of charge to encourage their use, the popularity of ridgers is rising rapidly. For example, Mayale OTC (Ox Training Centre) east of Makambako (Njombe District) has only 5 ridgers (due to lack of supply from UFI) but got some 200 advance bookings from neighbouring peasants in the 1982/83 weeding season, one year after their introduction in the area. The Iringa Project could sell an increasing number of ridgers, were it not for lack of supply. Use of ridgers is also picking up in Shinyanga, where the World Bank funded RIDEP is undertaking peasant farm demonstrations of equipment and fieldvisit training of Kilimo extension workers.

It is unfortunate, and quite astonishing, that the Government has decided to raise the price of ridgers by almost 300 per cent to Shs. 2,453/- at the same time as the Government has adopted, and is claiming to promote, a policy of comprehensive ox-mechanization by such statements as: the peasant must adopt a full package of equipment. The prices of inter-row cultivators and harrows have also been raised by 300 per cent to simi1 a r exorbitant levels.

Needless to say, such price increases on new intermediate equipment - which under the current circumstances could provide the next important step in peasant farm mechanization - amounts to discouragement of comprehensive ox-mechanization. 
1.3.3 The Ox-Drawn cultivator (jembe la Kupalilia) is also imported by UFI from Cossul/India. Its design is similar to the conventional and outmoded cultivator design used by the European settler farmers in eastern and southern Africa from the 1920 s until the Second World War, when tractors replaced ox-powered equipment on the large estates. All the various flat bars used are steel rolled (forged). The wheel is cast iron. A large number of different nuts and bolts holds the cultivator together.

\section{OX-DRAWN CULTIVATOR (COSSUI)}

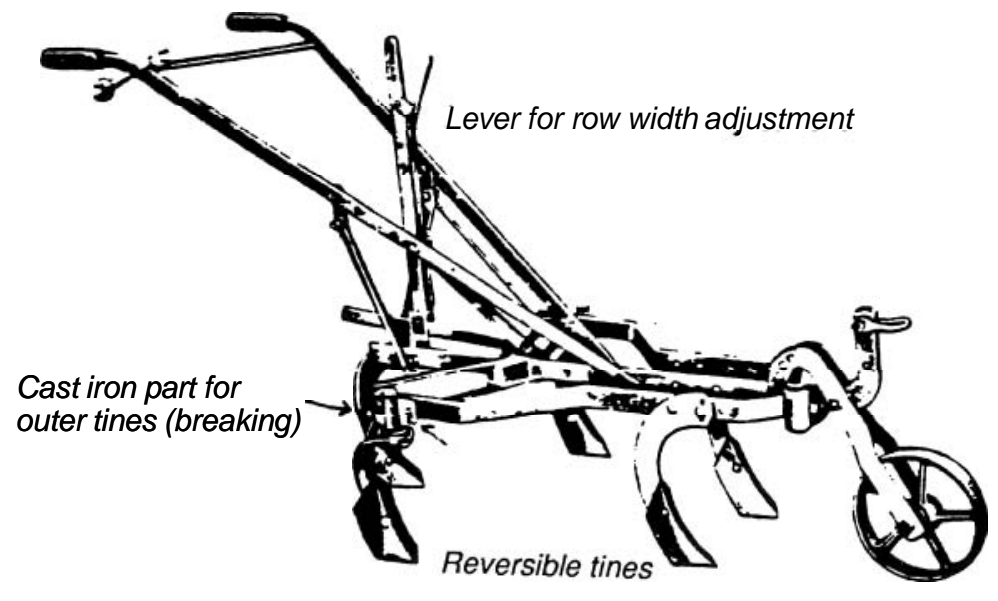

There are two major and unnecessary problems with the Cossul cultivator. First of all the row-width adjustment mechanism, activated by pulling the lever, is an overly useless and sophisticated mechanism, involving fragile movable parts and a whole range of loosely fitted nuts and bolts - loose enough to enable movement of the mechanism but also loose enough for the bolts to wear down and get lost under peasant farm conditions. Since the adjustment mechanism cannot be operated when the cultivator is working, it is an unnecessary sophistication which lends itself to rusting and breakage. Servicing and maintenance of this cultivator requires frequent greasing and grease is just not available in the villages. 
In a 11 the West African countries (Senegal, The Gambia, Sierra Leone, Mali, Upper Volta, Nigeria, etc) where ox-cultivation has progressed well beyond the stage of Tanzania, the designs used and most widely adopted on peasant farms, involve tines fixed to and adjustable for row width by means of clamping systems fixed to Tframes of rectangular or square steel beams (of the Sine Houé, the Multi-Cultivateur, the Pecotool, etc). This gives strength, durability, simpleness and cheapness.

The other problem, connected with the first one, is that the two outer row-side tines are fitted to the steel bar frame by means of a cast iron piece which can be turned along its vertical axis to enable proper readjustment of the tine cutting angle, whenever the cultivator's row width is adjusted. In all places visited by the team this cast iron piece was reported to break and no spares are available. Unless a welding service is within reach, the implement has to be scrapped something which is not popular among the peasants who have made the investment. And a welding service is mostly not within reach in the rural areas.

Like the Cossul Ridger, the inter-row cultivator is a fairly light implement. Light-weight ox-implements are highly valued among the peasants, and objectively this is also most appropriate, due to the very - and increasingly so - small size of draught oxen in most parts of Tanzania, and also because young boys and even women are increasingly operating the implements. The light weight is also an advantage in transports and when making turns at the headlands. But this does not change the fact that the implement is too fragile, overly sophisticated and too expensive for Tanzanian peasant farm conditions.

Like the ridger, the cultivator is still a rare implement on peasant farms, with most of those sold by RTC's and TFA in Njombe/Iringa and in Shinyanga. The Regional Survey of 1976 recorded 204 cultivators in rural areas. The figures from the FAO/Kilimo Survey (1976-78) cannot be used since the report (Dagg, 1978) lumps 
weeders (cultivators) and harrows together in one category. Of the 5999 items in this category, 5291 were recorded to be found in Aru-Meru District, a figure totally out of proportion both with reality and with the figures given in the table for other parts of the country (for further details, see kjærby, 1983:82).

\subsubsection{Harrows and Planters}

The ox-drawn harrow ('harro') is found in two main types in Tanzania. The first type of harrow, produced mainly by TAMIU and by the Mafinga Workshop in Iringa is a rectangular or angular wooden beam spike-tooth harrow. The second type is a factory-made spike-tooth harrow with a rectangular steelframe imported by UFI from Cossul, India. Like the Cossul cultivator, it is an overly sophisticated implement on which spiked tines (forged) can be lifted in horizontal position by pulling a lever so as to allow collected weeds to slide off the spikes and to ease transport to the fields.

In 1983, UFI ordered 5000 zigzag spike-tooth harrows from Northland Engineering in Zambia under the Tan-Zam barter agreement. These harrows are of the more simple and conventional zigzag design with fairly small sections of appropriate size, which can be attached to each other to extend the width and length of cultivation. By December 1983, only 75 harrows had been received and sent to RTC's. It is doubtful whether receiving RTC's actually sent firm orders on harrows to UFI since many of them have non-moving stocks of Cossul harrows which are impossible to sell.

\section{RECTANGULAR HARROW (Spike Tooth)}

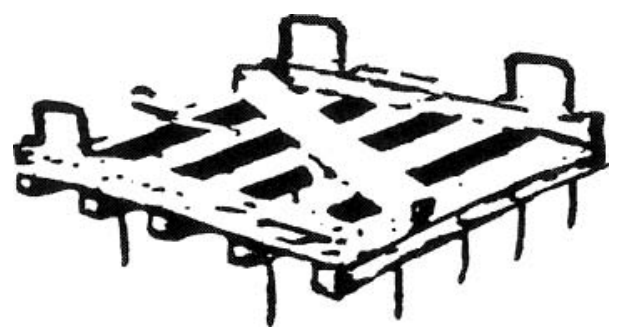

Price: (retail) (as at 1.5.80) Tsh $700.00 \quad(\$ 86.00)$
The TAMIU harrow was described in detail by Kjærby (1983). The main problems with the harrow are that it is too heavy, too difficult to operate and too expensive for being a single-purpose implement of limited utility . 
The Cossul harrow has many adjustable parts, some of which tend to break. The ex-RTC price of both the Cossul and the Zambian harrows was raised from 1,000/to 3,323/- shillings in August 1983.

There are extremely few harrows actually being used on peasant farms in Tanzania. Whatever the design, they have not been adopted, despite their availability. The statistics tend to hide this fact. The RDD survey (end of 1975) recorded a total of 1576 harrows in rural villages, of which 1153 were supposed to be in Mbeya Region and 188 in Arusha. These figures are most likely overestimates. Between 1971 and 1978 TAMTU produced only 53 wooden beam harrows, and probably a similar number were produced at TAMTU's Rural Craft Workshops (Kjærby a:106). Most of these harrows are found at Ox Training Centres and at district agricultural offices.

The figures from the FAO/Kilimo Survey (Dagg 1978) are a lso exaggerated: 5999 harrows in the country, of which 5291 were supposed to be in Arusha and now only 122 in Mbeya. Between 1978 and 1980, TFA in Njombe sold 72 Cossul harrows and TFA in Iringa sold 24. Njombe is a fairly humid highland area with some wheat cultivation, and the use of harrows here is probably justified - although there are no proper research results to confirm this.

The Iringa Oxenization Project has sold very few of its poorly designed triangular harrows. Even in the immediate vicinity of $\mathrm{OTC}^{1} \mathrm{~s}$, very few farmers are interested in borrowing harrows free of charge. In 1982/83 harrows were distributed on credit from TRDB. As noted by the well-informed Regional Oxenization Officer, M Masunga, "It is very easy for peasants to accept implements on credit terms".

It is far from everywhere that the harrow can be considered an appropriate and improved implement in Tanzanian peasant farming systems. Certainly, there is a much greater need for, and also benefit in introducing, appropriate multipurpose ridgers and cultivators, 
preferably as toolbar attachements, before using limited man-power and scarce resources on introducing harrows.

Harrows may be appropriate and have some justification in the wet highland areas, in particular on non-sloping land. On slopes, harrowing may simply increase erosion and water run-off because of the fine flat seedbed created. Again, harrowing before planting may contribute to better and faster seed germination of wheat, sorghum and fingermillet, but not necessarily for maize. Harrowing may improve weed control if done during a dry spell but it may also increase weed germination if done during a wet spell.

In the dry-land areas of Shinyanga, Singida, Arusha and mbeya, harrowing may be inappropriate. Weeds are collected, instead of being left on the ground as mulch for preventing sun burning, soil capping by rain and evaporation. Thus harrowing may cause yields to decline in the drier areas. Harrows should not be promoted until local-specific adaptive experimental research on peasant farms in different areas shows that harrowing is agronomically appropriate and economically justified.

Harrowing is a necessary pre-condition for using oxdrawn seed drills. Some qualified attempts to plant with seed drills of the Cossul and TAMTU designs have failed at OTC's in Iringa. The TAMUU design does not work, and the extremely expensive and sophisticated three-row seed drill from Cossul is insufficiently robust. Most OTC's in Iringa have stopped using planters.

TAMTU OX-DRAWN PLANTER

Price: (as I _ 180) Tsh. 1500.00 (\$185.00)

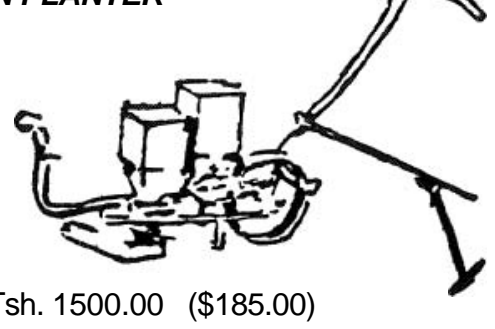


Experience from most African countries generally confirm that ox-drawn planters are, by their very technical nature, sophisticated and expensive implements with many delicate movable parts which tend to break, damage the seeds or clog.

Their usage requires a smooth seedbed of a certain (dry) moisture level as well as high quality graded seeds of good germination power. The technical problems of ox-drawn seeders require an advanced servicing level. Under Tanzanian conditions, all these factors make ox-drawn seeding an expensive technological complex which is unlikely to be adopted. Generally, the fairly limited time used in planting (except for fingermillet), together with the fact that the planter is a singlepurpose implement means that planters are largely unable to relieve labour bottle-necks in African peasant farming. More important, and as confirmed in most other African countries with advanced ox-cultivation (e.g. The Gambia, Senegal, Sierra Leone, Upper Volta), planters are unable to ensure economic returns on the investment made. A good number of peasants in the Gambia and Upper Volta have been pushed into indebtedness through foreign donor and local government efforts to promote the so-called comprehensive package of ox-equipment to farmers on a credit basis.

\subsection{Village Visits}

\subsubsection{Introduction and Methodology}

The purpose of the village visits was to get a first hand impression of the peasants tool inventories, the state of the tools in use, the usage patterns and peasants' own opinions as to the availability of tools from rural blacksmiths and from the formal and informal distribution systems. Our observations were related to the knowledge and experience of the Regional Agricultural Development Officers, RTC and village shop managers, and village leaders. At almost all interviews several peasants were present. Each interview was con- 
cluded by getting general consensus on life-span of implements, average household requirements, shortages, etc.

The survey was conducted as a rapid rural appraisal (Robert Chambers (1980) Rapid Rural Appraisal: Rational and Repertoire, Development Paper No 155, IDS Sussex) on the general farm implements situation in 9 selected regions. As far as we are informed, such a type of farm implements survey is the first of its kind in Tanzania. Despite being spotchecks, we believe that this rapid survey methodology has yielded useful results and may have relevance for other users. The methodology used is described in Appendix 2: .

The detailed results of our interviews and discussions were recorded in Appendix 4:1 of the original report.

\subsubsection{Main Conclusions from Village Visits}

Although we would like to caution against too farreaching conclusions based on our material (we use the term rapid rural appraisal rather than village surveys - and we know that many of the peasants we discussed with were relatively well-off, and not representative of "the average small-scale farmer") our findings seem to confirm the following:

- Household tool inventories consist of 3 to 4 hoes, 1 to 2 matchets, usually one axe, and implements specialized for the crops locally grown.

- There will normally be at least one hoe for each able-bodied household member; the man using the heaviest (and newest) and the female a more worn hoe for primary cultivation and weeding, and children using even more worn hoes for weeding.

- The wear of hoes is basically a function of the abrasiveness of the soil, the intensity of use and quality. Around Mwanza, for example, with strongly abrasive sandy soils and intensive use, a hoe for 
primary cultivation will last as little as one season, whereas around Kilimanjaro and Mbeya, where volcanic soils dominate, a hoe may serve this purpose for 3-4 years.

- A matchet will last at least 4 years before a replacement is considered necessary (even if the handle will often have to be repaired earlier).

- We believe that it is important to study regional preferences for types of hoes and hoe usage. The round-eyed hoe (which comes in 3 sizes) is widely used, but the tanged hoe is preferred in the southern highlands and other areas. The strength of preference varies so that in southwest Iringa, for instance, peasants will purchase and use round-eyed hoes if the tanged hoes are not available, whereas in Rungwe district only tanged hoes are acceptable. It is important that the marketing of this type of implement is based on more detailed investigations of the preferences than what we have been able to make.

- In certain areas special weeding hoes (such as the imported factory-made half-moon hoe or small hoes made by blacksmiths) are in demand, whereas in other areas worn down hoes serve this purpose.

- Factory-made hoes and matchets dominate, but in areas of scarcity (or strong blacksmith tradition) locally made hoes are often found. As far as axes are concerned, blacksmiths make lighter types, whereas the heavier are imported. Locally specialized implements, such as bill-hooks, sickles and many others are normally made by blacksmiths.

The state of wear is generally rather high, but it would not be correct to say that there is a "tool famine" as other studies have concluded.

- There is a marked preference for factory-made implements. However, many peasants complain about the quality of UFI-hoes (the heat-treatment is not properly done, resulting in rapid wear). 
- Repair of broken implements is normally done locally by blacksmiths. A tang is often rivetted to the hoe-blade when the eye has broken off.

- We are convinced that in most cases money is no restriction to the peasant if he has the opportunity to buy new implements.

As has been elaborated in other studies, the use of oxen for draught purposes is restricted to certain areas. The state of the present national stock of oxploughs is rather bad, as the shortage of spare parts is severe. Certain plough parts such as shares, landsides, chains, bolts/nuts, wheel assembly parts, right handles, etc., are in very great demand.

\subsubsection{The Impact of the Farm Implements Shortage on Productivity}

Interviews with peasant households were in most cases completed by discussing the general farm implements situation in terms of tool inventories, average household requirements, usage pattern, shortage situation and the quantity of implements passing through village shops, the black-market situation, etc. Furthermore, the impact of the shortage situation and the poor condition of the implements were discussed. Increased time and drudgery of labour were everywhere mentioned as having become a big problem. In addition, poor tillage of too low depth was mentioned as a problem. There was a tendency to say that the acreage cultivated had gone down in such terms as: "Well, if we do not get hoes, how can we cultivate?" However, when specifically asked whether the acreage cultivated had declined in this very village or whether this had happened for those present, there were generally no clearcut answers or examples, and there was reluctance to reply.

This makes us conclude that there has not been a severe tool famine, but the general shortage and poor condition of tools may have had a negative impact on yields because of poor tillage and because more drudgery has been involved, which further constrains peak labour periods in primary cultivation and weeding. Regarding 
ploughs, there has been a virtual famine of ploughs and spare parts, partly because of the increasing demand for ploughs and partly because the cultivation factor per plough is very high at present.

Essential parts like shares, landsides, wheel assemblies, etc., have been more or less impossible to get for most plough owners, making many ploughs unfit for cultivation and weed control. If more ploughs and spare parts had been available, a larger potential acreage could have been cultivated. Whether this could have raised the total output is an open question, with less clear-cut answers, and dependent on a number of factors, not least the availability of labour for weeding a larger acreage at the right time. Furthermore, the amount and distribution of rainfall, the incidence of weeds and crop pests, the quality of seeds, the application of fertilizers or manure and not least, crop prices, are among the factors which will influence total output in a more direct way than availability of ploughs. This means that there will not be a boom in the output of crops even if there is a boom in the supply of ploughs.

1.4.4 Summary of Household Tool Inventory and Requirements and the General Supply Situation

In this section we have made a regional summary of our village visits and interviews. This summary includes briefs on (1) the farming systems and predominant soils; (2) common household tool inventories for factory-made implements, including the average 1 ife span of the implements and average household purchase requirements; (3) the general shortage and supply situation for farm implements, including briefs on the role or liquidity position of village shops and the role of blacksmiths for supplying farm implements.

Table 1.3 presents an overview of the number of specific farmer interviews by region, district and by socio-economic stratum to which the farmers or households belong: 
Table 1.3 Overview of Farmer Interviews

\begin{tabular}{|c|c|c|c|c|c|c|}
\hline Region & District & $\begin{array}{l}\text { Number } \\
\text { Plough } \\
\text { owners }\end{array}$ & $\begin{array}{l}\text { of int } \\
\text { Rich } \\
\end{array}$ & $\begin{array}{l}\text { erviews, } \\
\text { Average }\end{array}$ & Poor & Total \\
\hline Coast & Rufiji & - & - & 1 & - & 1 \\
\hline Sing id a & $\begin{array}{l}\text { Singida } \\
\text { Rural }\end{array}$ & 2 & - & 4 & - & 4 \\
\hline Tabora & Nzega & 2 & 1 & 1 & - & 2 \\
\hline Shiny anga & $\begin{array}{l}\text { General } \\
\text { Information }\end{array}$ & $n-$ & - & - & - & - \\
\hline Mwanza & Mag u & 3 & 3 & - & - & 3 \\
\hline Arusha & Hanang & - & 1 & - & 2 & 3 \\
\hline $\begin{array}{l}\text { Kiliman- } \\
\text { jaro }\end{array}$ & $\begin{array}{l}\text { Moshi } \\
\text { Rural }\end{array}$ & - & 1 & - & 1 & 2 \\
\hline I ringa & Njombe & $2(9)$ & - & $3(2 g$ & ) - & 3 \\
\hline Mbeya & Tukuyu & 1 & 2 & 2 & - & 4 \\
\hline 9 regions & tota $1 \mathrm{~s}$ & 10 & 8 & 11 & 3 & 22 \\
\hline
\end{tabular}

$(\mathrm{g})=$ grom: farmer interview

The interiews with 22 farmers in 9 regions cannot provide a scientific or representative basis for generalizing on household tool requirements and we recommend that a more general and wider market survey is undertaken to substantiate requirements. Such a survey should in particular cover different areas of environmental types and farming systems selected on the basis of general soil characteristics (with soil abrasiveness as the main factor) and on general tool type preferences as well as tool-crop specificity.

Our basis for generalization stems from the following factors: 
1. Discussions with marketing organizations, regional, district and local authorities. Our farmer interview results generally correspond with official information, in particular with that of local officials.

2. Each household interview was completed with a general discussion with groups of farmers present to get general consensus. Two interviews in different areas of Iringa were group interviews, and these are much more useful as a basis for generalization, although details of repair, breakage, special tools, etc. are lacking.

3. The life span of most implements, in particular of hoes, shares and matchets, is generally so short that it leaves little room for intra-district variance in time.

4. In most cases we have tried to confirm our data through discussions with other people, met more or less accidentally during our $21 / 2$ months stay in Tanzania.

5. Generalizations are, last of all, based on our general and specific knowledge of the farming systems and soil conditions in the different areas. This applies in particular to Coast, Kilimanjaro, Arusha and Singida regions.

Contrary to the general un-informed generalizations made in the TISCO Report (1980), our data are based on a methodology, actual visits in the field and lengthy interviews.

Coast Region, Rufiji District, Ikwiriri Village

In the district there is intensive double-cropping of rice, maize, cotton and cow-peas on alluvial clay soils in the flood plains; and upland shifting cultivation on sandy soils with cassava, pigeon-peas and sesame and a mixed, perennial mosaic of fruit trees and cashewnuts, with low tilling intensity. In the whole district and 
in other coastal regions, there is intensive use of axes, matchets and indigenous bill-hooks for clearing fields and for charcoal production.

An average household with two able-bodied persons cultivates some 2-3 acres with a tool inventory of 1-2 large hoes (mostly R/E), two matchets (there is a preference for curved) and 1-2 axes (R/E or indigenous tanged). A 1 arge hoe 1 asts at least 3-4 years, matchets the same and axes some 5-7 years. A household needs to buy 2 new hoes every 4 th year or 1 new hoe every 2-3 years, a new matchet every 2 nd year and at least one axe every 5 th-6th year. These figures are approximations and not generally confirmed.

The supply of blacksmith-made tools is very important and may affect the rate of purchase of factory-made tools. There is a shortage of large hoes and a severe shortage of matchets and axes. There is lack of village shop liquidity for procuring implements.

\section{Singida Region, Singida Rural District, Utaho \&}

\section{Sekoture Village}

This is a semi-arid region with mainly poor sandy soils and more limited cultivation on black cotton clays. There is small-ridge farming of bullrush millet and sorghum with manuring. In the northern parts of the region there are sandy to clay loams with ox-ploughing and manuring of maize, sorghum, bullrush millet, cotton and sunflower.

An average household with two able-bodied persons cultivates some 3-5 acres, in the north where ox-ploughs are used this increases to 6-7 acres. The household has two large R/E hoes, an indigenous bill-hook, perhaps a matchet and at least one indigenous tanged axe. A large hoe 1 asts $2-3$ years and a normal purchase requirement is one new hoe every year or 2 hoes every 2 nd year, in the north 2 hoes every 3 rd year. A plough share 1 asts $1-11 / 2$ seasons. 
Matchets and axes are generally not in great demand due to the importance of the supply of blacksmith-made implements. There is a virtual famine situation as regards ploughs and plough parts and a critical shortage of the preferred R/E 3 lb hoes. Village shops are in a poor liquidity position as regards supplying farm implements, In a national context, Singida is unfavoured (compared to other regions) in terms of the supply of farm implements.

Tabora Region, Nzega District, Iduguta\&

Miguwa Village

Nzega District is fairly densely populated with the largest ox-plough population (24 000) of any district in Tanzania. The agricultural system is fairly intensive with both ridge and flat cultivation, manuring and diversified cropping of maize, sorghum, rice, cassava, groundnuts, cotton and some tobacco in the south. Soils are sandy to sandy loams.

An average household with two able-bodied persons would cultivate 3-5 acres, more for households owning ploughs. An average household tool inventory would consist of at least two large R/E hoes ( $31 \mathrm{bs}$ preferred), 1-2 matchets and at least one axe. A large hoe used for weeding only lasts 2 years, but only $1-11 / 2$ years if used also for primary flat cultivation. A matchet lasts 4-5 years and an axe 6-7 years. In Urambo and Tabora Districts, there is intensive use of axes and matchets for field clearing and tobacco cultivation (cutting of miombo wood for tobacco curing).

A household needs to buy at least one new hoe per year and possibly 1 1/2-2 hoes per year if primary cultivation is done manually. Two plough shares are generally required per season, and a plough becomes worn out after 5-7 years. There is a starvation situaton for ploughs and plough parts and a serious shortage of hoes and matchets. Blacksmith-supplied implements and repair work is very important. Village shop liquidity is poor. 
Mwanza Region, Magu District, Kabilu \& Ng'haya Village Mwanza Region is generally a densely populated, fairly humid region with a long crop-growing season and with intensive ridge farming on exhausted sandy soils. The cropping system is diversified with a large variety of crops grown, often in mixed stands. Important crops are cassava, sorghum, rice, maize and pulses. Ox-ploughing is of increasing importance due to a decline in tractor cultivation and withdrawal of youths (traditional age group work parties) from agriculture.

An average household with two adult able-bodied persons cultivates 3-5 acres, plough-owning households 6-7

acres. A normal tool inventory consists of 2 or 3 large R/E hoes ( 3 lbs), and at least 1 matchet and 1 axe. The large hoes last only one season, giving a requirement of 2 new hoes per household per season. Axes may last around 10 years and matchets (preference for curved) 5-6 years. Two shares are required per plough per season and a plough only lasts some 5-7 years with the present high cultivation factor.

In Magu there was a general shortage of hoes, a critical shortage of matchets and axes and a famine situation for ploughs and plough parts. Blacksmiths are of great importance in Geita but less so in the eastern areas. We saw one very well-managed village shop without liquidity problems.

\section{$\underline{\text { Shinyanga Region }}$}

Our visit to Shinyanga coincided with a visit of the Prime Minister and there was consequently no opportunity to meet regional and district officials and to undertake village visits. Most time was spent visiting SIDO and the large informal sector producing ox-carts and various accessories. We received both detailed and general information on the farm implement situation through an interview with the RIDEP coordinator Charles Wortmann,

Shinyanga is by far the largest ploughing region in Tanzania and ox-carting is very important. Flat cultivation of maize, sorghum and cotton with ox-ploughs is 
prevalent in the treeless eastern part of the region with prevalence of clay loams and black cotton clays. Kahama in the west has upland manual ridge cultivation on sandy soil, has forest and bushland and is important for charcoal production.

In Kahama, a household needs to buy two R/E hoes ( 3 Ibs) every year and the use of matchets and axes is fairly intensive. In the eastern districts, $1-11 / 2$ large R/E hoes are required per household annually. At least one and ideally two shares are required per plough annually. The requirements for matchets and axes are much lower here.

In Shinyanga, there is a severe shortage of hoes and a desperate shortage of ploughs and plough sparts. These are still partly handled by the parallel market.

\section{Arusha Region, Hanang District, Nangwa and Mogitu}

\section{Village}

The area visited is of medium to high population density with medium rainfall. There is flat cultivation of mainly maize and beans, with some sorghum, on very fertile neovolcanic clay - loam soils. Tractor-hire cultivation is very common for primary cultivation but ox-ploughing is on the increase due to high charges for tractor cultivation. The firewood is mainly softwood.

An average household with two able-bodied persons cultivates 4-5 acres and has an inventory of 2 arge hoes ( $31 \mathrm{bs}$ R/E preferred by men, $21 / 21 \mathrm{bs}$ tanged by many women), 1-2 matchets (preference for curved) and 1-2 axes (preference for 31 bs by men, $21 / 2$ by women). Ideally, husband and wife each would have one axe and one matchet. On average, a hoe 1 asts 4-5 years, a matchet 8-10 years and an axe up to 15 years if both husband and wive each have an axe and a matchet. A household needs to buy no more than one hoe every second year. Plough shares 1 ast 2 years although many would prefer to buy a new share every year. 
Arusha Region has generally been favoured in the supply of farm implements, and apart from some shortage of hand tools in 1980 and 1981, there has been no real shortage of hoes and matchets although there is some problem in getting axes. There is a general to severe shortage of ploughs and especially plough parts.

Village shops generally suffer problems with liquidity and embezzlement of funds and supply very few of the farm implements used. Blacksmiths are of some importance in supplying knives, tanged hoes and plough shares.

Kilimanjaro Region, Moshi Rural District, Dakau Village The majority of the regional population live in the humid Coffee-Banana belt on the mountain slopes with a highly intensive farming system characterized by a dense mosaic of mainly perennial crops and with 2-3 annual vegetable crops. Many households have fields of 1-3 acres in the lowlands which are cultivated with tractors and grown with maize and beans. There is limited ox-cultivation in Hai District.

An average household would cultivate $11 / 2-21 / 2$ acres with coffee, bananas and vegetables (especially beans) on the mountain, and 1-2 acres with maize and beans in the lowland. The household tool inventory is very complex, characterized by a variety of blacksmith-made special tools. A household generally needs 2-3 large $\mathrm{R} / \mathrm{E}$ hoes (preference for $3 \mathrm{lbs}$ by men and $21 / 2$ by women), one forked hoe ( 3 prongs), two matchets (preference for curved $16 \mathrm{inch}$ ) and one axe ( 3 lbs). Half-noon hoes are possessed by perhaps 25 per cent of the households.

A 1 arge hoe 1 asts 3-4 years, a forked hoe 5-7 years, a half-moon weeding hoe 6-8 years, a matchet 5-7 years and an axe 10-12 years. A household needs to buy $1-1$ $1 / 2$ large hoes every second year.

There has been some shortage of forked hoes and there is a high unmet demand for half-moon hoes. Otherwise there has been a good supply of farm implements and an excess supply of ox-ploughs. Blacksmiths are extremely 
important and highly skilled and there is a good supply situation. Most farm implements are sold through the open market system and through private shops.

Iringa Region, Njombe District, Ikelu and Mayale Village

The southern and western parts of the region are fairly humid and densely populated, while the northern and eastern intermediate upland has medium rainfall. The unfertile sandy loams are intensively cultivated with maize, beans, sorghum and some tobacco and sunflower in the drier northwestern area, with general and intensive use of fertilizer and/or manure. Ox-ploughing is common and interrow cultivation with ploughs and ridgers is spreading. Locally made wheel-barrows are common.

The average household cultivating 3-6 acres has two large ( 3 lbs) R/E hoes, one matchet and one axe, plus additional indigenous tools. Sickles used to be common as well but are being phased out for lack of supply. Tanged Ufipa hoes are preferred in the hilly southwestern highlands.

The 1 ife span of large hoes varies and is up to 3 years in the highlands and only 1 year in the more sandy intermediate uplands. Matchets and axes last only 3-5 years, slightly longer in the highlands. A household needs to buy at least 1 1/2 hoes annually in the southwest and 2 R/E hoes ( 3 lbs) annually in other areas. A sickle 1 asts 3-5 years and a plough 5-6 years. Two shares are needed annually. There has been a general shortage of hoes and a more servere shortage of matchets, axes, sickles, ploughs and plough parts. We lack information on village shops, but the region has had the advantage, like Arusha, Kilimanjaro and Mbeya, of having TFA and of being supplied with ploughs through the Regional Agricultural Development Project. Blacksmiths are important for special tool supplies. 
Mbeya Region, Tukuyu District, Matwebe \& Mpugusu

\section{Villages}

Mbeya Region is characterized by great variance with respect to farming systems and altitudes. Tukuyu, and to a lesser extent parts of Ileje, Mbozi (southeastern) and southeast Mbeya district are densely populated, humid and generally hilly areas with fertile volcanic clay loams. The farming system is intensive, with perennial groves of coffe and banana, with large-ridge cultivation of sweet potatoes, maize and vegetables, and with flat or small-ridge cultivation of maize, rice and potatoes on flat plateaus and in river valley depressions (rice). Ox-ploughing is mainly found in the Kyela floodplain (rice) and in parts of Mbozi and Mbeya districts.

In Tukuyu an average household cultivating 2-3 acres would ideally have 2 large tanged Rungwe Hoes (4 1bs); if not available, then one Rungwe hoe and one $21 / 2-3$ $1 / 2$ lb tanged Ufipa hoe or one 3 lb R/E hoe. R/E hoes are not liked. Ideally the household should have a matchet (curved) and a R/E axe ( 3 lbs) but most households do not possess these because of unavailability. Indigenous tanged axes (smaller) and bill-hooks of various sizes are necessary parts of a household tool inventory together with other special tools. R/E axes are borrowed for felling big trees and might, $1 \mathrm{ike}$ matchets, 1 ast up to 10 years. Rungwe and Ufipa hoes last about 5 years. A household needs a new Rungwe hoe every $21 / 2$ years; in Kyela a new Rungwe hoe is needed sooner (about 2 years) due to more sandy soils. A plough share lasts 2 years in Mbeya and Tukuyu and 1 year in Kyela, It is our impression that village shops do supply implements when they are distributed, but private shops and TFA are important as well. Blacksmiths are skilled and very important for supplying special tools. 


\subsection{Ox-Mechanization}

In the early $1980 \mathrm{~s}$ Tanzania has seen an unprecedented expansion and development of the use of animal draught power in peasant farming. The expansion in ox-cultivation, through extended use of the single-furrow mouldboard plough, and through increased adoption of oxcarts, is a result of a number of factors, which can be summarized as follows:

1. There have been changes in land-use and increased labour constraints imposed by villagization, which have facilitated or increased the benefits of animal traction, including the use of ox-carts to overcome increased homestead-to-field distances.

2. In some regions like Arusha, Iringa and the Lake Zone regions there has been a decline in tractor cultivation and soaring hire rates for tractor cultivation as well as high rates for hiring wage labour, the costs of which can be reduced by the use of ox-cultivation.

3. There have been changes in cropping patterns in a number of regions (e.g., Rukwa, Iringa, Arusha, Mwanza, Shinyanga and Mara) from labour-intensive hand-cultivated crops towards more extensively cultivated maize which lends itself to ox-cultivation.

4. Cash is available for the purchase of ploughs, carts and young oxen due to high black-market prices on food crops and high livestock prices. This income largely cannot be spent on the usual consumer goods due to shortages.

5. There has been a withdrawal of older boys and young men from productive agricultural work into education and into petty trading. Many households are faced with a growing problem of labour shortage which is then offset by adopting ox-cultivation. 
6. In some regions like Iringa, Arusha and Singida, there has been support for and supply of ploughs and carts through RIDEPs and missions. 1

There is now a high and growing demand for ox-ploughs and for high-quality, durable (and expensive) carts, pulled by oxen or donkeys.

At the same time, there are improvements in the use of ox-drawn equipment. Some farmers have started to use mouldboard ploughs to throw ridges (e.g., in Mara, Mwanza and Nzega), to undertake double-pass inter-row weeding and to improve row-planting by planting in ploughed furrows. The use of ridgers for ridge preparation, inter-row weeding and potato and groundnut harvesting has started, as has the use of inter-row cultivators for inter-row weeding and early land preparation in a few areas, where extension activities and supply of improved implements have been extended to farmers (mainly Iringa and Shinyanga, due to RIDEP activities).

The use of farm-yard manure, facilitated by means of ox-carts and wheelbarrows, is increasing, and so is supplementary feeding of draught oxen through collection of maize stalks, etc. A few farmers have started to fit locally made wheels and fixed draw-bars to their sledges to reduce draught power requirements and increase loading capacity.

In short, both local spontaneous innovations and government/RIDEP induced improvements are adopted. The peasants' interest in ox-cultivation and related improvements is high. So far this interest has been frustrated by lack of improved implements, or by supply of poor quality or inappropriate implements

1. For a further discussion, see Kjærby: Problems and Contradictions in the Development of $\mathrm{Ox}$-Cultivation in Tanzania (1983). 
(e.g., the Cossul cultivators and ridgers imported by UFI). Apart from the Iringa RIDEP Oxenization Project, and Shinyanga, there has been virtually no demonstration and extension of improved implements on peasant fields.

There is a large unutilized industrial and workshop capacity for producing farm implements in Tanzania and both the public and the private sector is getting increasingly involved in production of ox-carts and ploughs. The straight wooden or steel beam design of some of these ploughs constitutes the basics of a toolbar frame to which ridger bottoms, cultivator tines, groundnut/potato $1 \mathrm{ifters}$ and harrows can be attached. The adoption of such toolbar designs is already common in a number of other African countries. There are now five plough manufacturers in Tanzania as compared to one just two years ago, and there is a need to work towards standardized and good quality designs which are adaptable to the farming systems and functional for industrial production and rural workshop repairs.

Of no less importance is the fact that Tanzania is at present experiencing something which could be likened to a "farm implements campaign", the origins of which can be traced to the complaints about shortage of implements, especially ploughs, in rural areas. Thus, a good deal of government effort is now concentrated on ensuring proper distribution of implements, increased production, etc.

The time is ripe for the introduction of improved implements as indicated by the interest shown by innovative peasants and by the successful oxenization project in Iringa.

What remains is to get appropriate implements into the peasants' hands for field testing, fact-finding and adoption in their own environment, rather than relying on conventional bureaucratic "institution building" with its academically oriented research, development and testing activities at R\&D Centres. 


\section{CHAPTER TWO}

INTRODUCTION AND DEVELOPMENT OF NEW FARM IMPLEMENTS

At several places in this report we discuss how to improve and develop the farm implements used in Tanzania in order to increase their utility to the peasant or to lower the cost of manufacturing them. However, we only exceptionally recommend that new implements should be introduced. In other reports, e.g., Phillips and Zachariah, there are long lists of new implements, which in their view would increase agricultural yield. In general we are sceptical about such proposals, as they appear to neglect the technological and socio-economic issues that have to be taken into account when introducing new implements.

Instead, we discuss some items of equipment which appear to have some chance of being adopted or which may be subjected to trial introduction under the conditions suggested by us.

Our main recommendation is that Tanzania should look to other sub-saharan African countries for suitable implements rather than looking overseas.

\subsection{Approaches to Technology Introduction}

Statistically, 80-95 per cent of the attempts aimed at introducing new or intermediate technology in peasant farming fail - and Tanzania is no exception. Catch words like peasant conservatism or ignorance are used to explain this. A brief review of the approaches of technology introduction in Tanzania shows, however, that the approaches themselves are one-tracked and miss a number of important technological and socio-economic issues which have to be taken into consideration. A technology cannot be successfully introduced unless 
there is a likelihood of adoption. This likelihood is based on the nature and change of the various peasant farming systems and not on any pre-considered technological or engineering idea of what should be an appropriate piece of technology.

Since the late 1960 's four main approaches to peasant farm tehnology development can be identified in Tanzania:

1. The Simple Village Technology approach developed by Macpherson at TAMIU in the early 1970s. This approach used basic farm implements (wheelbarrows, harrows, cultivators and single hand jab planters of simple wooden frame designs), but had little impact because there was no peasant interest, nor perhaps any needs for this technology at the time.

2. The Progressive Farmer Technology approach which has been and still is very popular at TAMTU/CAMARTEC and among many Tanzanian agricultural engineers. Sophisticated farm machinery developed for maximum productivity, such as the disc-harrow, double-furrow plough, planter, 4-wheel wagon, UAC Tool carrier, are the products of this approach. This equipment is very heavy, expensive and some of it even clumsy and still insufficiently developed to function properly. It has not, and will not, be adopted beyond a few exceptional large-scale ox-farmers.

3. The more recent Full Package or Full Range approach based mainly on importing and/or copying Indian Equipment. 1 The few designs imported by UFI

1) Phillips \& Zachariah (1980) propose a full range of Indian equipment for tilling, earth moving (for soil conservation), irrigation, etc. TEMDO and Kilimo have been given the following publication to use for farm implements technology development in Tanzania: "Briefs on Human-Powered and Animal-Drawn Improved Farm Equipment". (College of Agricultural Engineering, Punjab Agricultural University, Lundhiana, India. March 1983). For a thought provoking critique of the 'appropriate' technology development exigencies of agricultural engineers at Indian R \& D Institutions, see V.S. Naipaul: India - A wounded Civilization . 
have not been sufficient for Tanzanian requirements. The Full Range approach is still new but judging from Kilimo's recent screening list of farm equipment, the idea is to get local manufacturers involved in producing samples for testing in allox-ploughing regions. If this is for the sake of testing only, it may be reasonable, but no attempt is made to identify priorities in this long list of equipment, most of which has neither been seen nor tried-out in Tanzania. We feel obliged to question of there is need for all this equipment in Tanzanian peasant farming systems.

4. Informal local development of designs and spontaneous adoption, in the villages, of innovations which tend to surface under stress and crisis conditions and which are aimed at overcoming constraints in production and transport. There is at present fast adoption of such innovations, which can be related to the effects of villagization and the present shortages. These innovations or local designs include private-sector ox-cart manufacturing, wheel-barrows (some of them 2-wheeled with car bearings made of sticks), fixing wheels to sledges and improved row-planting, inter-row cultivation and ridging with UFI ploughs.

A lot can be learnt from this spontaneous process of design and technology adoption, first of all because it reflects the most immediate technology needs of the farming systems - which should consequently receive priority - and secondly because it is based on local raw material and skills. Tanzanian $R \& D$ institutions have basically been out of touch with this essential process. They have been lagging behind and some staff members are even disinterested, claiming that this is not proper development. However, the trend cannot be reversed but can be supported with required raw material and with the development of more effective equipment - in a dialogue with the local process.

This is, perhaps, the place for a few critical comments as regards importing and/or copying Indian farm equipment - and for that matter technology or technological concepts from elsewhere in the world. India has a long history of animal draught power and a highly developed usage of and manufacturing sector for animal draught 
equipment, from which a lot of ideas and experiences can be gained. Bat India is also worlds apart from Tanzania, both in terms on the level of rural craftsmanship, engineering sector-skills and raw material supply, as well as in terms of the nature of farming systems. Indian farm land is destumped and has been under intensive double-cropping with irrigation for centuries. There is a culture of caring for and servicing the technology. Thus, both simple woodenframed and sophisticated steel-framed equipment will work under Indian conditions but cannot withstand the rough handling, the land conditions and the lack of a service infra-structure in Tanzania. Why has Tanzania not looked to other African countries for a screening list of appropriate farm equipment?

In terms of irrigation, tillage equipment, water lifting devices and post-harvesting equipment (especially cane crushers and oil presses), a lot can be learnt from India. And we believe that more can be learnt from identifying equipment developed and used for ages in rural areas than from the desk designs of improved equipment developed at academic $R \& D$ institutions.

Finally, there is a fifth approach, the comprehensive testing programme which is being tried in Kenya with funding from UN agencies. Between 1977 and 1981 altogether 95 pieces of farm equipment were tested according to criteria of suitability for peasant farming and whether they could be manufactured locally, particularly by small rural workshops. While the majority of items proved technically or economically unsuitable for use in Kenya, seven pieces of equipment were found to have potential, in some cases after modification, for local conditions.

These items are:

- a hand weeder, which reduced the time needed to weed one hectare by 81 per cent

- a manually operated maize sheller

- three different types of ploughs/cultivators, including a multipurpose toolbar

- a hand planter for maize and beans

- an ox-cart wheel and axle 
In 1982, a new UN project started with the aim of producing copies of these items and making them available to farmers, along with training through farmers train ing centres. Between 1982 and 1984, the Kenyan Government budgeted $8 \mathrm{mill}$. K.shs. on the local manufacturing component (Daily Nation 10/10/83).

This approach appears solidly comprehensive, starting, as it does, from the full range list. But it is very resource-demanding. Tanzania can save on resources by drawing on the experiences of this programme, rather than embarking on the full range approach with Indian equipment, However, the outstanding drawback of the Kenyan programme is whether or not the identified equipment will actually be adopted on a sufficient scale.

\subsection{Selective Priorities for Implements and Designs to Improve Likelihood of Adoption}

There are some important technology issues which are crucial for actual, commercial adoption of new implements on a wider scale, and which are often overlooked by those who define technology needs for the peasants and by those engineers who design equipment. The experience from most countries, and from African countries in particular, shows that actual adoption or the likelihood of adoption can be defined according to a set of selective criteria or priorities, which potential or actual adopters tend to use in their decisions to adopt. These can be summarized as follows:

1) The implements (in particular ox-equipment) must be light, simple (for repairs and adjustments) and durable. If not, they become a strain on oxen and operations as well as constituting an investment risk which the potential buyer will not take. He also considers availability of spare-parts an important risk factor.

2) The implements must be able to relieve major labour bottle-necks (and drudgery of work) and they must be agronomically appropriate. If not, they are useless. In agronomic or technical terms, the implements must be able to do the job at least as well as the traditionally used tool. 
The implements must be able to ensure economic returns on the investment made and they must increase income per unit of labour time required for using the implement on a certain task or acreage. A further important advantage is that per capita income is raised. Thus, we are talking about a return on capital, labour and a general increase in family income. The economics of a technology is often a most tricky issue, of which peasants nonetheless have an intimate perception.

Needless to say, the cost of the implement is of crucial importance. However, the cost factor is affected by the multi-purpose nature of the implement and the extent to which its capacity can be utilized. Thus, the relative economic advantage of buying and using an implement is also affected by potential income from being able to hire it out, and by the subjective cost and objective availability of family labour and the real cost of hiring in wage labour. Furthermore, availability of cash and preferences for alternative expenditure, as well as the real price obtained for crops, is of major importance.

One cannot simply predict or define a list of implements for peasant farms. But light, durable, cheap and apropriate multi-purpose implements do have a clear advantage. The development of peasant farm mechanization in Tanzania should take these selective priorities as a serious proposition. Even the provision of credit to speed up extension of equipment is bound to be a costly if not shortlived affair, which will not contribute to solving the real problems of peasant farm mechanization unless the implements are appropriate in terms of the above criteria.

Finally, given all the present constraints of manufacturing, manpower and transport in Tanzania, there is a narrow limit to what can be done and achieved for the time being. Thus the priority must be to introduce equipment which, first of all, can relieve the most serious constraints in production (and transport), and which can ensure economic returns. If adoption of new technology can relieve these constraints, then new constraints will subsequently crop up and these conse- 
quently constitute the next step for technology development, Our catch-word is step-by-step priority selection, rather than trying to do everything at once and ending up having done nothing. The full package deal is only a surface convenience for 'bankable' programmes, administrators and politicians.

\subsection{New Hand Implements for Cultivation}

Design aspects, manufacturing and introduction of rivetted tanged hoes and press-hardened welded hoes have already been discussed. Suffice it here to add that 30,000 welded hoes have been imported from Northland Engineering in Zambia under the Tan-Zam barter agreement. UFI has sent 6,000 of these out to RTC's. Despite the shortage of hoes, the welded hoes are not selling, due to their poor quality. UFI has taken a decision to stop further distribution and is left with a useless stock of 24,000 hoes. Ideal Casements Ltd. has also sent out samples of welded hoes to RTC's for test-marketing but RTC managers state that these do not sell either.

Cotex has started to produce straight matchets. The choice of producing straigth matchets has been made to save on raw material and to ease manufacture. In some areas of Tanzania there is no particular or strong preference for either straight or curved matchets. But in a number of regions, there is a clear preference for curved matchets, e.g. in coast-line regions, Mwanza, Arusha, Kilimanjaro, and the Southern Highlands. The reason is that curved matchets are sharpened on the upper inclined curve and can be used as a bill-hook and sickle for cutting grass. Thus, if both straight and curved matchets were available for consumer choice, it is likely that curved matchets would take a much higher share of sales. For a peasant, the particular quality, material, shape, curvature and weight of an implement is of crucial importance, however simple this implement may appear to those who make decisions on imports and local manufacturing. Market surveys, initial trial testing under peasant farming conditions and 
test-marketing of small batches can fairly easily be done. We advise against the idea proposed by some designers and manufacturers that the present shortage situation can be exploited to manufacture and market new designs. According to the criteria of priority selection to overcome labour constraints and ensure economic returns, there are, however, two manually operated implements which deserve consideration. These are hand weeders and rotary jab planters (singel row).

The hand weeder has already been mentioned. Samples should be imported from Kenya and field tested in various areas, in particular in Mwanza, Mbeya, Arusha, Kilimanjaro and Tanga - i.e., in areas with intensive systems of manual cultivation, high rainfall and rapid weed growth - to test suitability before any local manufacturing is taken up.

The rotary jab or injection planter is already under trial introduction in Refugee Settlements in western Tanzania and on peasant farms in Shinyanga, where it is being produced by Wigehe RCW and by Mr. Mahembo's general engineering workshop. By October 1983, the 1 at ter have produced 30 on order for the RIDEP at a price of 2,200 Tsh. per piece. The rotary jab planter has a number of advantages compared with most animal-drawn planters. It injects seeds ( 2 and 4 per hole for maize and sorghum respectively) even on a rough surface which has been ploughed or hoed only once. It enables faster planting than planting in the furrow after an ox-plough pass since it is not dependent on slow ox-team movement and time-consuming turns at the headlands. It is cheaper than an animal-drawn planter. Rotary jab planters should be fitted with a furrow disc to ensure parallel row width.

\subsection{Ox-Drawn Equipment}

The recent local design modifications of ploughs with UFI plough bottoms were described in Chapter 1.3.1. Ridger, cultivators, harrows and seed-drills were described in Chapters 1.3.2, 1.3.3 and 1.3.4. Ox-carts are described in Chapter 3.6. 
In terms of locally manufactured toolbar design, let us briefly describe the Kabanyola Toolbar, made by Themo Farm Implements Company in Arusha. The Kabanyola is a Ugandan adaption of a British design, which Themi modified several times after a series of field tests to strengthen it and to adapt to locally avaliable material. The first frame adopted for manufacturing consists of a straight pipe beam with welded hitch, depth wheel, adjustable pipe handle assembly (welded) and a vertical bar to which the UFI plough bottom is bolted.

The weeding tine attachment ( $\mathrm{trial}$ produced) is a square, hollow-box-bar (open angel A-frame design), bolted to the beam and holding bolt clamps with 5 angle bar tine holders. Narrow reversible ripper tines (sold by RTC) were fitted. These are not suitable for weeding (leave broad strips of land uncultivated), and are hardly suitable for harrowing and scarifying when attached to an open A-frame. This frame with an UFI bottom is 3-4 $\mathrm{kg}$ heavier than the UFI plough. A number of these frames with plough bottoms were sold, mainly in Singida and Arusha, at prices of around 1,800/shs., i.e. 1,000/- shs. above the price of the UFI plough.

While the operating stability and ploughing performance of this design is generally good, there have been a number of complaints from farmers about heaviness, cracking and breaking of welds (especially the hitch) and, of course, the high price. A member of the team took this plough to 3 villages in Hanang District for peasant farm testing. The instant reaction on seeing the plough was that the farmers examined a 11 the welds in detail and found small cracks.

The A-bar weeding frame was unfit for interrow weeding, while an attached and modified German ridger body from CAMARTEC worked excellently for inter-row weeding. The spanner supplied with the toolbar is difficult to use and we had to rely on other spanners. 
Recently the design has again been changed to a hollow-box beam and the hitch has been strengthened. A light weight (about $31 \mathrm{~kg}$ ) and a heavier weight design has now been produced in response to individual farmer and local-specific preferences. Themi has also bought 30-50 old ridgers, being part of a non-moving surplus from Kilimanjaro RTC, in order to use the ridger bottoms as toolbar attachments.

Within a period of only one year, Themi has been responsive to initial design and quality problems. Themi undertakes testing of its product in the field and is in contact with farmers who visit the factory. In retrospect, however, the choice of the Kabanyola design was probably a bit premature.

The remaining problem is the high price, which is partly a reflection of non-subsidised manufacturing and limited batch production. The Themi toolbar will be unable to compete with the UFI plough if UFI ploughs become available in larger quantities. UFI is, however, indirectly subsidized. If the demand for ridgers and cultivators increases, Themi has the advantage of being able to supply an all-in-one toolbar provided a better weeding attachment design is adopted. Due to the desperate shortage of trek chains and foreign exchange, there has been an ill-conceived idea to supply sisal ropes as a substitute without investigating first whether this was feasible. During the second World War, Ukiriguru Research Station tested this idea using iron loops for attaching the trek rope to the plough hitch. Even so, this required two ropes per season. Kilimo/ RIDEP in Shinyanga is testing means of hitching ropes with leather straps. Still, the rope as such is bound to rot as an effect of wet season cultivation.

During our mission, we found large stocks of heavy trek rope, which the RTC's were unable to sell. The rope is so thick that it cannot be directly attached to the plough hitch or safety hook. In Hanang, a few farmers have twined 4 cattle trek ropes together as a substitute for chains. The cost of these cattle ropes at 
cattle auctions was 14/- shs. each, and thus a plough trek rope cost 56/-., which is equal to the chain price. Three to four of these were required per season and some of the farmers had given up because of the trouble entailed.

As a result of the rope adventure and the cry for chains (brought up in Parliament), chains had to be flown in urgently.

\subsection{Simple Post-Harvesting Equipment}

Simple post-harvesting equipment includes manual or pedal powered equipment like maize shellers, grain grinding (flour) mills, winnowers, groundnut shellers, threshers (e.g. rice hullers) and seed-dresses. Until recently there have been only few attempts to introduce maize and groundut shellers, and winnowers made by TAMTU, UAC and the Singida Regional Workshop. There has been no adoption of these designs.
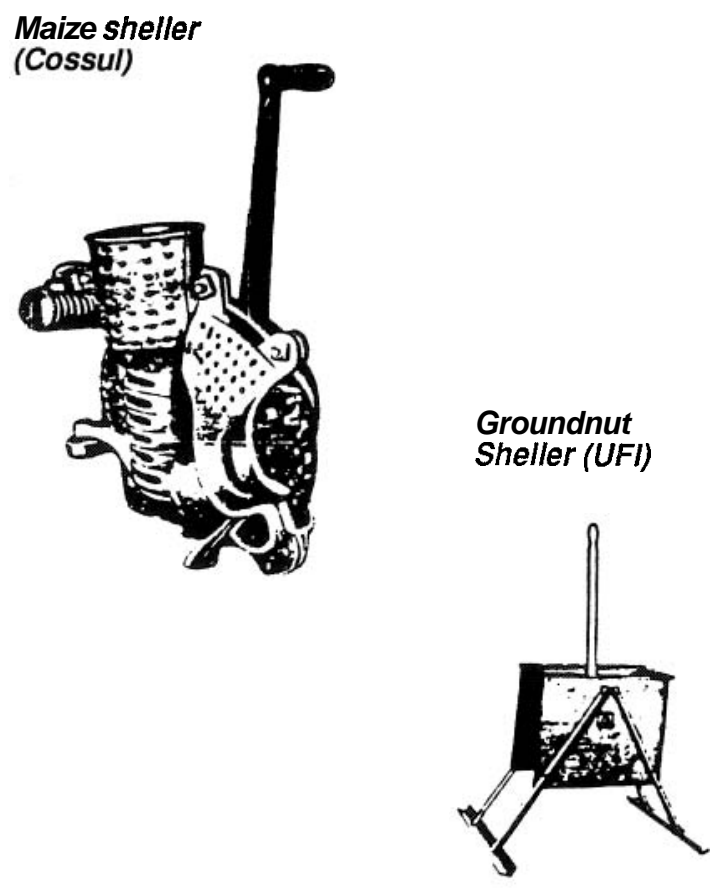

UFI has made a limited number of groundnut shellers and has imported cast-iron maize shellers from Cossul. In the period 1978-80, UFI's national sales of maize and groundnut shellers averaged about 200 and 50 units per year respectively, and most of these are in RTC stores. In Kilimanjaro, TFA has sold some Cossul maize shellers. TFA reported problems with them breaking, both the cast-iron fittings and other parts. 
"In assessing the need for, and the value of, postharvesting equipment in the small-scale farming and rural sector context, it is important to recognize that in most if not all cases, the operations that these appliances perform can also be carried out with relatively simple and often self-provided equipment .... The fact that there are alternative ways doing the work of these machines means that there can be no absolute measures of the adequacy or otherwise of local inventories; this stands to be determined only by the opportunity cost of peoples'time". (IFAD 1983, annex II:11)

We agree with the IFAD report. Threshing of maize (grain removal from the cob), sorghum, millets and beans (pod removal) is mainly done by stick beating which has no tool cost and is often done by co-operative labour. Threshing of wheat, sorghum, millet, beans, and possibly paddy, can also be done by pulling simple animal-drawn threshing sledges (which can be made locally of wood) in circles over the grains spread out in a yard, provided that the quantity of grains justify this. This is a common method all over Asia. In Hanang, harvested beans are placed on village roads for tractors to drive over. Green maize and beans are removed by hand.

In the major sorghum and paddy areas, e.g. Kyela, Sukumaland and Singida, an attempt can be made to introduce the harvesting sledges (see FAO 1969: Farm Implements for Arid and Tropical Regions. Rome). Maize shelling generally requires considerable time. Furthermore, grain-bin storage or bagging of maize is apparently one simple way of reducing the serious 'Scania' beetle attacks, because the size of the beetles prevents them frotn moving in stacked maize grain and thus they mainly attack cob maize stored on rafters (pers. comm. with Joel Strauss and Charles Lane, OXFAM, Arusha), Consequently, the maize sheller identified by the UN-Kenyan programme should be tested with priority given to Tabora (most affected by Scania), Arusha, Kilimanjaro and the Southern Highlands (important maize areas). 
The grinding of flour from maize, other grains and cassava is an extremely arduous and time-consuming activity for women when done manually by using grinding stones. Alternatively, many households spend considerable amounts of money monthly on taking maize to the engine-powered hammer mills so popular in the villages. Many of these are now at a standstill owing to lack of diesel and spare-parts. Stocks of locally manufactured hammer mills cannot be sold because of lack of power prime movers.

Hand mills are common in certain other African countries, e.g. Swaziland. OXFAM has started an interesting testing and extension programme for hand mills in a number of regions in Tanzania. Six imported mills have been tested and two of the mills, costing $2-2,500 /-$ shillings (CIF) appear to have good potential. According to the programme worker, Ian Leggett, 2,000 hand mills could be sold annually in districts like Makete and Njombe, where milling is done for other households against hire charges. In poor regions like Singida and Dodoma, adoption is slower. To be cost effective in capacity utilization, some ten households have to co-operate in using the mills, and this constitutes a socio-cultural problem as to where the mill should be placed, etc. This project should be closely followed before any other less-informed attempts are made to import or develop local designs.

We lack information about the merits of groundnut shellers in Tanzanian peasant farming systems. West African countries like Senegal should have advanced experiences on such shellers. Traditional manual paddy shelling or hulling is, however, time-consuming, and hand paddy shellers might be a priority implement for Mbeya, Tabora, Sukumaland and some coastal regions.

Given the priority selection criteria, we do not believe in winnowers and seed-dressers (e.g. for dressing pesticides in stored grains). Winnowing is an easy task utilizing skilled hand movement and windpower. Seed dressing with pesticides is also an easy manual task. 


\subsection{Research, Testing and Extension}

\subsubsection{Introduction}

There appears to be a very small market for improved implements. The August 1983 price increase of 200 percent on improved ox-drawn implements like ridgers, cultivators and harrows is likely to perpetuate this situation. RTC's have not been able to get their supplies of improved implements out to villages to allow potential buyers to assess their quality and utility. The Indian designs imported for the Tanzanian market are generally not appropriate for Tanzanian conditions and very few have been sold.

With respect to appropriate designs, research and extension activitities have largely failed both to develop appropriate prototypes and to introduce well proven prototypes from other African countries into Tanzanian peasant farming systems.

With two important exceptions, i.e. the Iringa Oxenization Project and the extension activities of the Shinyangya RIDEP, government extension services to farmers have not made headway because of the lack of properly tested and proven implements and lack of knowledge of their required specifications and performances, not least including the types of implements most needed and which should be given priority for farming systems.

Generally, Kilimo's extension staff lack useful knowledge about the necessary priorities and details of the selective development of comprehensive ox-mechanization. Many of them have never seen appropriate prototypes. They lack up-to-date knowledge about ox-mechanization and the whole interrelated set of technological, agronomic, economic and socio-cultural conditions which determine adoption of innovations. We found that even district functional officers were unaware that in their district the peasants themselves had taken to adopting local spontaneous innovations of improved methods such a sow planting with parallel row width, inter-row cul- 
tivation and ridging using UFI ploughs, supplementary feeding of draught oxen on crop harvest residues, fitting wheels to sledges, etc. It could be said at present that experimentally oriented and innovative farmers in villages have reached a stage, brought about by increasing labour constraints and the general crisis, where they are ahead of the general level of expertise in goverment and in the research and development sector.

Two major impressions arise from our analysis of the $R$ \& D system as it exists at the moment:

1) The focus is on academic and theorectical research and impractical experimentation rather than on adaptive research and development work, not to mention implementation.

2) Considerable emphasis has been put on institution building as opposed to solving problems in the field.

There is thus a clear need to:

1) shift activities away from the desks out into the villages;

2) concentrate on a field and peasant oriented approach in order to catch up on the development process of adoption of local spontaneous innovations, and to continue from there;

3) establish the need and priorities for those particular implements and sector activities which stand the best chance of adoption and which have the best potential for supporting the development of peasant agriculture;

4) recognize that peasant societies operate according to a logic of their own and that this logic has so far been poorly understood by development theories;

5) accept that it is difficult and sometimes counter-productive to impose innovations according to a top-bottom approach which the peasants are not interested in, as innovations are unlikely to become adopted on any scale unless a felt interest among potential users has developed and unless 
there are objective advantages - social, economic and technological - associated with this innovations.

\subsubsection{CAMARTEC (The Centre for Agricultural Mechaniza-} tion and Rural Technology), Arusha

The Centre for Agricultural Mechanization and Rural Technology (CAMARTEC) was established as a parastatal under the Ministry of Industries in November 1981. The parastatal is the result of a merger of the Tanzanian Agricultural Machinery and Testing Unit (TAMTU) - formerly under the Ministry of Agriculture and since 1978 under the Ministry of Industries - and the Arusha Appropriate Technology Project (AATP), formerly under the small Industries Development Organization (SIDO). TAMTU and AATP were in many respects two opposite poles, differing in size and capacity, objectives, interests and organizational structure and style.

TAMTU's activities date back to 1955 and entailed testing of local and imported agricultural implements and machinery, development and testing of prototypes of both hand and animal operated implements and batch production of prototypes at TAMIU and its six rural craft workshops (RCWs) located in different areas of the country. Over the last few years, TAMTU has suffered from lack of funding. Its research and developpment activities have for some years been run at a low level with little orientation towards peasant adaptive research and development. Both testing and batch production a t TAMTU and the RCWs have been well below capacity. Most RCWs have for some years been managed by regional authorities or SIDO and are facing problems of poor organization and direction, and shortage of materials. The main success of TAMIU has been its ox-cart design which was adopted by most public ox-cart workshops in the country. There has also been some production of spike tooth harrows, but actual adoption and use of these by peasants has been negligible. Other ox-drawn implements developed by TAMIU have in most respects been inappropriate. They are too heavy, too sophisticated and too expensive for standing any chance of adoption in peasant farming. 
This applies to the rectangular spike tooth harrow, to the disc harrow (not adopted for batch production) and to the planter cultivator, and double furrow plough (Kifaru). TAMTU's prototypes have hardly been in use on peasant farms, apart from a few pieces of equipment tested by TAMTU in a couple of villages near Arusha. Both during our recent survey and during previous surveys we found TAMTU equipment (planters, cultivators, double-furrow ploughs, harrows and ox-carts) lying unused or broke at District Agricultural Offices and Ox-training Centres (OTC's).

TAMTU has mainly concentrated on two concepts of technology development, both of which have proved of limited utility in the Tanzanian context:

1) The simple village technology (SVT) concept introduced by MacPherson. When MacPherson left TAMIU in the mid $1970 \mathrm{~s}$ th is work was apparently discontinued.

2) The Maximum Productivity concept or the progressive farmer approach, based on the development of sophisticated heavy and expensive equipment like the double-furrow plough and the TAMTU planter. This is the type of equipment still preferred by many agricultural engineers in Tanzania, and MacPherson also played a role in the development of $\mathrm{th}$ is equipment.

In general TAMTU has suffered from the injection of alien ideas about technology development, and its designs are now generally obsolete. Despite being well equipped with machinery geared towards batch production, TAMTU has had a history of producing very little. Only ox-carts have been sold to peasants for lack of better designs. A number of craftsmentrained by TAMTU have left for better paid jobs in a more inspiring and productive environment. CAMARTEC has had to take over the remaining staff of officers, craftsmen and skilled workers. TAMTU has also suffered from being "isolated" in the middle of a military camp at the old Tanganyika Packers site. 
In terms of organizational structure and style TAMTU was highly structured and bureaucratic (Whitcombe and Miles 1981:9) while AATP was more flexible and democratically structured, which among other things provided an inspiring working environment for the AATP staff members.

AATP was started in 1977 and has received considerable Swedish assistance. Its main activities consisted of research and development in building materials, rural transportation, energy and water supply. AATP's research and development effort has been mainly adaptive, with some success with soil-cement blocks, a blockmaking machine and a village chain pumnp, while introduction of a number of energy devices - solar, biogas and wind-powered - has not been successful.

AATP conducted a lot of training courses and extension activities in village level technology and developed an extension mechanism and extension programme based on a concept of resource-intensive, participatory, villagelevel extension. There is no doubt that this approach has considerable merit but that it has also been resource-demanding in terms of time, manpower and fin ance.

In contrast to most other $R \& D$ institutions, this approach involved surveys and discussions in rural areas on villager's perceived technology needs, in order to determine which type of technology would be most required. Attempts were then made to achieve consensusinthe villages on acceptance and introduction of the technology. Finally, local craftsmen were encouraged to join in groups for the production of prototypes based mainly on available resources in the villages. The whole process was time-consuming and has mainly been successfull as regards chain pumps and brick-making in some villages.

The lengthy and difficult process of acquiring village consensus and village cooperation basically stems from the prevailing political concept of the village as a unit of production and organization. But, in contrast 
to the political ideology of the Tanzanian state, the village generally does not function as a unit of production or as the focal point for adoption of innovations. AATP can hardly be blamed for the political state of affairs, but when appropriate technology is the issue, then it becomes pertinent to adopt a more realistic approach.

Seen in retrospect - and given the present process of adoption of local spontaneous innovations unaided by institutional extension agents - the approach must now be to take up and support those spontaneous development activities, which can be seen to improve both productive conditions and community 1 ife. The extension approach of AATP has a lot of merit, insofar as it is based on the local dialogue approach, identification of perceived needs, etc. Even so, AATP had a tendency to start too much from scratch, in addition to experimenting with impractical or uneconomical devices like solar cookers.

AATP did not engage in the development of improved farm implements although a few of the staff menbers had a solid background for doing so. The main reason for staying out of this field was that is was considered TAMTU's domain both by AATP and SIDO.

In mid 1979, the Tanzania Industrial Studies and Consulting Organization (TISCO) was commissioned by the Ministry of Industries to undertake a study on the reorganization of TAMTU. There were reservations within the Ministry with regard to the recommendations of TISCO and the Ministry established a Planning Team to review the matter. In early 1980, the Planning Team presented very different recommendations to the Ministry.

Both the TISCO and the Planning Team proposals envisaged the establishment of a parastatal to deal with agricultural mechanization and rural technology based on

TAMTU and AATP. However, there was no consensus as to the functions of the new parastatal, and consequently no consensus as to the parastatal's organizational 
structure, manpower and other resources, operating mechanisms and work prograrnmes.

There was consensus, however, on the location of the new organization at Tengeru near Arusha, and on the broad requirements of the organization in terms of buildings and physical plant. Accordingly, a site was selected, a physical plan developed and finance allocated. Construction began in late 1980. Shortages and other problems have delayed the construction programme and occupation of the new facilities. Full occupation of the facilities is now expected during 1983/84. Workshop machinery and testing facilities were moved to Tengeru in November/December 1983.

In December 1984 two consultants from Intermediate Technology Consultants Ltd (ITC), London, produced a report advising on "the concept and functions of the planned organization, and, in general terms, on its organizational structure, manpower and other resources, operating mechanisms, and initital work programme" (Whitcome \& Miles 1981:1).

As far as can be gauged, the ITC report is not the final one and does not present clear-cut recommendations, but rather discusses the above-mentioned issues in broad terms and generally advocates that the institution should undertake only a limited number of relat ed functions and a limited number of work programmes within these functions.

Some months later, at the request of the Ministry, another consultant from the same consultancy outfit produced a report on the functional role and operational policy of CAMARTEC (URT/Ministry of Industries 1982). According to the report, the principal function of CAMARTEC would be "to help meet the basic needs in the rural sector through inputs of advice, technical assistance and training to sectoral development programmes operating at regional level", It will be problem-oriented and will concentrate on exploiting the "technology shelf" before engaging in $R$ \& D effort. 
Production of equipment will be mainly technical and economic value analysis, and will be oriented towards demonstrating the potential for local manufacture. Statutory testing is expected to constitute a relatively minor part of CAMARTEC's work".

The report recommends that technical staff be organized in professional cadres or panels, concentrating on agricultural mechanization, water supply and rural construction, supported by an economic evaluation unit and a workshop unit and with liason officers to provide the required linkage to the regional development programmes and to SIDO. Focus should initially be on aiding the development programmes in two regions: Arusha and Singida.

According to a brochure published by CAMARTEC, the functions of the Centre include:

"a) To carry out applied research designed to facilitate the designing, adaption and development of machinery and equipment suitable for use in agricultural and rural development.

b) To develop and manufacture approved prototypes, components and cultural techniques and technologies, and evaluate their suitability for local ad aptation.

c) To adopt foreign designs of agricultural machinery and equipment intended for use in agricultural and rural development in the United Republic and to publish their results,

d) To perform tests on a 11 types of machinery and equipment intended for use in agricultural and rural development in the United Republic and to publish their results.

e) To conduct short training courses designed to provide practical training and knowledge to village communities in the use and maintenance of agricultural machinery and other appropriate technology devices.

f) To offer consultancy services on the designing, testing and other technical aspects of agricultural mechanization. 
g) To act as the national link with other national and international institutions engaged in activities related to the functions of the Centre."

The organizational structure comprises three directorates and one division under the Director General; viz:
a) Directorate of Technology Developrnent
b) Directorate of Testing and Production
C) Directorate of Extension and Training
d) Division of Finance and Administration.

\section{$\underline{\text { Programmes of the Centre }}$}

"a) Research and Development Programme

The directorate of technology development will research on and develop machines, implements, building materials and energy sources that are suitable to the rural people in Tanzania. Already gobar-gas has shown good results. Agricultural processing machines, wind power and solar energy systems are areas of priority of the centre. Improvement of rural houses by developing local building materials, is one project that has a big demand. Other areas are in water pumping systems, health facilities, crop storage and transportation at a cheap cost.

\section{b) Testing and Production Programme}

In this programme testing of various implements, power units, machines and techniques will be necessary before recommendations to the field are made. The sources of these equipments are outside and inside the country. Any newly developed device by the centre will also be tested before production or use in the field. The centre will continue to produce from chosen prototypes those machines where field demand is big and where the demand cannot be satisfied by local producers.

\section{C) Extension of Training Programme}

In order to pass technology to the people who need it, a comprehensive extension programme will be pursued by the centre.

The centre will have field contact with regional heads and relevant staff who are engaged in manufacturing the prototypes approved by the centre. The centre then will have a coordinating role between the sources of techno- 
logy and the end users. A feed back from the field to CAMARTEC will be necessary so that improvement of existing technology or techniques can be done.

In regard of the above, it is important that training be done by the centre. Training will therefore, be centre based or field based.

At the centre, selected groups of people will undergo short term practical training so that they can go back to the villages and teach fellow village technicians on learnt skills. Field training will be done by centre personnel in identified villages or field centres to village people or groups of skilled villagers or what CAMARTEC finds benefit them. It is through training that technology can spread to the users. In conducting extension and training, various proven communication skills will be used. The emphasis will be to train the people to help themselves using whatever resources are available in the locality. The idea of technology at a reasonable cost will be one area of concern.

\section{d) Manpower Development Programmes}

The major resource of CAMARTEC is the $\mathrm{staff}$. There is a great need to have skilled, well-qualified, creative and innovative staff. This will depend on the ability of the centre to recruit competent staff and to provide opportunities for staff development through short and long-term training in an out of Tanzania. Staff development will also depend on the initiative of individuals to read, participate in seminars and tours and benefit from that exposure. In this case then, CAMARTEC will try to secure funds for staff development from within the country and abroad. The number of people to go on for further studies will depend on staff position, available training slots and funds."

The description given above about the way in which CAMARTEC was established provides an example of how a new large research and development institution is created, apparently without making really qualified and detailed assessments of what the role and functions of the institution will be in relation to the most urgent needs of the rural sector, and whether the activities of such a large centralized institution can actually reach out to the rural sector.

CAMARTEC's functions and work programme would seem to constitute an enormous task, which is to cover not just 
two pilot regions, but initially 8 regions. In fact, the functions and work programme would seem to represent not just a continuation but an extended, combined version of the programmes of the two former organizations, largely to be carried out by the same staff as before.

Given the current problems of recruiting qualified staff and the shortage of funds, means of transport, material supply, etc, which constrain most institutions in Tanzania, it becomes pertinent to establish priorities which a t least will have some impact. For CAMARTEC the task has not been made easier by inheriting two quite different $R \& D$ institutions with different orientations and work programmes.

Even with a dynamic Director General and four qualified Directors in charge of the directorates, CAMARTEC will have to assume a sense of direction in the selection of priorities to have an impact on the development and spread of innovations.

It might, therefore, be advisable to follow the recommendations of the report cited above in terms of concentrating activities on exploiting the existing technology shelf in the rural areas; and above all, to concentrate on those technologies which are most likely to increase labour productivity and income per head, which are within the economic means of peasant households and for which a demand is developing.

$\underline{\text { Views gained from vis its t o CAMARTEC }}$

CAMARTEC has 90 employees coming from two very different institutions. It was established in an economic crisis with shortage of funds, qualified manpower, means of transport, material, etc.

Since its start in 1981, almost all of CAMARTEC's development funds have gone into the new big site at

Tengeru. CAMARTEC has been in a very difficult position with locations at three sites and with lack of operational development funds to initiate its general R \& D 
programme. It is thus too early to evaluate the performance and impact of this programmme, but some observations can be made with respect to building the base for future work and with respect to the present orientation of CAMARTEC. With the recent completion of construction work at Tengeru - though some office buildings are still lacking - the bottleneck of intersite transport and communication has been relieved. The new workshop building is spacious, the machine inventory is fairly good, and in mid December 1983 it remained only to connect power, already installed, to the machines for starting up production of ox-carts and double-furrow ploughs.

Raw material for the production of about 2,000 ox-carts at Tengeru and some of the RCW's has been secured, partly through a USAID/TRDB financed scheme of raw material import support. In 1982/83 CAMARTEC had only 2 old vehicles. By the end of 1983, 5 new vehicles had been secured together with a fuel allocation, thus greatly improving the transport situation. Telephone and telex communications has also been secured.

Housing, higher parastatal salaries and various fringe benefits, (e.g., food allowances) had been secured for the staff members. Thus morale is said tc have improved and CAMARTEC is ready to start production with an initial target (also for at least four RCW's) of some 2,000 ox-carts and 50 double-furrow ploughs.

Procedures for field testing of farm implements (ox and tractor drawn) are better and lengthier than those of other institutions (e.g., Uyole A.C.) and a number of different designs of ox-ploughs, received for testing during 1982 and 1983, have reportedly been brought to farmers in Mbuguni Village, which has all-the-yearround cultivation with irrigation, allowing for continuous field testing under peasant farm conditions. The officer in charge of testing at CAMARTEC has long experience in testing from his work in TAMTU.

However, although some of the ploughs had been at CAMARTEC for more than a year and although preliminary 
testing reports were nearing completion by December, 1983, CAMARTEC has earned itself a poor name among some of the manufacturers and designers in Tanzania because of the poor response given. CAMARTEC's testing field at Tengeru should allow for initial testing even during the dry season. Preliminary testing results should be sent to the designers and manufacturers to allow for design improvements and subsequent peasant farm testing so as to avoid wasting time.

Recent reports trying to identify CAMARTEC's role and function have suggested that there is at present no great need for statutory testing of farm equipment in Tanzania, since proven prototypes which could be imported from abroad have already been well-tested, both in statutory and field testing terms.

However, a number of new and/or modified plough and toolbar designs have recently been made in Tanzania, and there are five new plough manufacturers in the country. Their trial products will require testing, both as regards material and in the field. Although the well established testing procedures and facilities of CAMARTEC should be utilized, a timely response from CAMARTEC will be required, as outlined above.

However, the trial products should also be tested by other institutions in different parts of the country to ensure variable environmental testing conditions, e.g., Uyole Agricultural Centre (UAC), Ukiriguru, and not least, selected OTC's of the Iringa Project. This project can lend equipment to surrounding experienced oxfarmers. This sometimes tends to involve rough handling of the equipment (not least because of poorly trained oxen), and weaknesses and breakages should then occur fairly quickly. This allows for a feed-back to the manufacturers.

2.6.3 CAMARTEC's Potential Role in the Introduction and Extension of Improved Farm Implements

It is our impression that CAMARTEC lacks direction and a pragmatic peasant-oriented approach when it comes to the selection of improved implements for testing and 
extension to peasants in the rural areas. This is also partly reflected in CAMARTEC's plan for producing double-furrow ploughs for which raw material has been secured. The plough is a sophisticated and expensive item for a small minority of wealthy ox-farmers, the production of which will take up scarce resources and capacity at CAMARTEC. If CAMARTEC can produce double-furrow ploughs, then they should be able to produce ridgers as well, and there is a much wider need and demand for these.

In general we consider it unnecessary to continue on the TAMTU track of developing intermediate types of farm implements, when we 11 proven and widely adopted equipment can be imported from other African countries where the development of comprehensive ox-mechanization and manual mechanization (e.g., hand planters, wheeled push hoes and knapsack sprayers) have progressed well beyond the stage of Tanzania. We thus recommend importation of batches of improved implements like the "Sine Houe" Toolbar (well adopted in a number of African countries), the Rotary Jab-Planter and the Wheeled Push Hoe (e.g., from Kenya) for peasant farm extension and testing in different farming systems, including those of Sukumaland, where both intensive manual cultivation and ox-cultivation is well developed and in need of improved mechanization to relieve labour and time constraints.

Members of staff from CAMARTEC will have to stay out in the villages with the farmers during the whole tilling season to ensure early cultivation, row planting, inter-row cultivation, etc. Such an activity involves as a prerequisite an attitude of respect for the peasants, an understanding of the whole farming system including its constraints and economics, and a sociological or anthropological approach to the selection of participating areas, villages and farmers.

It is perhaps a reflection of CAMARTEC's orientation that it has tried to recruit only agricultural engineers, and not persons with a background in farming systems, agricultural economics and sociology. It is 
revealing that the target group for CAMARTEC will be existing government institutions, which in the context of farm implements are RADO's and their staff (Kilimo Extension Agents) and Agricultural Research Stations, according to the Director General of CAMARTEC.

In our opinion, this institutional set-up has failed to undertake extension in peasant farm mechanization, and is still poorly equipped and trained for doing it, with few exceptions. CAMARTEC has a good basis in its Training \& Extension Directorate, with rural experience from the AATP period, to reach out to the real adopters, the peasants, directly and immediately. The experience gained from a CAMARTEC programme of farm testing, training and extension, involving resident Kilimo extension officers, can provide a sound practical bas is for training of higher cadres and members of staff of research stations. We believe that the bottom-up approach of AATP has more merits than the heavy topdown one, including the sending of people abroad for further formal training. The extension problems and the practical implementation work are located in the villages and not at higher institutions of formal learning abroad.

Finally, direct extension of improved imported farm implements in the villages can be utilized for applied research on the nature of the process of adoption of technologies and on the technology needs of the rural population. As far as we are informed, CAMARTEC has only one Extension Officer, trained as a sociologist, who has a good experience in rural research. We believe that this experience should be utilized for extension and research activities.

The Extension \& Training Directorate has a relatively well-stocked Documentation Centre at the AATP site, and the work of keeping it up-to-date should be supported. Before getting involved in any $R \& D$ work, a 11 relevant literature, in particular from Tanzania and other African countries, should be studied. 
As regards the development of ox-cultivation, CAMARTEC should take note of the fact that there are other projects in Tanzania which have acquired considerable, useful and up-to-date experience in introduction, extension and training activities. In particular we have found that there is an urgent need to learn from the experiences of the Iringa Oxenization Project.

\subsubsection{Uyole Agricultural Centre, Mbeya}

Uyole Agricultural Centre (UAC) was initially established in 1969 as an agricultural research institute and became a parastatal under the Ministry of Agriculture in 1977. Its functions have widened from crop research and soil science to include a number of other disciplines including agro-engineering. UAC is supported by the Nordic countries.

Most of the research and development work in animal draught power at UAC was started in 1977 by the Agricultural Engineering Research Department (AERD). In recent years AERD's research and development work has concentrated on improved grain storage, maize shellers, rural transport equipment, animal harnesses, modifying the UAC toolcarrier, and setting up a village technology workshop.

Work on the UAC tool carrier started in 1977 and has continued since then. The objective of the reseach project was to develop a simple and cheap tool carrier to suit the needs of villagers.

The original idea was also to develop an ox-drawn multipurpose and minimum tillage implement which could drill seeds on land not already prepared through cultivation, and which could perform subsequent weeding. After some years of $t r i a l$ and modification the seed drill system now works, but the bearing design causes a lot of friction and thus high draught power requirements for pulling the carrier.

The same problem with heaviness, bulkiness and too high construction costs would seem to apply to the fourwheel wagons constructed by the Department. These 
wagons may work on the smooth roads and surface at UAC, but they would be much too heavy and difficult to operate under tough village and field conditions and, in terms of costs, would be far beyond the economic means of peasants.

The Department has been involved in field testing of various equipment at the Centre, including the new plough from ZZK and the wooden beam plough from SIDO. Implements are also expected from abroad for testing and local adaptation. More efforts should be concentrated on these activities.

There has been a tendency to undertake too many research projects and to focus on specific technical problems in an isolated way rather than working out an integrated research and development programme in collaboration with other relevant departments, e.g., the departments of extension and agricultural economics. Too little attention has been given to the real needs and constraints of the peasants, including their technological and economic capacity for adopting innovations. The Departement has been slow in responding to the criticisms and preferences of the peasants and in adapting its testing, research and design work to peasant farming systems.

The Farmers Training Wing of the Extension Department has also been active in promoting the use of improved ox-drawn equipment and undertaking demonstrations of ploughs made by SIDO and ZZK in pilot villages in the neighbourhood of UAC.

The wooden beam plough has been tested fairly intensively at Uyole. The most intensive use stems from the Draught Animal Unit hiring out the ploughs with oxen and operator to members of the Centre's staff. One of the operators stressed that he was extremely satisfied with the performance of the plough, and that he would prefer to buy it to the UFI plough. Another member of staff from the Farmers Training Wing, who spends a lot of time with farmers in the surrounding villages, was rather critical about the idea of wooden beams. 
The general impression gained from UAC is that it is one of the few agricultural research institutions in the country which has been productive in turning out research results of a fairly high quality by academic stand ards.

A general observation is that large, bureaucratically organized R\&D institutions like CAMARTEC and UAC very easily tend to get absorbed in their own isolate spheres of academic or experimental work rather than concentrating on the actual problems and constraints in the existing peasant farming systems.

2.6.5 The Regional Oxenization Project, Iringa (A component of the Agricultural Development Project (ADP), Iringa Region)

The Agricultural Development Project in Iringa Region (ADP) was started with assistance from the European Development Fund in 1977. The first phase of the project was completed by the end of June 1981, and the second phase was from 1981 to 1985. Apart from other project components, including the distribution of seasonal inputs and the propagation of sunflower and pyrethrum cultivation, ADP runs a fairly large and successful ox-training programme combined with provision of improved implements.

By November 1983, 12 ox-training centres (OTC) and 116 ox-training units (OTU) had been established (about one OTC for each division), and for phase II there were plans to construct an additional two OTC's and 48 OTU's. During phase I, some 560 peasants were trained in the use of improved implements and ox-training methods, and 7,000 pairs of oxen were trained, initially by using the nose ring method. An additional 3,500 pairs of oxen were to be trained during phase II with an annual training programme for some 300-400 peasants.

Mainly young school leavers and some older peasants are selected by their villages to be trained for three months at the OTC's and they can bring their oxen for training at the centre, After completing the course the 
trainees are supposed to return to their villages and propagate the improved methods.

The ADP has also established a workshop in Mafinga for producing ox-carts, harrows and wheelbarrows, 'which started to operate in October 1982. The workshop has an annual capacity for producing 1,000 carts, but so far only 86 carts have been produced. The triangular spike-tooth harrows, of which 41 had been produced by November 1982, are of poor craftmanship, and a number of them have broken during tests at the OTC's.

The ADP has played an important role in the distribution of both improved implements and the common UFI plough. In co-operation with the project, TRDB operates a credit scheme for implements distribution on the basis of a revolving fund to which the project contributes $40 \%$ and the bank $60 \%$. By November 1983, 1,008 ploughs, 148 ridgers, 197 inter-row cultivators and 87 harrows had been distributed by this scheme to 44 villages with loans approved by TRDB. The rate of repayment is better than for seasonal input distribution.

The oxenization programme of the Iringa A.D.P. is by most standards a rather successful development project with a fairly impressive performance when taking the present difficult conditions in Tanzania into consideration. Project organization is good and both the Tanzanian and expatriate (mainly w. German) staff have been committed, well informed and geared towards peasant farm mechanization.

The Iringa ADP, has, as far as we know, been the first project in Tanzania to develop and extend a feasible system of mechanized weeding.

Since use and demonstration of ridgers (and cultivators) started at the OTC's in the 1980/81 season, there has been a recent and relatively rapidly growing interest in them.

The promotion of harrows has generally received a poor response among farmers, although harrowing may well be a suitable method in the highlands of Njombe. 
In general we would like to warn against extension of credit for a full package of equipment. The provision of a full set of equipment to include an ox-cart, a harrow, a ridger and a cultivator would represent a drastic increase in capital acquisition for individual peasant households, the full income realization of which it might take years to achieve. The consequence of such a credit-based full package deal might well be indebtedness for the peasants and problems of recovering outstanding arrears.

The EEC Delegation in Dar es Salaam, which is channeling funds for the project, has approved foreign exchange for and has had an order of 2,000 Sine Houe toolbars from France for the project. These toolbars are among the most widely adopted pieces of improved ox-equipment on peasant farms in Africa. Further, they have the merit of being light and also combine attachments of mouldboard ploughs, cultivator tines - which should include hiller blades - ridger, groundnut lifters and sometimes even harrows in one frame, making the purchase of each tool relatively cheaper.

The first batch of Mafinga ox-carts was criticised for their poor design and craftmanship, and we do not recommend such carts for the northern and central zones of Tanzania.

The final issue which deserves mentioning is whether the Iringa project is replicable in other regions and whether this is justified in terms of costs and expected benefits. First, it should be noted that there are 12 OTC's, with another two in Makete District nearing completion. Despite this large number of OTC's, some of them serve two divisions and up to around 30 villages. In addition there are 116 OTU's with an additional 48 planned for completion. There is a total of about 600 villages in the region, not all of which can be oxenized.

Using 1980 prices, the approximate costs of establishing and running an OTC and an OIU were budgeted as shown below. To this should be added transport costs. 


\begin{tabular}{|c|c|c|}
\hline Budget postings (Phase II) & OTC & OTU \\
\hline Construction of buildings & 100,000 & 5,000 \\
\hline Equipment (ox and transport) & 40,000 & 11,300 \\
\hline Running costs (oxen, etc.) & 80,000 & 3,700 \\
\hline Personnel ( 5 persons annually) & 15,000 & \\
\hline Unit cost & $325,000^{*}$ & 20,000 \\
\hline $\begin{array}{l}\text { Total cost of } 14 \text { OTC's and } \\
116 \text { OTU's }\end{array}$ & 820,000 & 2232,000 \\
\hline
\end{tabular}

Amounts are in 1980 prices

* The foreign exchange component of this amount was $42 \%$.

If termination of construction of two OTC's is excluded $(300,000 /-)$, the recurrent budget for running 14 OTC's amounted to 3 million shillings on the 1983/84 budget, with only a $10 \%$ foreign exchange component. The budget covers wages for trainees and OTC staff, and provision of seasonal inputs $(130,000 /-)$ and equipment replacement. In addition there are transport costs, H.Q. project staff salaries and housing which were not included. The total cost of establishing and running such a project over 5 years could well exceed 10 million shillings, in 1980 prices. With OTC's becoming more than just isolated focal points, the establishment of a large number of OTC's and OTU's, as done in Iringa, is required for such a type of project.

In the present circumstances, with a high rate of inflation, lack of building materials, transport and fuel, the very cost of replication would be prohibitive. In general, however, we are of the opinion that the investment made in Iringa by EEC and Tanzania has been worthwhile. Both the present and likely future impact, and the experiences gained, have been extremely useful and a lot can be learnt from them. Furthermore, the project should be of future interest in terms of the experiences that can be learnt from its social equity orientation and from its non-bureaucratic and efficient approach.

2.6.6 Kilimo Extension Service, Ox-Training Centres and the Shinyanga RIDEP Extension Approach

As an effect of the Second Five-year Plan, about two OTC's were set up in virtually every region in the 
country, and these have been the recipients of most of the improved ox-equipment available in the country, produced mainly by TAMIU in the 1970's or imported by UFI.

We have visited two of these OTC's and have found them virtually inoperative with large stocks of unused, broken or rusting equipment - quite a pathetic sight. One explanation for the decay was that Decentralization i n 1972 involved concentration of funds, vehicles and manpower under the regional development directorates and that the agricultural sections within the directorates were neglected.

With respect to the propagation of improved farm implements, we are not convinced that the establishment of a number of Farm Service Centres (FSC's) will have any tangible impact, since both OTC's and FSC' will of geographical necessity and transport contraints remain focal points from which little diffusion can be expected. In fact we tend to believe, based on our findings, that institution building is generally not a solution to the promotion of improved farm implements and methods of cultivation.

As noted several times, the main constraint on the spread of improved implements and methods of mechanized cultivation has been lack of appropriate prototypes and lack of testing of good prototypes on peasant farms. Kilimo extension services have had little to offer because there was no appropriate equipment to demonstrate. Their experience and training is consequently poor, and this applies to many of the regional and district mechanization officers, who probably know more about tractors than about toolbars.

If Kilimo extension service is to play a role, it might require a major overhaul of the system, if not a very different approach. Such an alternative approach might take as its point of departure the existing technology level and constraints of the local peasant farming systems. This would require incentives, democracy (effective decentralization) and control from below, 
rather than control, orders and blanket recommendations imposed from above.

\subsection{Conclusion}

As regards the attempts to introduce new farm equipment for adoption on peasant farms in Tanzania, the uncritical import of cheap untested equipment from India (and now Zambia) has by and large been a costly mistake. Furthermore, most attempts to design and develop useful farm equipment have failed, both in terms of basic technology criteria and in terms of adoption. The attempts have been uninformed of peasant farming, influenced by unqualified political decision-making, and attempts have not been guided by the selective priorities which determine the likelihood of adoption.

In addition, there have been a number of designers and agricultural engineers - expatriate and Tanzanian - who have apparently had an implicit wish to invent their own piece of design, according to the 'do it all myself' approach. There have been virtually no serious attempts to follow up and undertake field tests of equipment which has shown good performance and adoption in other African countries. The only exception to this is the OXFAM Hand M ill Project and the introduction of the rotary jab planter in refugee settlements and in Shinyanga by M C. Wortmann/RIDEP.

In terms of design details and trial testing of oxequipment, a very useful publication from Sierra Leone could be consulted in the future: Paul starkey (1981): "Farming With Work Oxen in Sierra Leone". Government Printing Dept. Freetown. ${ }^{1}$ This publication has been written on the basis of an intensive field testing and

1) Write t o Sierra Leone Work Oxen Project, Ministry of Agriculture \& Forestry, Tower Hill, Freetown - or to Njala University College, Private Mail Bag, Freetown, Sierra Leone. 
trial programme for cultivating maize, groundnuts, cowpeas and swamp rice, using a range of potentially useful equipment from other African countries, i.e. 3 toolbars, and several ploughs, harrows, planters and simple irrigation equipment. The report has a lot of excellent illustrations on use and design details and provides good discussions of these with a verdict on the likelihood of adoption. It further deals with numerous other useful and necessary subjects, including work oxen husbandry, diseases, yoking, crop cultivation, trial lay out, etc. In terms of usefulness, perspective and quality, this report is worlds apart from the Indian publication now used in Dar es Salaam. 


\section{CHAPTER THREE \\ DEMAND ESTIMATES}

In this chapter we will record and compare some of the studies that have previously attempted to assess the demand for farm implements in Tanzania, concluding with our own assessments. We are concentrating the review to implements in high demand.

\subsection{Hand Implements}

a) - The National Industrial Development Corporation (NIDC), an Indian consulting company, in 1973 forecasted the demand figures shown in Table 3.1:

Table 3.1 NIDC demand figures, hand implements, 1973

\begin{tabular}{|c|c|c|c|}
\hline It e m & 1979 & & 1986 \\
\hline Hoes & $2460 \quad 000$ & 2730 & 000 \\
\hline Matchets & 1346000 & 1650 & 000 \\
\hline Axes & 1016000 & 1250 & 000 \\
\hline Pickaxes & 23000 & 26 & 000 \\
\hline Slashers & 91000 & 95 & 000 \\
\hline Sickles & 95000 & 110 & 000 \\
\hline Shovels & $60 \quad 000$ & 70 & 000 \\
\hline
\end{tabular}

The demand for hand implements was worked out as function of number of households, household stocks, productive 1 ife of the implements and the assumed growth rates. Generally speaking, the NIDC study remains one of the most meticulous studies on demand.

b) - In 1977 Miller estimated the annual demand for hoes to 2.5 million. This estimate was based on the 1969 rural household survey, and theoretical assumptions of replacement and growth rates. 
C) - The figures of the TISCO study from 1980 are shown in Table 3.2:

Table 3.2 TISCO demand figures, hand implements, 1980

\begin{tabular}{|c|c|c|c|c|c|}
\hline$\underline{\text { Item }}$ & \multicolumn{2}{|r|}{1980} & \multicolumn{3}{|c|}{1984} \\
\hline Hoes & 4400 & 000 & 4 & 800 & 000 \\
\hline Matchets & 4000 & 000 & 4 & 300 & 000 \\
\hline Axes & 173 & 000 & & 240 & 000 \\
\hline Shovels/spades & 370 & 000 & & 670 & 000 \\
\hline Sickles & 91 & 000 & & 110 & 000 \\
\hline \multicolumn{6}{|l|}{ Cane and sisal } \\
\hline knives & 150 & 000 & & 260 & 000 \\
\hline Slashers & 70 & 000 & & 120 & 000 \\
\hline
\end{tabular}

As far as hoes are concerned, TISCO based its figures on the assumption that every rural and every 10 th urban household buys one hoe per year (in Mwanza two per year) and that there is an accumulated demand equal to $50 \%$ of this. Approximately the same would apply for matchets. For axes, shovels and knives (with a life span assumed to exceed 8 years) trend line analysis based on previous supply is used. Sickle demand is also computed on the basis of an assumption of numbers per household and their replacement every 5 th year.

In the TISCO study for the new Mwanza plant, these figures are maintained, except in respect of shovels where possibly a typing error had distorted the previous 1984 figures. It is now, however, set at 300,000,

d) - Phillips and Zachariah (June 1980) adopted the estimates in the NIDC study, but made a correction of the sickles estimate. However, the study did not contain any field observations additional to previous studies.

e) - The "offical" demand figures for 1983, as calculated by the Ministry of Industries (basically on the TISCO figures), is 4.7 million hoes, 4.3 million matchets and 0.224 million axes. However, the General Manager at UFI is of the opinion that the figures are 
too high. The Ministry of Agriculture estimates the demand for hoes as 3.9 million in 1983, but the Minister in an interview stated that he believes this figure is too high; he would put the figure between 2.5 and 3 million hoes per year.

f) - Our demand projections are based, as most previous studies, on the number of households, which according to the 1978 population census can be estimated at $\mathbf{4 . 3}$ million in 1984, of which 0.7 million are urban households. Our field assessment, based on our own observations and discussions with peasants and regional officials, indicates that TISCO's method of assuming a national average figure is too simplistic. We have instead worked out an average replacement figure for all the regions we have visited (or are otherwise known to US) ranging from up to 2 hoes per year to one hoe every $4 \mathrm{th}$ year, and computed this to the number of households. Depending on the assumptions made, we arrive at a hoe demand figure varying from 2.7 million to 3.1 million hoes per year as a realistic demand figure. The addition of accumulated demand is considered by us to be incorrect. At this high level of replacement, accumulated demand is taken up by the annual demand.

For matchets we have found that the replacement is every $4 \mathrm{th}-5 \mathrm{th}$ year, thus an annual demand of $0.9 \mathrm{~m}$. We suggest adding $75 \%$ t o cover pent-up demand. For axes the same method is more unreliable as far from every household has a factory-made axe. We suggest that every second household would buy such an axe every $8 \mathrm{th}$ year, giving a demand figure of 270,000. It was not possible for us to collect hard data on demand for other items mentioned above, but as the NIDC and the TISCO studies largely agree (with the exception of shovels) we suggest taking an average of these figures.

Shovels, which are only to a small extent agricultural tools, although their importance is increasing, seem to be overestimated by TISCO.

g) - These figures, which should be regarded as theoretical, should be correlated to actual supply, 
which for the last 4 years of shortage must be regarded as minimum figures, as well as to the regional requirements reported by the RTCs.

Actual supply (ex UFI) is shown in Table 3.3:

Table 3.3 UFI supply, hand implements 1979-1983 (inmillions)

\begin{tabular}{llllll}
\hline & 1979 & 1980 & 1981 & 1982 & 1983 \\
\hline Hoes (a 11 types) & 2.7 & 1.9 & 1.1 & 1.6 & 1.7 \\
Matchets & 1.2 & 0.7 & 0.03 & 0.8 & 0.5 \\
Axes & 0.292 & 0.126 & 0.056 & 0.269 & 0.083
\end{tabular}

RTC requirements (as reported by BIT) for 1983/84 a re given in Table 3.4:

Table 3.4 RTC requirements, hand implements $1983 / 84$

\section{$1983 / 84$}

Hoes ( $r / e$ ) excl Singida and Ruvuma Matchets excl Singida and Ruvuma Axes excl Singida and Ruvuma

$2.9 \mathrm{~m}$
$0.4 \mathrm{~m}$
$0.129 \mathrm{~m}$

h) - Our demand estimate below is a national figure intended to guide manufacturing industries. However, when it comes to actual production, the following aspects must be taken into account.

As shown in Chapter 1 the type of hoe in demand varies. We do not have figures to suggest what percentage of total hoe demand refers to tanged hoes, and amongst those to Rungwe hoes or to Ufipa hoes, but we consider it quite possible for the marketing departments of either RTC or UFI t o assess this. UFI has a travelling salesman, who should be able to collect data in this respect.

A further point to note is that different regions have different preferences in respect of the weight of the hoes used. This is also an area for more detailed market studies, 
To some extent, farmers are prepared to accept alternatives for their preferred hoe but also this varies from area to area.

The same type of assessment should be made for matchets (which come in two shapes and two sizes) but it is our finding that preferences are not as definite as for hoes.

In the longer term perspective, there are some dynamic factors that will influence demand. For hoes, increased ox-ploughing is such a factor. For axes, deforestation will lower demand, whereas resettlements will increase it.

Our demand estimates for the most common hand implements used by peasant farmers in rural areas (thus excluding slashers, shovels/spades and pick-axes), based on our field assessment, are shown in Table 3.5:

Table 3.5 Annual demand estimate for hand implements 1984

Implement Annual demand 1984

Hoes ( $r / e$ and tanged)

$3.0 \mathrm{~m}$

Matchets

$1.0 \mathrm{~m}$

Axes

$0.25 \mathrm{~m}$

Sickles (NIDC and TISCO figure)

$0.11 \mathrm{~m}$

Cane and sisal knives (TISCO)

$0.26 \mathrm{~m}$

The growth in demand for any of these items is not expected to exceed population growth, approximately $3 \%$ per annum.

The estimates above are not price-related, At the present official price level, there is only a very small proportion of the population that would not be able to purchase the implements they need for lack of funds, particularly considering the present scarcity of consumer goods.

i) - For future demand estimates we recommend a more detailed application of our method. This will include 
) grouping the country into areas with similar soil (for hoes) or vegetation (for axes and matchets) conditions and similar usage patterns for the implement studied;

b) working out the average annual replacement rate for every area per household;

c) computing the number of households (deducting urban population and in some cases groups of people falling outside the usual pattern (pastoralists in some areas) ;

d) compiling regional and national figures;

e) comparing with actual sales figures (to check on over/under-estimation).

\subsection{The Demand for Ox-Ploughs}

Several figures have been advanced, ranging from the more conservative estimates of manufacturers over TISCO's 75,000 ploughs to Kilimo's 126,000 for 1983. TISCO's figure seems to be the officially accepted one, although Kilimo tends to prefer its own.

It is rarely specified to what extent the demand figures contain accumulated or pent-up demand, and how much of this is annual replacement demand and annual increase in demand.

In this study we have adopted a methodology of calculating the demand for ox-ploughs based on the regional population of ploughs. To arrive at the latter figure we have juxtaposed estimates and census figures from a 11 studies available to us, ranging from the end of the colonial period to the most recent regional counts and estimates. Based on a comparison of these we have tried realistically to arrive at regional plough popu1 at ion $\sim$. have then included the most recent regional distribution of ploughs from UFI as well as information on legal and illegal movements of ploughs arriving at certain RTC destinations and then being resold to other regions. 
From these figures an annual replacement rate - varying inter-regionally due to different soil conditions and usage patterns - has been deducted. Thus we arrive at regional ox-plough populations for early 1984.

Table 3.6 shows the regional plough population for different periods and surveys.

Table 3.6 The Regional Plough Population for Different Periods, as Given by Different Surveys and Estimates

\begin{tabular}{|c|c|c|c|c|c|c|c|c|}
\hline Region & $\begin{array}{l}\text { (a) } \\
1956-61 \\
\text { Agricult } \\
\text { Reports }\end{array}$ & $\begin{array}{l}\text { (b) } \\
1973 \\
\text { Kilimo } \\
\text { (Kayumbo) }\end{array}$ & $\begin{array}{l}\text { (c) } \\
1975 \\
\text { RDD } \\
\text { Survey }\end{array}$ & $\begin{array}{l}\text { (d) } \\
1976-78 \\
\\
\text { FAO- } \\
\text { Kilimo } \\
\text { Survey }\end{array}$ & $\begin{array}{l}\text { (f) } \\
1979 \\
\\
\text { TISCO }\end{array}$ & $\begin{array}{l}(\mathrm{g}) \\
1982 \\
\text { Kilimo } \\
\text { (Kayumbo) }\end{array}$ & \begin{tabular}{|l} 
(h) \\
1983 \\
RADO Est \\
\& cenus \\
in Regions
\end{tabular} & $\begin{array}{l}\text { early } \\
1984 \\
\text { SIDA } \\
\text { F.I. Study } \\
\text { Estimate }\end{array}$ \\
\hline $\begin{array}{l}\text { Arusha } \\
\text { D'Salaam } \\
\text { Coast } \\
\text { Dodama } \\
\text { Iringa } \\
\text { Kagera } \\
\text { Kigama } \\
\text { Kiliman- } \\
\text { jaro } \\
\text { Lindi } \\
\text { Mara } \\
\text { Mbeya } \\
\text { Morogoro } \\
\text { Mtwara } \\
\text { Mwanza } \\
\text { Rukwa } \\
\text { Ruvuma } \\
\text { Shinyanga } \\
\text { Singida } \\
\text { Tabora } \\
\text { Tanga }\end{array}$ & $\begin{array}{c}\text { n.a. } \\
\text { n.a. } \\
16,000 \\
13,000 \\
\text { n.a. } \\
\text { n.a. } \\
4,000 \mathrm{e} \\
1,000 \\
\text { n.a. } \\
25,000 \\
10,000 \mathrm{e} \\
5,000 \\
\text { n.a. }\end{array}$ & $\begin{array}{r}17,000 \\
\text { n.a. } \\
\text { n.a. } \\
\text { n.a. } \\
328 \\
\text { n.a. } \\
8 \\
118 \\
\text { n.a. } \\
5,152 \\
16,325 \\
8 \\
- \\
1,200 \\
1,820 \\
- \\
23,137 \\
24,775 \\
6,288 \\
-\end{array}$ & $\begin{array}{r}381 \\
566 \\
6,606 \\
19,492 \\
38 \\
63 \\
3,397 \\
3,012 \\
28 \\
25,629 \\
25,617 \\
6,588 \\
36\end{array}$ & $\begin{array}{r}27,463 \\
\text { n.a. } \\
24 \\
1,835 \\
\text { n.a. } \\
141 \\
17 \\
\\
1,166 \\
512 \\
10,135 \\
18,676 \\
71 \\
83 \\
6,000 \\
3,012 \\
16 \\
33,592 \\
26,585 \\
33,536 \\
85\end{array}$ & $\begin{array}{r}13,640 \\
\text { n.a. } \\
\text { n.a. } \\
\text { n.a. } \\
\text { n.a. } \\
\text { n.a. } \\
\text { n.a. } \\
\\
381 \\
\text { n.a. } \\
13,000 \\
21,564 \\
\text { n.a. } \\
\text { n.a. } \\
1,230 \\
5,000 \\
\text { n.a. } \\
38,559 \\
26,600 \\
33,600 \\
\text { n.a. }\end{array}$ & $\begin{array}{r}25,164 \\
1,175 \\
\\
6,175 \\
9,284 \\
228 \\
42 \\
\\
3,720 \\
627 \\
12,866 \\
24,485 \\
96 \\
96 \\
14,858 \\
5,358 \\
39 \\
33,954 \\
29,220 \\
8,137 \\
96\end{array}$ & $\begin{array}{c}32,000 \\
\text { n.a. } \\
\text { n.a. } \\
\text { n.a. } \\
25,000 \\
\text { n.a. } \\
\text { n.a. } \\
\text { 'few' } \\
\text { n.a. } \\
\text { n.a. } \\
21,000 \\
\text { n.a. } \\
\text { n.a. } \\
19,000 \\
\text { n.a. } \\
\text { n.a. } \\
\text { n.a. } \\
22,000 \\
34,0001 \\
\text { n.a. }\end{array}$ & $\begin{array}{r}24,000 \\
n . i . \\
n . i . \\
4,500 \\
24,000 \\
\text { n.1. } \\
\text { n.i. } \\
\\
1,400 \\
\text { n.i. } \\
15,000 \\
21,000 \\
\text { n.i. } \\
\text { n.i. } \\
17,000 \\
6,500 \\
\text { n.i. } \\
36,000 \\
24,000 \\
29,000 \\
\text { n.i. }\end{array}$ \\
\hline otal & 75,000 & 96,153 & 115,509 & 162,949 & n.a. & 175,616 & n.a. & 202,400 \\
\hline
\end{tabular}

Codes: e) Our estimate n.a. = no account, n.i. = not included. Dash = nil.

Table 3.6 shows that the largest number of ploughs are i n eastern Shinyanga, northern Tabora and northern Singida Regions, all falling within the flat and fairly treeless, grain-growing "cultivation steppe" of the north-central plateau.

These areas have low rainfallandhigh cattle populat i o $n$ and ox-ploughing is a means to either extend cultivated acreages, or to try and beat time in land preparation, or both. Together with Mara and the Kyela floodplain at Lake Myassa, these areas have histori- 
cally been the most important ox-ploughing areas in the country.

Since the commissioning of UFI in 1971, the annual, total supply of ploughs to Mainland Tanzania has not been able to meet demand. In the years following the villagization campaign (1974-76), the demand for ploughs has been increasing steadily. Over the five-yer period 1974-78, the total supply averaged only some 7,600 ploughs per annum (as compared to 9,000 ploughs sold in Shinyanga in 1961). Over the four-year period 1979-82, the total supply averaged 10,500 ploughs per annum, and if the exceptional supply of $1983 \quad(26,000$ ploughs) is included, we get 13,600 ploughs which can be compared to an offical demand figure of 75,000 ploughs for $1983 / 84$.

Equitable distribution of ploughs and spares has to be based on the regional plough population and not simply on regional requirements worked out according to different methods in different regions and subject to more or less random political inflations and deflations.

We have distinguished the present demand for ploughs in Tanzania in terms of three factors:

1) Annual replacement demand for maintaining a given plough population in operating condition. This demand is a percentage-of the plough population. If the average lifespan of ploughs is 10 years the rate of replacement needed to maintain the stock is $10 \%$. The lifespan of a plough is determined first of all by the abrasiveness of the soil and secondly by the cuitivation factor per plough (i.e., the annal average rate of cultivation or the average number of acres cultivated per plough annually).

2) The accumulated demand, found in most but not all ploughing regions of Tanzania, which is here defined to include: (i) overdue replacement, required because the majority of ploughs are in a deplorable condition. ( $i$ i) a pent-up or increase in demand from would be ox-farmers who have been unable to get ploughs. 


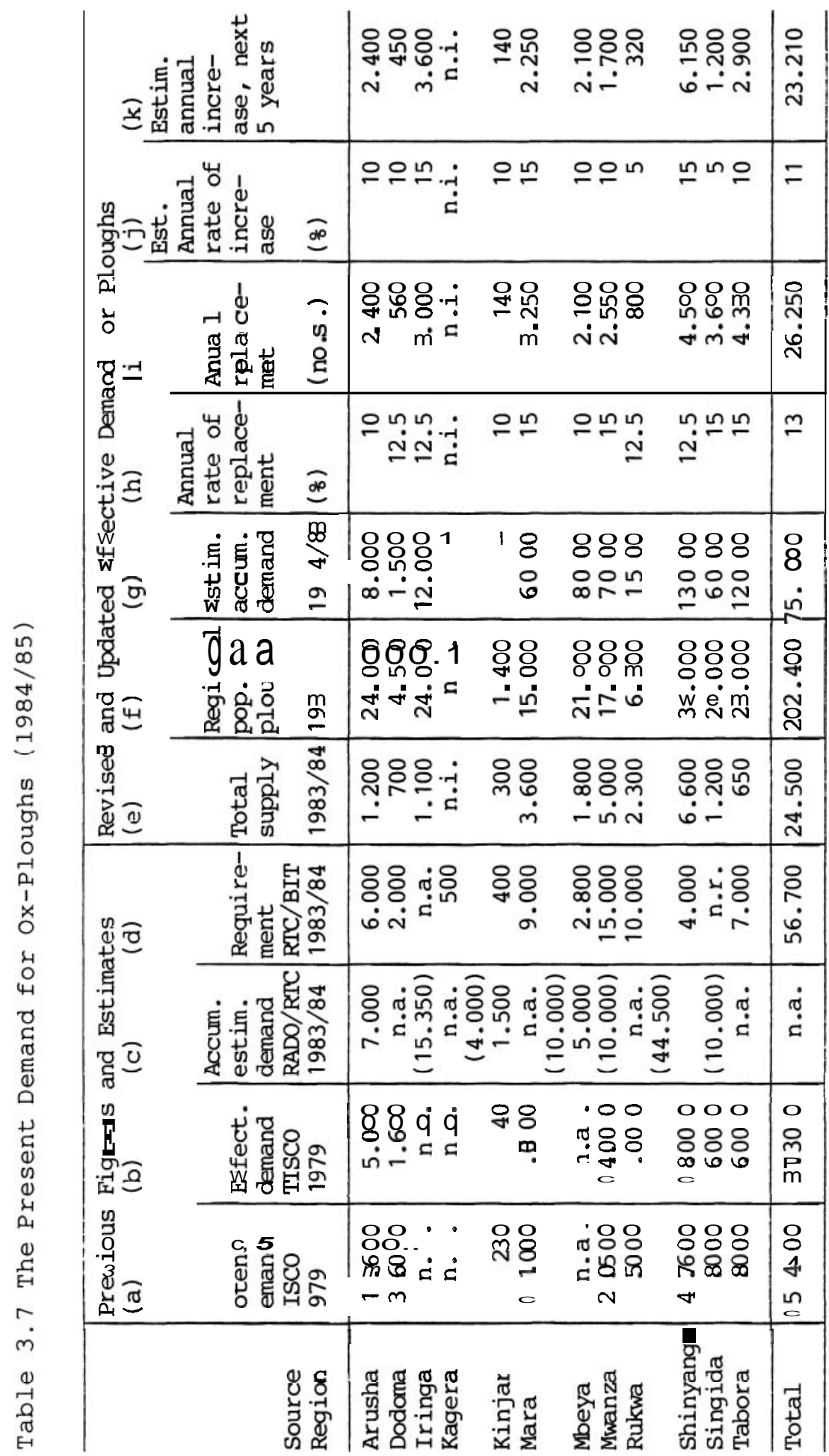


Explanations to Table 3.7:

n.a. = No account

n.r. = Not received

n.i. = Not included

dash $=\operatorname{Nil}(-)$

(c) = Figures in brackets indicate estimated accumulated demand.

(a) + (b) Totals include an added 5\% for n.a. regions.

(g) Estimated accumulated demand includes overdue replacement and pent-up demand. It has been assessed by weighing against each other the following factors:

1) The regional population of ploughs and their condition which effects overdue replacement demand.

2) The regional supply of ploughs 1983184 (e) as well as previous supplies which reduce pent-up demand and overdue replacement.

3) The recent overall increase of supply in ploughs vis-à-vis the overall availability of oxen and land for expansion in oxploughing, i.e., constrained future demand or the potential for increase.

4) The regional availability of tractors for contract ploughing which in particular applies to areas in Arusha and Kilimanjaro Regions. These have already got or are likely to get the majority of the Swaraj and Valmet tractors coming in.

5) Effective demand in relation to purchasing power which may in particular constrain demand in Singida and Dodoma Regions.

6) RADO, DADO and RTC managers' assessment of accumulated demand where these appear to be realistic and consistent with the above points, e.g., in Arusha, Iringa and Mbeya.

The present pent-up demand is not constrained by access to oxen and land. If it was, it would not be a pent-up demand but rather a constrained potential demand of the future which we shall attempt to assess below.

3) The increased demand or annual growth in demand is basically of the same nature as the pent-up demand. The increased demand derives-from the expected future increase in buyers of ploughs. It may also be positively affected by pastoralists taking up ox-ploughing, as happened some 10-15 years ago in some areas of Hanang District and in a few areas of Maasailand. 


\section{General Conclusions on Present Demand}

In Table 3.7 we have presented current demand figures from previous estimates andourrevised and updated effective demand figures for ploughs.

Based on fairly detailed information and taking into account a whole range of historical, economic, environmental and political factors in the methodology spelled out in detail above, we have arrived at a national plough populaton of about 200,000 ox-ploughs in use in Tanzania for early 1984. On the basis of this figure we have worked out an initial annual replacement demand of some 26,000 ploughs based on updated rates of replacement $(10-15 \%)$ for each region.

The estimated accumulated demand of 75,000 ploughs at present has been assessed by weighing a whole range of determining factors. The accumulated demand is high because the low supply over the last 5-8 years have amounted to a virtual starvation situation, causing the overdue replacement demand to peak.

The estimated annual rate of increase in demand ranges from 5-15 per cent depending on the extent to which the potential for further expansion has been exhausted and on the assessed available purchasing power.

In conclusion, we estimate the continuous annual demand, consisting of replacement demand and increase i n demand, to be approximately 50,000 ploughs. In addition, there is an accumulated demand of a once-off nature of 75,000 ploughs.

The accumulated demand, which is of a once off nature, could theoretically be satisfied by the injection 75,000 mainly imported ploughs, followed by a replacement demand of some 36,000 ploughs (13\% of the national plough population of the 277,000 ploughs), and theoretically an annual increase in demand of some 16-17,000 ploughs at a rate of increase of $6 \%$ per annum, i.e. a total effective demand of around 50,000 ploughs. 
We have arrived at a total potential number of ploughs of 400,000 for the coming 5-10 years based on the potential availability of draught oxen.

\subsection{The Supply and Requirements for Plough Spare Parts}

It has to be stressed that there is a severe shortage of essential spare parts for ploughs in all the regions visited. It further has to be stressed that a proper supply of required spare parts can contribute significantly to reducing both overdue and annual replacement demand for complete ploughs by extending their working life-span.

It is also obvious that it is cheaper both for the consumers and for the national economy at large to ensure that the required supply of spare parts reaches out, rather than concentraing all funds and efforts on producing and distributing complete ploughs to cater both for replacement and for pent-up and increased future demand.

The actual distribution of plough parts from January to November 1983 generally falls far short of both the official regional requirements and of the demand, with the partial exception of shares and chains. The supply of these is still insufficient but much higher than for any previous years.

No landsides, safety hooks, wheel bushes, wheel holders and beams were distributed. Landsides, wheel bushes, wheel holders, axles, wheels, right handles and nuts/ bolts for plough bottom and handle assembly are those parts which are most badly needed to rehabilitate the ploughs. Beams and frogs have a very low demand though some could probably be sold in Iringa, Singida, Tabora, Mwanza and Mara. Beams and frogs are not first priority. 


\subsection{The Potential for Ox-Ploughing in the Next Decade}

The potential for expansion of ox-ploughing is not as high as believed by many government officials at central level. First of all this potential is effectively limited by the availability of draught animals. Secondly, it is constrained by availability of land. The second constraint works itself out in a much more subtle way and is related to the villagized settlement pattern, the nature of existing farming systems, rainfall, bush infestation, availability of grazing, topography and so on. The commonly heard statement that Tanzania has ample, fertile land resources is not wrong as such, but it is an oversimplification, in particular when applied to the potential for ox-cultivation.

The total number of potential ploughs then works up to 450,000 at a mean ox-team factor of 3.4 oxen. For the next decade we consider this the absolute potential, which we shall have to reduce even further to arrive at a more probable figure of potential demand. If we deduct another 30\%, we arrive at a rounded figure of 300,000 potential ploughs which means a total potential increment of some 100,000 ploughs (discounting replacement) over the next 7-10 years, with a baseline of 200,000 existing ploughs. At the very most it could amount to 150,000 ploughs. This will make little difference for the planning of manufacturing capacity.

The fact that many oxen are still untrained is no constraint on the potential for ox-ploughing. In fact ploughing with an ox-team is a fairly simple technology to adopt by peasants who have grown up with cattle.

\subsection{The Demand for Ridgers, Cultivators and Harrows}

As the total market demand for ploughs gradually starts to decline and falls short of installed manufacturing capacity, the unutilized capacity can be used for producing ridgers. There is at present no real effective demand for ridgers (or cultivators) of a magnitude 
which warrants installation of new capacity for the manufacturing in Tanzania. There are at present a good number of idle and partly incomplete ridgers in stock at RTC go-downs, which could farily easily be rehabilitated and sent out to the rural areas.

For the next couple of years we would tentatively assess the national requirement for ridgers at 2-3000.

\subsection{The Demand for Ox-Carts}

\subsubsection{Background}

As with ox-ploughs, there is at present a boom in the demand for ox-carts. This is related to the effects of villagization which has brought about changes in settlement and land-use patterns. The distances to fields and firewood sources have increased. Distances to water sources have increased in some villages, because the installed water schemes are not operating, due to lack of maintenance of poor scheme construction. In general, transport constraints and the problem of head porterage have increased considerably, in particular with regard to transport of harvested crops and firewood.

However, villagization has also had other more positive effects, which have had an impact on the increased utility of ox-carts, wheelbarrows and other means of transport. The field and land-use pattern is now more permanent than the previous pattern of fallow and shifting cultivation systems characterized by changing foot path systems. Paths are now more permanent, tracks or village roads have been laid out and cleared, and the conditions for cart movement have improved. Rural house construction, using bricks, has become more common and the need for transporting building material from brick-making sites and firewood for brick-making has increased. The farming system has intensified in many areas and has become more dependent on the use of manure and fertilizer (in Iringa, Mbeya and Rukwa). These are bulky or heavy inputs, the transport of which is eased by mechanized transport. In some areas supple- 
mentary feeding of oxen during the early tilling season has increased, and bulky maize stalks are collected from the fields upon harvest with ox-carts and are brought to the homesteads for storing.

Innorthern Singida and in Igunga, stalks of maize, sorghum and bullrush millet are collected for firewood. The increased intensity of labour during the cultivation seasons has enforced increased reliance on stocks of firewood, collected from far away and brought with ox-carts or sledges during the dry season.

The more recent decline in the number of tractors and lorries in operating condition and shortage of diesel in the rural areas has involved soaring hire charges for these means of transport. Ox-carts have to an increasing extent taken over the discontinued bus and lorry transport services in rural areas, including long distance transport of people in eastern Shinyanga.

Apart from the high prices of ox-carts, the general transport situation has contributed to pushing up the hire rates for ox-cart transportation, thus ensuring high economic rates of return to investments made in ox - carts.

This fact also explains why there is a demand for high quality and expensive carts, and not poor and cheap carts. Given the long distance involved in carting and the good opportunities for incomes from hiring them out, it becomes important that the carts are reliable and durable. If the wheel set of a cart breaks down, it is extremely difficult to get spares or to have it repaired. Customers cannot rely on a hired cart which breaks down all the time and willopt for another cart in the village if available.

Cart owners have recovered their investments in one or two crop harvest seasons. Partnerships of two or three households in purchasing and operating of carts are common.

Finally we should note the social benefits of ox-carts and wheelbarrows which have important implications for 
both the sexual-and aged-based division of labour in rural areas. Since men and youths, even young boys, are so far the main operators of ox-carting and ox-sledge teams, women are relieved of the arduous and time consuming work of being "pack animals". The male team operators apparently tend to take over such tasks as water fetching, the cutting of firewood and collection of grain stalks for fodder. For example, in the case of water fetching it is the team operators who fetch water and fill the drums to be carried on sledges or carts, and the water fetched is stored in drums, which may improve water quality. Ox-carting, in contrast to mouldboard ploughing for primary cultivation, may thus change rural life in Tanzania.

Seen in the general context of long distance movement of goods and people, the change from motorized

transport to ox-carting can be considered a step backwards. In terms of intra- and intervillage transportation, the general development of ox-carting, whether based on high quality cart or on home-made sledges with wheels, is an important step forward. All means of transport required in the villages, whether manufactured by specialized workshops or made through simple but functional and cheap inventions in the villages, should receive support.

\subsubsection{The Present Demand for Ox-Carts}

In Table 3.8 we have attempted a conservative estimate of the present demand for high quality ox-carts, worked out on the basis of the scant data available on regional ox-cart populations and on our impressions gained from the recent field visits.

In Table 3.8, a comparison of columns (A) and (B) indicates a rapid increase in the regional cart populations but only over a couple of years. This is likely to remain so even if census figures had been more accurate. As regards column (C) we know that there are no large number of ox-carts in Arusha, Mwanza,

Shinyanga, Singida and Tabora. We also know that there are much larger numbers in Iringa, Mara and Mbeya than 
Table 3.8 Regional Ox-Cart Population 1975-1983 and Estimated Demand for Ox-Carts 1984-1986

\begin{tabular}{|c|c|c|c|c|c|}
\hline & (A) & (B) & (C) & (D) & (E) \\
\hline$\underline{\text { Reg i o n }}$ & $\begin{array}{l}\text { RDD } \\
\text { S u r v e y } \\
1975\end{array}$ & $\begin{array}{l}\text { FAO/ } \\
\text { Kilimo } \\
\text { Survey } \\
76-78 \\
\end{array}$ & $\begin{array}{l}\text { RADO } \\
\text { est. o r } \\
\text { cens us } \\
1983 \\
\end{array}$ & $\begin{array}{l}\text { Regional } \\
\text { RADO re- } \\
\text { quirements } \\
1983 / 84\end{array}$ & $\begin{array}{l}\text { Our cons. } \\
\text { demand } \\
\text { estimate } \\
1984-86 \\
\end{array}$ \\
\hline Arusha & 46 & 205 & 4,300 & n.a. & 2,000 \\
\hline Dodoma & 34 & 65 & n.a. & n.a. & 200 \\
\hline Iring a & 20 & $n \cdot r$. & n.a. & 2,525 & 2,000 \\
\hline Kilimanjaro & 36 & 23 & n.a. & very few & 50 \\
\hline Mara & 50 & 50 & n.a. & n.a. & 500 \\
\hline Mbeya & 133 & 69 & 3,500 & n.a. & 1,000 \\
\hline Mwanza & 181 & 61 & 732 & n.a. & 1,000 \\
\hline Rukwa & 12 & 12 & n.a. & n.a. & 250 \\
\hline Shinyanga & 325 & 325 & n.a. & n.a. & 2,500 \\
\hline S ingida & 118 & 168 & 772 & n.a. & 1,000 \\
\hline Tabora & 260 & 754 & $1,300^{1}$ & n.a. & 1,500 \\
\hline Tanga & 10 & 38 & n.a. & n. a. & n. i \\
\hline Total & 1,225 & 1,769 & n.i. & n.i. & 12,000 \\
\hline
\end{tabular}

$\mathrm{n} \cdot \mathbf{a} \cdot=$ no account

n. i. = not included

1) Our estimate. Nzega District alone has 857 carts, and in Igunga we continuously saw ox-carts as well.

Comments to Table 3.8

(A) The RDD survey figures look reasonable on a regional comparison, but Arusha, Iringa, Shinyanga and Tabora are probably understated.

(B) The FAO/Kilimo survey figures also look reasonable, but are probablyunder-redorded for Mara, Mbeya, Mwanza, Shinyanga and possibly Rukwa. Despite likely under-recording, note the overall rapid increase in numbers.

(C) The RADO estimates for Arusha and Mbeya are much too high. Mbeya might have some 500-800 carts taking into account among other things, production figures from the RADO workhop. Arusha should now have some 1,500-2,000 ox-carts, given the production from TAMTU and four other public workshops, plus a large number of village craftsmen. Shinyanga should have at least 2,000 carts. In Singida, at least $30 \%$ of the carts are inoperative due to the poor quality of the carts, made from the SIDO/RDD workshop in Singida Town.

(D) The regional requirements for Iringa are based on written requests and probably also expectancy of credits. In Kilimanjaro, one ox-cart workshop is facing problems in selling its cart, but this may be due to poor quality of the product, which we have not seen. 
(E) Figures for Dodoma, Mara and Rukwa are estimates only. Apart perhaps from Iringa, our estimates for the remaining regions are based on our assessment of the regional cart population and on our discussions and impressions in the regions. The figures are conservative estimates for high quality pneumatic tyre carts, and for Arusha, iron wheel carts as well.

indicated in columns (A) and (B). We believe that the figures shown provide enough evidence for the increase in the number of ox-carts following upon villagization $1974-76$.

Our demand estimate in column (E) applies to high quality expensive ox-carts. This demand represents accumulated demand, i.e. overdue replacement demand for carts in poor operating conditions, and an increased demand associated with the problems of transport and expected profits from a potential investment.

3.6.3 Some Notes on the Relationship between Design and Demand for Ox-Carts

We have noted above that carts have to be of a better quality - and consequently more expensive - than the conventional TAMTU design or the designs adopted by Uyole Agricultural Centre, the Mafinga workshop in Iringa and the Singida Regional workshop. Wooden wheel rims, and bearings of hard wood have provided no durable solution and are avoided by those cart buyers who can avoid them. Iron wheel rims are accepted in Arusha, but not necessarily preferred.

Given the transport constraints and the slow pace of movement of ox-carts - it is hardly a speed - there is preference for the larger ox-carts with higher loading capacity. Overloading will remain a problem until carts are designed strong enough to carry the required load. In Shinyanga and Tabora it is common to team six oxen 
or a mixed six-head team of oxen and donkeys to pull carts. These factors should explain why cart owners prefer Landrover or small lorry wheel sets, despite the difficulty of obtaining them and despite their high cost. There is an urgent need to work out axle-wheel set designs which are strong, durable and appropriate for heavy loads. At the moment a total cost of a cart up to Shs. 16,000 does not seem to be a constraint on demand.

Even so, there is a likely limit to the number of expensive ox-carts which can be sold because most households will find it difficult to pay this considerable investment on normal cash terms. Those with enough cattle can sell two fullsized steers to realize the required amount.

Although many households in a village benefit from the possibility of hiring ox-cart services for transport of crops to buying points, and of water, firewood, manure and building material, it is also clear that both the price of the carts and hiring charges in villages with only few carts tend to be very high because of the critical shortage situation. Thus, many households could save on transport expenditure in the long run if they acquired their own carts, particularly so if $2-4$ households joined into partnership to buy and use a cart. Expensive hiring charges will drive up the demand for carts, but there is stilla limit to the demand for expensive carts.

The wheel set design should be worked out with a view to both quality and to the likely future costs of manufacturing them in Tanzania. Initial import of bearings is a necessary precondition for a reasonably rapid and beneficial satisfaction of the present demand. When more carts become available in the rural areas, hire charges will decline. This also means in the future a more competitive demand in relation to the cost of manufacturing the carts.

Since the demand for expensive carts is so high at present, and since a number of potential buyers can and 
will enter into partnerships to buy carts, with the likelihood of the investment being realized through livestock sales, we do not see the need for credit as the main problem at present.

For those public workshops and R\&D institutions which still think and work along the lines of the conventional cheap designs with wooden wheels and wooden bearings, we suggest that they go on a survey visit to villages with a high number of ox-carts to investigate the often differing design details of existing carts, discuss preferences with actual and potential owners and visit private manufacturers to discuss design and quality. A lot can be learnt from such a brief undertaking and time can be saved by investigating market preferences rather than thinking out designs at desks. 


\section{CHAPTER FOUR}

LOCAL PRODUCTION AND REPAIR FACILITIES

FOR FARM IMPLEMENTS AND OX-CARTS

\subsection{Blacksmiths}

In Tanzania's some 8000 villages, blacksmiths are by far the most important source for production and repair of farm implements. The 1967 Population Census showed that the category blacksmith and related activities (plumbers, welders, tool-makers and machinists) amounted to $0.09 \%$ or 12,600 persons of the total rural population (14 million). However, due to problems of definition, access, distrust and seasonal production cycles in rural areas the figure is not reliable. Later surveys of blacksmith activities in some regions and districts give an equal or higher percentage of metal workers in the total rural population, for Tanga region $0.29 \%$ (1974), for Rukwa region $0.35 \%$ (1977), for West Lake region $0.12 \%(1974)$, for Bagamoyo, Same/Pare and Kyela districts $0.09 \%$ (1974) and for Rufiji district $0.15 \%$ (1979) (Müller 1980, Perkins 1978 and Havnevik 1980.) As this type of study only covers some regions and districts it is not possible to derive from it a national total of the blacksmith population. This is particularly so because the distribution of blacksmiths is very uneven both between and within regions. The heaviest concentration seems to be in the traditional areas for iron smelting, in West-Tanzania and the Lake Zone, and in parts of the coastal areas. In spite of problems of arriving at a specific figure for the blacksmith population, both our findings and those of others warrant the conclusion that the number of blacksmiths and their role in local production is sufficiently significant for their inclusion in national development planning. 
Investigations indicate that iron was smelted as far back a s 500 B.C. in north-western Tanzania. This implies that metal working was well established at the time of Arab and later European intrusion. In fact, numerous explorers tell tales of the blacksmiths' master of their craft. During German and British reign in Tanzania, from around 1890 to 1961, the authorities banned metal working activities, for several reasons: opening up avenues for metropolitan metal products, obstructing local gun-making and hindering intradistrict trade. The effect was to drive blacksmiths partly into hiding, yet still producing for the local communities requiring their services. The demand for locally produced commodities may have stagnated or dropped but to claim the eradication of the craft seems to be far from the truth. At Independence blacksmith activities were again legalized but attitudes remaining from the colonial period led neither to immediate recognition nor registration. These attitudes are only recently giving way among many bureaucrats and government officials. Many still regard the blacksmith technology as obsolete and backward; nothing to be given a place in "modern" development strategies.

The effect of historical events and present attitudes is easily discerned during visits to blacksmith workshops. Official persons do not even seem to know the whereabouts of blacksmiths, local people have to give directions. The team had the opportunity to visit blacksmith units in Coast, Singida, Tabora, Arusha and Kilimanjaro regions. The information obtained and observations made during the study tour combined with results from previous surveys, provide the foundation for the present report.

The average blacksmith is a rather old man. He has learnt the skills from his father and he passes it to his sons or relatives. Hence, there is a tendency for the skills of the craft to move from one generation to the next within the extended family or clan. However, the average age of blacksmiths seems to be increasing. This is due to poor recruitment which reflects difficult production conditions and poor prospects facing the craftsmen. 
Government agencies did not realize the critical role performed by blacksmiths in rural areas until recent years. The Ministry of Culture and Youth was the first to recognize their role and initiated in the mid-seventies various, albeit limited, programmes and campaigns for support like "Jembe ni Mali" and "Jipemoyo" (Ministry of Culture and Youth 1976 and Kiyenze 1981). At the end of the 1970s the interest in blacksmith activities had spread to other government agencies and external donors. One important reason for this, in addition to the awareness for blacksmiths created by the Ministry of Culture and Youth, seems to be the mounting supply problems of means of production in rural areas due to the deepening economic crises. In the next section we will focus on support programmes for blacksmiths initiated by or related to SIDO, which is the body with the major responsibility for promotion and support of rural crafts and small industries.

The need for repair of farm implements, hoes and ploughs, repair of bicycles etc. is felt much stronger when the flow of commodities and spare parts has come almost to a complete halt. In addition to repair, the blacksmiths also have a place in production of particular area-specific farm implements not produced on a large scale. When supply of traditional farm implements from imports and national industry improves there will still be need for repair and also area-specific production of this kind. Hence, these are the major roles we see for blacksmiths in rural areas in the future. Their skills and production represent a necessary local complement to large-scale national industries and also a technological basis on village level from which improvements can start. This requires that their conditions, possibilities and constraints are understood and support programmes realistically designed,

The blacksmiths operate mostly alone with assistance from one or two apprentices. Some skilled craftsmen have joined together. However, cooperation, which includes specialization of work processes, is still in its embryonic stage. The work is mainly done in thatched roof sheds; some times trees suffice as a shelter. One assistant operates the bellows while the second may 
assist the master in forging, all seated on the ground. This traditional working position is certainly not ideal for working heavy hammers. It may be a remnant from the time when blacksmiths were often on the move to avoid restrictions and bans, hence little heavy equipment could be utilized.

Most often tools consist of anvils, some use old engine blocks or stones half sunk in the ground, beside the charcoal fire. No blacksmiths were found to use coal for firing which would increase temperatures and improve the quality of products. A few knew about the properities of coal but stated that it was not available. The bellows are most often made by the blacksmith from goatskin. Other materials like cow hides and paper bags (cement bags) may be used if goat skins are not available. The bellows are activated by sticks and the air is blown through wooden and clay pipes. Most tongs and hammers are also made by the craftsmen themselves. Chisels are used to cut the redhot iron and holes are made by self-made drills. The self-made tool shows a great deal of ingenuity. The tool inventory is, however, particulary limited when it comes to anvils and vices, tools which cannot easily be produced by the blacksmiths themselves.

The rural blacksmiths have good knowledge of the quality and limitations of various types of raw materials. They have an extremely low percentage of waste in their production. The quality of repair and new products was high, the main limitation being the problem of proper raw material supply, After heating and forging, the products are hardened in water. The production process of blacksmiths clearly indicates a high level of skills and knowledge, given the operating constraints.

Previously the supply of raw material was assured by smelting of iron in some areas (Geita, Mufindi, Ufipa etc.). This labour intensive activity gave way gradually and at present there are hardly any blacksmith clans who engage in this. Scrap iron of various kinds is generally used, if necessary being removed from car wrecks and old tractor ploughs along the roads 
or from abandoned mines. The competition for scrap has increased considerably through establishment of largescale resmelting plants. Thus, production conditions for blacksmiths have deteriorated further. This has happened at a time when demand for blacksmith 'services is on the increase. Today, many customers actually bring their own scrap when ordering a particular item. On other occasions the blacksmith and his assistants themselves go on a search for scrap. Our investigations and those undertaken by others indicate that availability of scrap today represents the most serious problem facing rural blacksmith production. It is our opinion that specific support activities to ease this problem will improve the conditions of blacksmith production and hence the maintenance and support of agricultural implements in the rural areas. In order to understand more fully the critical role of blacksmiths let us look at the types of products identified on our study tour which have particular reference to agricultural implements,

Area-specific agricultural implements produced by blacksmiths were found in most regions. In Coast Region (and along the coast and in the southern part of the country) the blacksmiths are producing the small tanged weeding hoe widely used by peasants. The blade is fitted to a short handle by driving the pin through it after heating or pre-drilling. This allows variation of the angel between blade and handle according to the terrain and agricultural tasks to be carried out. This implement is not produced by large industries. Other implements specific to many regions and which are commonly used are bill-hooks and sickles (Kilimanjaro, Singida, Mbeya and Coast). These are curved implements of various size and thickness which are sharpened on the inside edge. They have to be sharpened regularly. This is done mainly on stones or, if available, by using files. In addition, wear and tear reduces the size of the blade which is fitted to a wooden handle.

In Singida region an indigenous bill-hook, hengo, is replacing the matchet. The hengo is made exclusively by blacksmiths from suitable car springs. The blade, slightly curved and about $1 / 3$ of the length of a 
matchet blade, is fitted to a wooden handle about one meter long.

In regions with extensive use of ox-ploughs the range of blacksmith products took on a different character (Singida, Tabora, Shinyanga and Mwanza). Many blacksmiths in these areas produce plough shares either by cutting and joining old ones or by using a suitable piece of car spring. Other plough parts reported to be produced by blacksmiths were landsides (from car spring), mouldboards (from sheet iron) and wheel shanks. The condition of ploughs inspected in the various regions was extremely poor. Unquestionably, without the plough-related blacksmith production many additional ploughs would be unable to operate. The most critical shortage, apart from complete ploughs, were shares which are wearing down fast both due to sandy soils and intensive use. Another reason for rapid wear of shares is the use of mild steel as raw material'. A programme for supply of proper raw materials for production of plough shares would in our opinion greatly enhance the supply and hence the efficiency of ploughs. Some blacksmiths were also found to produce hammers for hammer mills and other spare parts for post-harvest processing equipment.

In addition to area specific products and services, more general ones were found throughout all regions. The production of large tanged hoes was taking place to a limited extent, due to lack of suitable iron as raw material. The technique of blacksmiths does not allow for production of round-eyed (R/E) hoes. However, sometimes blacksmiths do repair hoes by joining an eye to a blade through rivetting. Large R/E digging hoes are however supplied from national industries (UFI and $Z Z K$ ) while tanged ones are imported. At present some blacksmith groups, particularly in the lake zone and coast region, are producing large hoes from rejects in national industries (UFI). SIDO has taken the initiative in identifying blacksmiths groups and facilitating distribution of the rejects. It is evident, however, that the role of blacksmiths in production of large digging hoes is restricted to periods of declining or low supply from large industries and imports. Future 
support to blacksmiths should accordingly not be geared to this product,

Tanged axes produced by blacksmiths, common in a number of regions (Singida, Tabora, Mbeya and Coast), are presently in low supply due to raw material constraints. They are generally of lighter weight and are made from car springs.

Production of the adze (tezo), which is a triangular small blade with a pin fitted at a right angle, to a short handle, is exclusively done by blacksmiths. The adze is used for preparation of house poles and handles for various types of agricultural implements (hoes, axes, bill-hooks etc.). The adze is also widely used by the numerous Makonde carvers along the coast and in the south of the country.

In addition to the varied range of products and repair activities falling within the category of farm implements, blacksmiths produce a series of items for other uses, such as various types of knives, spears, arrow heads, bracelets, large nails for bridge construction, the metal pieces of coconut graters (mbozi), needles, various types of tools, hammers, tongs, drills mainly for their own use. They also perform numerous simple repair services on bicycles, post-harvesting equipment, water pumps etc.

The versatile production carried out by blacksmiths in rural areas imply that their services are called upon by many rural dwellers and for different purposes. In fact, the size of the market does not represent a limiting factor to production. Only one blacksmith visited (Nzega district) stated lack of market to be a problem. The others emphasised shortage of raw materials as the main problem. Some also indicated the need for more advanced tools (Kilimanjaro).

\subsection{Support Programmes}

The UTUNDU Programme

Major projects for promoting village blacksmiths have been scarce. According to Jens Müller (Müller 1980) 
there had been only four major project proposals in this respect (Rao 1975, Kienbaum 1976, SIDA 1976 and G.A. MacPherson 1975) prior to the UIUNDU programme. Common to them all is an analysis which only partially reflects the rural production conditions and the general economic situation in the country. According to Miller this explains their narrow and inappropriate scope. Hardly any of these proposals were implemented, hence there is no basis for evaluating the effects of these projects.

However, all documents contained useful information which to some extent assisted in the design of the UIUNDU programme. The name UIUNDU (which means stubborn in Swahili in the sense of insisting, inventing, trying again) was carried over from the SIDA (1976) proposal. The new UIUNDU programme was written up in 1 ate 1976 and approved and adopted by SIDO in mid-1977. Underlying the programme was a survey of blacksmith activities in many regions coupled with centrally available data and information provided by SIDO's regional offices. The general hypothesis, contrary to most of the previous programmes, was "that the traditional technology of the smiths constitutes a productive force which can be revived, increased and employed to contribute towards the self-reliance objectives of the country" (Miller 1980). The results of Müller's survey confirmed this hypothesis. Later surveys have added further evidence to this effect (Perkins 1978, Phillips and Zachariah 1980, Havnevik 1980). Our field observations, including visits to several blacksmith units in different regions, also supported the hypothesis.

The aims of the UIUNDU programme was to promote rural, small-scale production and repair of iron and metal items, farm implements, tools for other craftsmen and small industries, and household utensils. The ultimate objective was not the promotion of the metal trade as such, but to contribute towards maintaining and increasing agricultural production. Hence farm implements were seen as the major product category. The basic assumption of the programme was that a substantial number of blacksmiths is in operation (about 10,000 in 
the whole country) and that they are highly skilled in terms of the techniques of their craft.

The programme had two main components, (a) product and process development and (b) regional implementation.

The former component consisted of two phases; the first being compilation of documentation and information about new product prototypes and improved iron work techniques, the other being dissemination of the results of phase I. Regarding component (b), regional implementation, this was split into various items. First came identification of groups and then selection of groups to be assisted within the programme. These groups or workshops were divided into $\mathbf{3}$ categories mainly based on market size considerations.

Another item was the specification of products. The UTUNDU programme not only aimed to build on existing skills but also to produce the type of implements already being made. However, the various workshop categories would have a somewhat different product mix due to different size of markets and different profiles in tools and equipment support. The programme also envisaged improved raw material supply through an arrangment where SIDO and UFI were responsible for distribution of blanks and rejects from UFI to the groups selected. Market assistance was seen necessary only when production was aimed for outside district markets and close consultation with RTC was then recommended. Notechnical advice and training were needed and hence not provided in phase $I$ of the regional implementation of the programme. On our study tour we saw no examples of RTCs handling blacksmith products.

In spite of solid ground work and reasonable assumptions (but maybe too high aspirations) the UIUNDU programme was never really implemented as proposed. In fact it was withdrawn by the government in 1980, the reason stated to be lack of funds. What emerged as the SIDO/UNIDO promotion of blacksmiths was a much more limited programme to be discussed subsequently. 
Consolidation of Village Production of Agricultural Implements by Local Blacksmiths. SIDO/UNIDO/Federal Republic of Germany (FRG) project

The project lasted from July 1979 to August 1980, with participation of one expert during the period and one foreign consultant for one month. Nine blacksmith groups were identified in the Kagera, Mwanza and Mara regions as capable of development given that appropriate tools and raw materials were provided and worksheds were erected.

In January 1980 a set of tools and equipment of a wide range was delivered free of charge to the 9 groups. They were purchased in Kenya for about \$30 000. In addition, leather bellows were manufactured locally. Scrap was purchased from UFI and distributed to the groups, 18 tons in $1980 / 81$ and $1981 / 82$ respectively and 15 tons in 1982/83. The average cost on site was TShs 1,000 per ton. The scrap was to be paid for by the groups in cash or on credit terms. Worksheds were designed by the project expert and manufactured by PIPECO in Dar es Salaam at a total cost ot TShs 108,000 ex works plus TShs 85,000 for transport which was supported by SIDO. The sheds were provided free of charge and erected during late 1982, except at one location.

The evaluation of this pilot project was carried out by a UNIDO consultant during 3 weeks in March/April 1983.

He managed to visit 6 of the 9 groups assisted plus one non-assisted unit. In the evaluation report the nonassisted group (in Kagera) was observed to show rudimentary workmanship with a limited product range (hoes, banana diggers and knives) made from poor raw material, To this is contrasted the situation in the assisted groups regarding improvement in quality through introduction of newer and more efficient hand tools:

"In comparison the use of proper anvil, heavier hammers and the supply of heavier scrap steels have enabled the assisted blacksmiths to make more sturdy tools. The use 
of good files and vices allows a better finish and sharper edge of cutting tools. The use of a proper leather bellow or crank blower allows a higher heating power fire and in turn a more appropriate forging temperature for the work piece.

The use of hacksaws, tinsnip, proper cold cnisels and hand drill has allowed some cold metal work and sheet metal work that is a broadening of the traditional blacksmith range of techniques.

The use of a work-shed, high and large enough (covered area: $4.4 \times 7.6 \mathrm{~m}$ ) enables the workers to move around and stand up more freely: this has certainly a positive, if indirect, effect on the quantity and quality of production." (UNIDO 1983).

In spite of this, considerable room for improvement was found. Among other things, it was emphasised that:

(a) Work sheds were expensive and could just as well have been constructed from local raw materials and be set up by the craftsmen themselves.

(b) The cost of tools purchased in Kenya was very high.

(c) Some of the tools and equipment like tube bench, stock dies set and drill bits did not correspond to needs and skills of the craftsmen.

(d) Anvils, firehearths and vices were not placed to allow standing position while working. The impact of SIDO field technicians is not seen to have been very effective in terms of technique.

(e) Although it was planned that the blacksmith groups were to pay for tools and sheds, in fact everything was given to them free of charge.

In our opinion the product range of the units is extremely limited in light of improved tools and equipment and existing demand for various farm implements. For instance, only a very limited quantity of plough shares was produced. The products were otherwize: hoes, knives, axes, adzes, diggers, wood planes, mining tools, spears and some sheet metal products (buckets, 
chicken feeders, drums, etc.). No ox-carts were produced and no other ox-plough related items. The turn-over of the groups is stated to increase steadily from TShs 393,000 in $1980 / 81$ to TShs 454,000 in 1981/82 to TShs 660,000 i n 1982/83. This upward trend indicates few problems regarding markets but is far from sufficient to warrant the high investment costs.

The activities initiated in the three regions have subsequently been extended by SIDO headquartes to several other regions. A special working group has been set up by the Ministry of Industries with representatives from the Ministry of Agriculture, NDC, UFI and Aluminum Africa to promote the decentralization of farming tools and implement design and manufacturing.

The UNIDO expert was satisfied with his findings in the three regions and drafted a project document of phase II with immediate objectives to increase the capacity of the 9 groups, to diversify their production lines, to upgrade the standard of production, to establish a permanent channel for purchase of adequate raw material, to train some of the blacksmiths in records and account book-keeping, an to train SIDO field technicians to supervise further blacksmiths group developments.

The three-year budget draft shows that The Federal Republic of Germany and UNIDO contributed US\$ 500000 and the Tanzanian government TShs 214,000. This excludes housing for international staff, Certainly this is a costly venture for the sake of upgrading skills and production of a limited number of blacksmiths in the lake zone.

SIDO's Blacksmith Promotion Activities

SIDO 's support to blacksmiths is taken up under the rural technology transfer programme. The objective is to assist village artisans in order to increase productivity and to produce quality goods and to bring village artisans on a regular production of farm implements and as well to assist them in the marketing of their products. 
A major part of this support consists in channeling raw materials to blacksmiths groups. The quality and shape of the scrap procured from UFI have, however, been far from ideal for production of area specific implements and plough spares.

According to an agreement with SIDO, UFI is to send scrap and hoe rejects to regional SIDO offices. The regional manager will distribute the raw material with assistance from regional and district authorities or blacksmiths may come to the regional office to collect the material. SIDO will charge the cost of raw material plus 5\% handling charge and transport costs. The distribution and costs of raw material from UFI under this arrangment during the period June 1982 to August 1983 are shown in Table 4.1.:

Table 4.1 UFI Regional Distribution of Raw Materials for SIDO; June 1982-August 1983 (Costs in TShs)

\begin{tabular}{|c|c|c|c|c|c|}
\hline Regions & Tons & $\begin{array}{l}\text { Cost of } \\
\text { Raw Mat. }\end{array}$ & $\begin{array}{l}\text { Transport } \\
\text { Charge }\end{array}$ & $\begin{array}{l}\text { Total } \\
\text { Amount } 1\end{array}$ & $\begin{array}{l}\text { Average } \\
\text { Cost per } \\
\text { ton }\end{array}$ \\
\hline Mwanza & 27 & 15.746 & 5.710 & 22.224 & 823 \\
\hline Kagera & $\begin{array}{r}14 \\
8\end{array}$ & 8.400 & $\begin{array}{r}7.277 \\
830\end{array}$ & $\begin{array}{r}16.097 \\
5.040\end{array}$ & $\begin{array}{r}1.149 \\
630\end{array}$ \\
\hline Mtwara & 8 & 4.800 & $\begin{array}{r}830 \\
3.905\end{array}$ & 5.040 & 630 \\
\hline Lindi & 5 & 3.000 & 3.905 & 7.055 & 1.411 \\
\hline Mara & 13 & 7.800 & 1.753 & 9.943 & 765 \\
\hline Tanga & 4 & 2.400 & 2.800 & 5.340 & 1.335 \\
\hline Singida* & 0.6 & 398 & - & 418 & 697 \\
\hline Rukwa* & 2 & 1.200 & - & 1.260 & 630 \\
\hline Kig oma & 2 & 1.200 & 2.321 & 3.581 & 1.790 \\
\hline Morogoro* & 1.5 & 650 & - & 682 & 455 \\
\hline \multirow[t]{2}{*}{ Irinąa* } & 1.8 & 828 & - & 869 & 483 \\
\hline & 79 & 46.422 & 24.596 & 72.509 & \\
\hline
\end{tabular}

ॠ Collected by own regional arrangement

1) Includes 5\% handling charges not specified in table.

Source: SIDO headquarters.

The prices quoted by UFI for SIDO purchases are on average TShs 450 for one ton of ordinary scrap and from TShs 500 to 600 for hoe rejects. Large industries using resmelted iron are however bidding up the price for UFI 
scrap. In the future this will lead to increased competition for the scrap available. In November 1983 UFI stated that it intended on charging TShs 800 per ton scrap.

By November 1983 SIDO stated already to have supported 26 units with locally produced tool sets, each worth TShs 6500, consisting of six hammers, six tongs of various shapes, two chisels and one flattener. Up to June 1984 the aim of SIDO is to assist 40 units. In SIDO's opinion the RTC system is not geared to distribution of raw materials to farm implement producers. SIDO therefore decided to build up its own channels for supply of raw material.

\section{Kilimanjaro Industrial Development Center}

A minor and non-SIDO support programme for production and training of blacksmiths is linked to the Kilimanjaro Industrial Development Center (KIDC) in Moshi. This project is part of the Japanese support to the Kilimanjaro Region. The project started in mid-1981 in premises outside Moshi, and consists of one forge shop, one small non-ferrous foundry, and an engineering workshop. The forge shop is equipped with a small oven and two hammers, one of which is pneumatic. The project is mainly training-oriented but it also takes some orders for production. KIDC has manufactured 10,000 small forged hoes, and has an order from RTC to manufacture additionally 20,000. This will take KIDC one and a half years to complete. The hoe blade is forged and the eye is then welded onto the hoe-blade.

An interesting activity at KIDC is the training of blacksmiths in more modern forging techniques. The blacksmiths are also given an opportunity of forging the tools they will require themselves. In the foundry, anvils are cast in brass.

There is only one Japanese technical adviser with the project at present.

This project merits further study in order to judge if it can be duplicated in other regions of Tanzania. The 
project experiences may also be of importance to SIDO's support programme for blacksmiths.

\subsection{Conclusion}

In our opinion the initiatives taken by UNIDO/FRG and SIDO to assist production of agricultural implements in the rural areas have a sound focus, however, their efficiency is likely to be low.

The UNIDO/FRG programme has from the outset a limited target, i.e., assistance to only 9 blacksmith groups in a specific area. It includes both relatively high cost items such as appropriate sheds and a series of improved tools. In our opinion the UNIDO/FRG programme could provide useful information regarding the possibility of improving the production processes and hence the quality of products. This should, however, in our judgement not be the prime priority of support programmes at the present stage.

The assistance given is too costly per unit supported. Thus only a fraction of the units capable of increasing production and repair services will be reached. The present state of supply and maintenance of agricultural implements require that blacksmith production is activated on a wide scale. Given limited funds available, this can best be done through improving the supply of appropriate raw materials in a rather dispersed manner coupled with a more limited support for distribution of a few vital tools, like proper anvils, vizes, hacksaws, chisels and files. Such support activities will evidently face transport constraints which must be considered. (Such an concrete programme is outlined in section 4.4 below.)

\subsection{Outline of a Raw Material Support Programme}

Earlier surveys and investigations and our own observations during the study tour indicate that the level of skills and knowledge and access to tools do not operate 
as major constraints in blacksmith production activities. Neither is the market posing an obstacle to increased production and repair activities. For some items, however, this will be the case when an increase in large-scale production leads to an improved supply of products, for instance hoes. It is our assessment that in the future there will be an important role for blacksmiths in production of implements which are complementary to those produced in large industries, in particular the area specific implements. In addition, we see blacksmiths play a role in production of important plough spares like landsides and plough shares which wear down fast and hence require continuity of supply. Against this background we will propose raw materials to be supplied, for instance for the following product spectrum:

(i) plough shares and landsides

(ii) bill hooks and sickles

(iii) axes and adzes (tezo)

(iv) small hoes (weeding hoes)

Evidently the shape of the raw material supplied should lenditselfto a rather easy transformation into the desired product. The products listed have the property that they may be carved out from a one meter long stee 1 bar of the width and thickness of a plough share.

According to the needs of particular regions the product mix may vary, however the raw material quality and shape can accomodate most preferences. Such bars are light enough to be handled by the blacksmith if collecting the material himself, it is small enough to require only modest cash outlays for its purchase and it is large enough and standardized in such a way that it is not cumbersome to handle in large quantities.

The cutting of the bar into suitable pieces is most efficiently done by the blacksmiths using hacksaws. Even though this takes some time, it saves the blacksmith from using the energy-consuming method of heating and then cutting with a chisel. Increased supply of hacksaws and blades would facilitate and ensure the user of the best possible method. 
The major constraint for the above support activities is the lack of a distribution system which is sufficiently grass-root oriented and at the same time prepared to keep regular stock of steel bars. In our judgement the RTC system does not possess such properties. At present RTCs are required to handle a very large number of commodities under various degrees of confinement, and hence do not have the capacity to handle a product of this special character. Thus SIDO with its net of regional offices stands out as the only possible alternative. As discussed earlier, SIDO already has a responsibility for support to rural blacksmiths and has gained some experience through support work carried out. In terms of raw material supply, the SIDO/UFI arrangement has been in operation for some time and a sizeable amount of scrap and hoe rejects have actually been distributed. The major problems facing this distribution channel are administrative delays, transport constraints, high costs and the final destination being regional towns. Further distribution from this point has to be undertaken in cooperation with regional and district authorities, unless items are collected by the craftsmen themselves.

In order to improve administrative efficiency and coordination, SIDO should look into the possibility of establishing a special desk in the headquarters for the purpose of facilitating raw material and tool supplies to metal working units in rural areas. The responsibility of this desk should be to respond to the demands of regional offices for raw materials and tools, locate suitable and cheap means of transport and ensure a sufficient flow of imports of steel bars and tools. To build a separate transport service for raw materials and tools to the regions will be costly, but if combined with other SIDO transport activities it may be economically feasible. SIDO must also improve its ability to locate possibilities for joint transports of various kinds (rail, lorry, landrovers, etc.),

The SIDO regional offices should be given the task to step up the work to identify blacksmiths units. This should not be limited to groups of craftsmen working 
together; individual blacksmiths with apprentices must be included. Supply of raw material should not be conditioned by formation of groups as in the past. The experiences have shown that this requires considerable amounts of incentives, sometimes pressure and the process of formation may take considerable time. Very often such groups disintegrate rapidly, as craftsmen joining from neighbouring villages in order to make the groups large enough to obtain support, return home.

Sales of steel bars should be limited to those groups or individuals identified and the regional offices, often located on industrial estates, should keep adequate stocks to satisfy anticipated demand. Regional managers must accordingly attempt to get a better picture of production levels of village blacksmiths. The managers must also take every opportunity to inform village officials and blacksmiths about the supply system established for this special item.

The above simply amounts to saying that SIDO regional managers should get more acquainted with village production activities. This may require a change of style and emphasis and it may be facilitated if regional offices are given additional funds for transportation and some type of incentives. This should be investigated by SIDO headquarters and if necessary followed up. The only way to sustain such a raw material support arrangement is to fix the price equal to the real cost, and make payment terms cash on delivery or on collection, Our discussions with village blacksmiths indicate that some are willing to pay such a price for appropriate raw materials if available, but some may be unable to and must continue scrap collection in the traditional way. Continuous supply of raw materials would improve the conditions for increasing cash incomes among blacksmiths and improve the prospects for the craft, which in turn may cause better recruitment conditions.

Improved raw material supply would enable blacksmiths to put in more days in production. At present the first encountered obstacle to increase the time used in production is availability of raw materials. Another and 
more serious constraint is due to the need for blacksmiths to engage in agricultural cultivation. This constraint cannot be removed without a fundamental change of the economic structure in the rural areas and is thus to be taken as a given fact. Hence, the actual production level of blacksmiths is far lower than the potential one.

The support progamme should take as its point of departure the actual average production levels, which according to various surveys can be fixed at $200 \mathrm{kgs}$ of raw material usage per blacksmith per annum. This is locally available scrap, which is becoming increasingly scarce. We envisage the imported raw material (bars) to compensate for the decline in locally available raw material. We estimate that the imported steel will, on average, replace $25 \%$ of the present raw material supply, i.e. $50 \mathrm{kgs}$ annually. Further, our assumption is that, on average, only $40 \%$ of the blacksmith population will make use of the new raw material offer due to problems of identification, information, transport and liquidity.

We propose that the programme shall be offered to regions where the use of area specific implements and/ or ploughs is common and blacksmiths exist in reasonable numbers. On this basis we suggest that 11 regions divided into $\mathbf{3}$ zones shall be included: the northern zone, Mara, Mwanza, Kagera, Shinyanga, Tabora and Singida; the western, Mbeya and Rukwa, Lindi,

Mtwara and Coast region. The products likely to be given emphasis in local production in these regions are:

Mara and Mwanza: plough shares, landsides and hoes. Kagera: specialized tools for coffee and banana cultivation, sickles, axes and adzes.

Shinyanga: plough shares, landsides, hoes and adzes. Tabora: plough shares, landsides, bill-hooks, axes, adzes and hoes.

Singida: bill-hooks, plough shares, landsides and hoes. Mbyea: axes, adzes, sickles and hoes. 
$\underline{\text { Rukwa: }}$ axes, adzes, sickles, hoes, plough shares and landsides.

Mtwara, Lindi and Coast: bill-hook, sickles, axes, adzes and hoes.

As discussed earlier, we propose that the unit of raw material to be supplied shall be a $120 \mathrm{~cm}$ long steel bar with cross section $15 \mathrm{~cm}$ by $1.5 \mathrm{~cm}$. The steel shall be of a quality proper for making durable plough shares. Such a blank can for instance be transformed into, alternatively, 4 plough shares, 4 bill-hooks, 4 large hoes of the Ufipa/Rungwe type and a variable number of adzes or weeding shoes.

The product mix will vary according to area specific tools or plough spare needs. The possibility to vary the product according to needs by using one standardized piece of steel, is of great importance to efficiency in ordering, handling and distribution.

One such steel bar will weigh about $20 \mathrm{kgs}$ which makes it relatively heavy in relation to its volume (2700 $\mathrm{cm}^{3}$ ). We assume that the steel bars, cut in the specified shape, will be imported to Tanzania from a competitive supplier. It is of importance that crates of steel bars can be transported sealed from the external supplier to the individual regional towns in Tanzania. In addition, the weight of one crate should be such that it can be handled by regional means of off-and unloading and regional transport. Hence we propose that the standard unit for transport is a crate containing 50 steel bars of total weight slightly above one ton. In order to secure efficient collection from railpoint or harbour and internal regional distribution, we suggest that the transport function at SIDO regional offices is strengthened to compile with the transport requirements of the blacksmith and ox-cart support prog ramme.

The support programme will to a limited extent include supply of tools. Hacksaws, blades and chisels shall be made available to SIDO regional offices on order. A limited number of anvils and vices is to be stocked in 
each region and sold at subsidised prices if in demand by blacksmiths. The use of these tools and equipment will allow a better finish of products and hence improve their quality.

In the outline of the programme care has been taken to include mechanisms which increase the chances for the raw material, tools and equipment to reach the target group, the blacksmiths. Given the present situation in Tanzania, some of the items supplied may not reach their target. According to our observations in the selected regions we are, however, quite sure that raw material and tools which fall in the hands of others will be used productively as well.

\subsection{Ox-Cart Manufacturing}

Over the last five to eight years, the production and use of ox-carts has grown fairly rapidly. We conservatively estimate the demand for ox-carts to be 12,000 carts (high quality and expensive) for the first 3-year period. Even if this demand is satisfied, there is still a likelihood of a subsequent demand of a similar order for good quality but cheaper ox-carts.

Ox-cart manufacturing, is generally not a specialized activity and most units - whether individual or large, private or public - engage in production of a range of products, including wheel barrows, hand-carts and not least furniture. A number of the public workshops - and some of the larger private ones with up to 10 employees (e.g. in Shinyanaga and Arusha) - also produce other types of farm implements such as harrows, furrow markers, plant-spacing wheels, 1 jab planters, plough shares and hand tools.

1. Only public workshops engage in production of these three implements since these products are not in commercial demand a $\mathrm{t}$ a 11 , but are bought by Kilimo for demonstrations. 
There are about 15 public workshops in Tanzania, most of them supported by regional directorates and operated under RADO supervision. Both the quality of their products and the economic performance of these workshops is generally very poor at present and has been so for a number of years. 1 Their products have been subsidized to lower the price.

Six RCW's in different regions were started up under TAMIU with West German as sistance. Only one of these (Nzega) is now managed under CAMARTEC. There is now a total of 9 RCW's, not all producing ox-carts, which are planned to receive technical assistance from CAMARTEC. Most of these are managed and supported by RADO and RDD offices.

Despite the demand for high quality, pneumatic tyre ox-carts, most of the public RCW's continue to produce mainly iron wheel or wooden wheel ox-carts of generally poor quality. Only in Arusha Region has there been consumer acceptance of iron wheels, mainly produced by Themi. Both these manufacturers are now working on pneumatic wheels.

Although most the these workshops complain that they lack machinery or that it is in need of replacement, the public workshops are in fact very well equipped with machinery if compared with the private ox-cart manufacturers and even the larger private workshops. The public workshops are over-employed and even the smaller ones have hierarchical management structured with at least two managers. Overheads and administrative costs are high. They have had problems with trained craftsmen leaving for better paid or more productive and inspiring jobs.

1. One exception can be found in the 3 RCW's started up in 1982 in association with Themi Farm Implements company. They are organized on a semi-public way and their carts are well made. 
Although they have had preferential access to raw material at official. (low) prices, their production has remained low. This is not to say that they have not been short of raw material, especially over recent years. Workshops which make furniture on order from the Ministry of Education have generally fared better in economic terms. Other type of farm implements with no commercial demand (e.g. harrows) are produced on order from the Ministry of Agriculture (RADO's).

In contrast, the larger private workshops with 5-10 employees, of which there are probably no more than 5-10 in the country (with several in Shinyanga), produce the preferred, high quality, pneumatic tyre oxcarts at prices of TShs $12-15,000$. Their machine inventory is much more limited. In Shinyanga, the workshops making wheel/axle sets, have lathes, power hack saws, power drills and mending vices, all of which they have made themselves by an amazing level of ingenuity in using old car differentials, etc.

Of much greater importance in terms of total output of high quality ox-carts - running on old Landrover and car axle/wheel sets - are a relatively large and unknown number of open-air workshops in villages and district towns.

Most of these consist of private individuals who employ only a few apprentices or skilled carpenters on a more or less temporary basis. They only use carpentry handtools and mainly produce on order or on contract. In the latter case, the cart buyer may bring his wheel set, the required nuts and bolts and even the timber, and the total cost of such carts is normally quite low. If an ox-cart is produced on order, the craftsman himself tries to get the second-hand wheel set, bolts, timber, etc. He may spend considerable time away on long distance travels to neighbouring regional towns looking for a wheel set, tyres, tubes, etc. and the bolts, which - if successful - he brings back by lorry or on a bus. The cost of the cart will then reach 15,000 shillings (oct 1983). 
Neither the larger nor the individual craftsmen interviewed mentioned lack of machinery as being a constraint, and they said that the market was insatiable. No doubt, the high demand for such carts helps to drive up the final price to high 'artificial' levels which would not be the case if the wheel sets and accessories had been available in the areas where ox-carts are produced,

Finally, there are probably some 10-15 mission-run workshops producing ox-carts. While some of these have tried to rely on the TAMIU ox-cart design, and employ a small group of craftsmen working with hand tools. We have heard about a couple of missions which produce on a larger scale with machinery. In comparison with the public workshops, the mission workshops would probably be run a t lower costs. They tend to have longstanding networks for raw material supply and they have access to foreign exchange for imports.

As regards the private ox-cart sector in general, the constraints on production are neither capital, machinery, overheads, skills, sales or timber supply (mainly mninga, mtundu, and grevelia), but rather the severe problem of getting nuts and bolts for joining the cart box, and second-hand car axles, wheel-rims, hubs, bearing, tyres and tubes. In the case of Shinyanga, the supply of old car wheel sets has been completely exhausted. Here, the fixed axle beam is made out of sisal estate rails or pipes, to which stab axles, drilled from mild steel bars, are welded. Increasingly the wheels are bent and welded out of sheet iron and round bars because old car wheel-rims are difficult to get.

Finally, it should be noted that the general transport crisis is likely to have caused an increase in the use of hand carts in regional and district towns, where such carts have been common for a long time. Most of these run on second hand saloon car wheel sets with pneumatic tyres, and there is an informal manufacturing sector, including some of the private manufacturers mentioned above, for the production of these as well. This means that even in regions with no or few ox- 
carts, e.g. Dar es Salaam, the second-hand wheel sets are in demand. Thus even on an inter-regional scale rural ox-cart users are indirectly competing with the informal transport sector in towns for scarce secondhand wheel sets.

Hence, in general, private ox-cart production is discontinuous in time and space because of 1 ack of raw material. Most of the public workshops are constrained by the same problem but their production was low even before the scarcity of raw materials, If the problem was not raw material, then it was power supply, poor machinery, lack of spares, the leaving of craftsmen, the lack of sales, the lack of transport for getting the material, poor support and supervision by TAMTU, lack of funds, embezzlement of funds, etc.

In short, most of the public workshops have had no incentive to produce and they have no history of production.

In Table 4.2 we present production and annual capacity figures for most of the workshops visited. Since we mainly asked on ox-carts, the table is incomplete for wheel barrows, hand-carts and harrows/(ridgers).

Since the annual production data collected are incomplete for the three years in question, even for oxcarts, and only represent a limited number of public and private manufacturers, the erratic annul output should not be taken to infer any trends in production.

The new Mafinga Workshop in Iringa Region is the largest manufacturer of complete ox-carts in the country, with the exception of Themi Farm Implements (TFI) in Arusha, which produces only the wheel sets for commercial sale to its 3 associated RCW's and to individuals and TFA. Mafinga has, among other things, suffered from several break-downs of its generators, and only about $1 / 3$ of its ox-carts have sold on commercial terms, although they have been brought out to the 14 regional ox-training centers. The carts are small, have iron rim wheels and are of very poor craftsmanship, costing 4,500 shillings. 
Table 4.2 The Production of Ox-Carts, Wheel Barrows, Hand-Carts and Harrows from $8 \mathrm{Public}$ and Private Manufacturers for the Years 1980-83

\begin{tabular}{|c|c|c|c|c|c|c|}
\hline $\begin{array}{l}\text { Workshop name/ } \\
\text { place (support/ } \\
\text { organization) }\end{array}$ & $\begin{array}{l}\text { Prod. } \\
\text { year }\end{array}$ & $\begin{array}{l}\text { Ox-car } \\
\text { Actually } \\
\text { prod. }\end{array}$ & $\begin{array}{l}\text { rts } \\
\text { Stated } \\
\text { annual } \\
\text { capacity }\end{array}$ & $\begin{array}{l}\text { Wheel- } \\
\text { Barrows } \\
\text { actually } \\
\text { prod. }\end{array}$ & $\begin{array}{l}\text { Hand- } \\
\text { carts } \\
\text { actually } \\
\text { prod. }\end{array}$ & $\begin{array}{l}\text { Harrows } \\
\text { \& (ridgers), } \\
\text { actually } \\
\text { prod. }\end{array}$ \\
\hline $\begin{array}{l}\text { Mafinga/Iri. } \\
\text { (RIDEP/RADO) }\end{array}$ & $\begin{array}{c}\text { Started } 0 \\
82 / 83\end{array}$ & Ct. $\begin{array}{r}1982 \\
86\end{array}$ & 1000 & $\begin{array}{c}\text { at least } \\
36\end{array}$ & n.a. & 60 \\
\hline $\begin{array}{l}\text { Mbeya RCW } \\
(\mathrm{RADO})\end{array}$ & $\begin{array}{l}80 / 81 \\
81 / 82 \\
82 / 83\end{array}$ & $\begin{array}{l}41 \\
77 \\
13\end{array}$ & $\begin{array}{l}100 \\
100 \\
100\end{array}$ & $\begin{array}{l}\text { n.a. } \\
\text { n.a. } \\
\text { n.a. }\end{array}$ & $\begin{array}{l}\text { n.a. } \\
\text { n.a. } \\
15\end{array}$ & $\begin{array}{l}\text { n.a. } \\
\text { n.a. } \\
50\end{array}$ \\
\hline $\begin{array}{l}\text { Nzega RCW } \\
\text { (CAMARTEC) }\end{array}$ & $\begin{array}{l}80 / 81 \\
81 / 82 \\
82 / 83\end{array}$ & $\begin{array}{l}24 \\
24 \\
11\end{array}$ & $\begin{array}{l}150 \\
150 \\
150\end{array}$ & $\begin{array}{l}1 \\
2 \\
0\end{array}$ & $\begin{array}{l}1 \\
2 \\
0\end{array}$ & $\begin{array}{c}\text { (ridgers) } \\
1 \\
2 \\
0\end{array}$ \\
\hline $\begin{array}{l}\text { Singida W. } \\
\text { (SIDO/RDD) }\end{array}$ & 1982 & 90 & 360 & n.a. & n.a. & $\begin{array}{c}\text { (capacity: } \\
720 \text { ) } \\
80\end{array}$ \\
\hline $\begin{array}{l}\text { Mazao Engin/ } \\
\text { Arusha (SIDO/ } \\
\text { private) }\end{array}$ & $\begin{array}{l}1982 \\
1983\end{array}$ & $\begin{array}{l}60 \\
34\end{array}$ & $\begin{array}{l}240 \\
240\end{array}$ & $\begin{array}{l}\text { n.a. } \\
\text { n.a. }\end{array}$ & $\begin{array}{l}\text { n.a. } \\
\text { n.a. }\end{array}$ & $\begin{array}{l}\text { n.a. } \\
\text { n.a. }\end{array}$ \\
\hline $\begin{array}{l}\text { Iringa/Ismani } \\
\text { (private vill- } \\
\text { age fundi) }\end{array}$ & $\begin{array}{l}1982 \\
1983\end{array}$ & $\begin{array}{c}\text { not stat } \\
6\end{array}$ & ated 30 & $\begin{array}{l}\text { n.a. } \\
\text { n.a. }\end{array}$ & $\begin{array}{l}\text { n.a. } \\
\text { n.a. }\end{array}$ & $\begin{array}{l}\text { n.a. } \\
\text { n.a. }\end{array}$ \\
\hline $\begin{array}{l}\text { Nzega Town } \\
\text { (private fundi) }\end{array}$ & $\begin{array}{l}1981 \\
1982 \\
1983\end{array}$ & $\begin{array}{l}7 \\
0 \\
7\end{array}$ & $\begin{array}{l}\text { n.a. } \\
\text { n.a. } \\
360\end{array}$ & $\begin{array}{l}\text { n.a. } \\
\text { n.a. } \\
\text { n.a. }\end{array}$ & $\begin{array}{l}\text { n.a. } \\
\text { n.a. } \\
\text { n.a. }\end{array}$ & $\begin{array}{l}\text { n.a. } \\
\text { n.a. } \\
\text { n.a. }\end{array}$ \\
\hline $\begin{array}{l}\text { Shinyanga Town } \\
\text { (private work- } \\
\text { shop) }\end{array}$ & $\begin{array}{l}1982 \\
1983\end{array}$ & $\begin{array}{l}42 \\
36\end{array}$ & $\begin{array}{l}180 \\
180\end{array}$ & $\begin{array}{l}\text { n.a. } \\
\text { n.a. }\end{array}$ & $\begin{array}{l}\text { n.a. } \\
\text { n.a. }\end{array}$ & $\begin{array}{l}\text { n.a. } \\
\text { n.a. }\end{array}$ \\
\hline $\begin{array}{l}\text { Total }(1980 / 81) \\
\text { Total } \\
\text { Total } \\
(1981 / 82) \\
\text { To82/83) }\end{array}$ & $\begin{array}{l}1981 \\
1982 \\
1983\end{array}$ & $\begin{array}{r}72 \\
293 \\
193\end{array}$ & $\begin{array}{r}250 \\
1,030 \\
2,060\end{array}$ & $\begin{array}{l}\text { n.i. } \\
\text { n.i. } \\
\text { n.i. }\end{array}$ & $\begin{array}{l}\text { n.i. } \\
n \cdot i \cdot \\
n \cdot i\end{array}$ & $\begin{array}{l}\text { n.i. } \\
\text { n.i. } \\
\text { n.i. }\end{array}$ \\
\hline
\end{tabular}

fundi $=$ skilled craftsman

n.a. $=$ not asked

n.i. = not included

Source: Data collected during visits, Oct,-Nov. 1983

The Meya RCW is among the most productive public $\mathrm{RCW}^{\prime} \mathrm{s}$ with an average annual output of about 60 ox-carts over the 1 ast 6 years and employing 22 persons, The carts mainly have wooden wheels, lined with old car tyres. The cost of production for a cart is TShs 5,000 and the 
selling price is subsidized by the RDD down to TShs 2,500. This unit.also manufactures hand-carts and harrows.

Nzega RCW has suffered from isolation, lack of supervision and lack of raw material. It is fairly well equipped for a small workshop but some of the machinery is old. The workshop has two oxen for testing and demonstration purposes and a fairly large piece of land, most of which is bush land. A cart box inspected was of good craftsmanship. The price of a Landrover wheel set cart was TShs 8,000. One or two iron wheel sets were sold to a missionary in 1981. The workshops has a manager, assistant manager (craftsman), one store-keeper, 2 clerks, 3 carpenters and 3 welders. The workshop competes with at least 5 smaller, private cart manufacturers in Nzega town.

The Singida Workshop, started by SIDO 1971 and transfered to the RDD in 1985, is a large workshop which engages in production of a number of farm implements, many of which are of poor quality or of no utility to the peasants. In 1983, re'gional authorities ordered the whole production of ox-carts to be returned to the workshop to rectify defects on the wheel-axle construction. The wheels are made of wood. Although the workshop, visited several times and employing 21 persons, gives a busy impression, we are not sure whether 90 carts were in fact produced in 1982. In 1982 the carts were sold at TShs 6,000, in 1983 at TShs 8,000. On a previous visit, the prices quoted were double as high. Singida has at least two private manufacturers making pneumatic tyre carts for around 15,000 shillings .

Mazao Engineering Company in Usa River near Arusha was started as a partnership by three private entrepreneurs i n 1981. The workshop received SIDO credit support of TShs 673,000 for a limited number of good machines, some of which may represent overinvestment in capacity. The workshop does not have as many machines as the public workshops and employs 6 persons ( 4 craftsmen) apart from the 3 partners. Mazao needs a new shed and 
suffers from lack of working capital for procuring raw material. In 1982 Mazao repaid only half of the credit amount due. The prices for ox-carts, made on order were set a t TShs 5,500 in 1982 and TShs 7,000 in 1983 in order to be able to compete with the subsidized CAMARTEC prices. The workshop now has an order for $100 \mathrm{carts}$ but cannot meet it due to lack of funds to purchase raw material. It also makes plough shares by welding together and forging two worn-down shares. Despite the financial situation, with attempts to get a TShs $100,000 \mathrm{NBC}$ credit for the purchase of raw materials for 50 carts, the workshop wants to expand. Customers prefer pneumatic tyre wheels according to the production manager.

The two small, private ox-cart manufacturers, one from Ilambilole village in Ismani, Iringa and the other from Nzega Town in Tabora, are of a similar nature in the sense that they produce a small number of carts on order annually. Both engage in agriculture and furniture making as well, and they both spend a lot of time on travels to find second-hand car-wheel sets.

For Nzega, the procurement cost (less travel expenses) of the complete axle/wheel set was TShs 3,300 in 1981, and almost TShs 8,000 in 1983; plus TShs 1,500 for timber and TShs 360 for bolts in 1981, which had gone up to TShs 2,500 and TShs 1,000 respectively in 1983. In 1983 an additional TShs 500 was spent to get the axle and wheels welded, giving an overall material cost of some TShs 10-12,000 for a cart. The craftsman's labour cost was set at TShs 100 per day over 3-4 days for making the cart box. However, the cart might be sold at TShs 13-15,000, depending on travel time and expenses to get the wheel sets. In Iringa, the cost of a complete wheel set was some TShs 5,000 in 1983, and a complete cart was sold at TShs 8,000 . Both craftsmen stressed that there was no 1 imit to the market for carts. The private workshop in Shinyanga town mainly concentrated on the production of cart boxes, with some 10 boxes lying at the workshop and waiting for wheels and axles. These are produced by four workshops with mainly self-made machinery. The workshop visited 
employed 3-4 persons when there was work to do. The complete large-sized carts were made ready and sold at TShs 13-15,000 since buyers preferred to see the finished product first.

In Shinyanga there are at least 5 ox-cart manufacturing workshops of the larger type, with the metal engineering workshops diversifying into a number of products to reduce dependency on raw material supply for only one product.

A group of 6-7 young boys made solid-looking foot and hand pumps for ox-carts totally out of scrap (shock absorber cylinders, old lorry brake-pedals, wire, etc.). The valve heads were cast in aluminium. A painted foot pump sold at TShs 1,400.

In general, Table 4.2 shows that actual utilization of stated capacity is very low both among public and private manufacturers.

\subsection{Support for Local Manufacturing of Ox-Carts}

The north-central zone of Singida, Tabora, Shinyanga and Mwanza has been identified as the area with the largest concentrated demand for ox-carts (i.e., 6,000 carts for the first 3 years) and with the most experienced and innovative private manufacturing sector for both the required metal parts, wooden boxes and accessories like pumps. The zone is generally of great agricultural importance and has a relatively high population concentration, while at the same time it is suffering from serious transport constraints and lack of essential raw materials.

We are proposing that a raw material support and design development programme is established for ox-cart manufacture. The distribution of the required raw material can be made through SIDO. The proposed programme is primarily geared towards raw material import support and distribution of this material to existing private ox-cart manufacturers so as to ensure economic effi- 
ciency in the utilization of this material. Both the well-established metal working workshops and individual carpenters in villages should be supplied with the material required.

To ease a potential constraint on the manufacturing of axle-wheel sets, the SIDO Common Facility Workshops (CFW's) in Singida (Azimio Workshop), Shinyanga and Mwanza, and/or private engineering workshops in Singida, Igunga, Nzega and other regional or district towns should be included in the programmes as component manufacturers, provided it can be ensured that the material supplied is used for ox-cart components. The first wheel sets made on trial should be tested in villages. Shinyanga, Mwanza and Tabora RIDEP's should be able to assist.

Once production increases, the wheel sets should be able to reach the village carpenters who are used to producing carts. Both formal and informal channels of information should be used to identify these individual carpenters and inform them. The programme should not require the formation of co-operative groups of manufacturers or carpenters for support eligibility. The close relations existing in Shinyanga between SIDO and the private manufacturing sector should be used as a model. The functioning and impact of the programme would be assessed after one year of operation to identify problems and bottlenecks. 


\title{
CHAPTER FIVE
}

\author{
INDUSTRIAL PRODUCTION OF FARM IMPLEMENTS
}

\subsection{Small Scale Industrial Production}

The development of small-scale industries in Tanzania is the responsibility of the Small Industries Development Organisation (SIDO). SIDO has built industrial estates in almost all regions of the country. Companies established outside the estates are also assisted on request. The SIDO regional managers have thus the function of supervising a) the SIDO estates (which have an estate manager), b) other small-scale industrial units in the region and c) village blacksmiths.

\subsubsection{Production Units within the SIDO}

Industrial Estates

We have visited the industrial estates in Singida, Shinyanga, Mwanza, Arusha, Moshi, Mbeya and Iringa. There is no company in these estates which exclusively manufactures farm implements. The Common Facilities Workshops (CFW), of which there is one in each estate, and some other units have a certain part of their operations geared to the sector. The CFWs are owned and operated by SIDO. In general they are well equipped with versatile machining equipments.

The SIDO CFW in Singida is well run and manufactures stoves in addition to making spare parts of various types and doing repair jobbing. The CFW in Mbeya has manufactured the wooden beam plough, and has the capacity to manufacture larger series of this implement. It is also making tools and dies for ZZK. SIDO CFW in Iringa has been proposed for plough manufacturing, once a collaboration agreement with a Swedish sister company is operative. The wooden beam design will probably be adopted. 
The SIDO workshop in Singida town, which falls under the Regional Commissioner, has some 20 employees and has made hand- and animal-drawn implements of inappropriate or nonfunctional design, of poor quality and at a high cost.

The Shinyanga SIDO estate works closely with the farmers in surrounding areas and is attempting to meet their requirements in spite of little support (see also under ox-cart manufacture).

Several companies a the Moshi estate are involved in the manufacture of farm implements. MAFOTCO (see below) makes plough shares, Moshi Hand Tools makes coffee pruners (in quantities sufficient to meet national demand), and Kilimanjaro Foundry Company has made prototypes for frogs for ZZK (but no order has been received since then) and covers for the hullers. KFC is also in the process of starting manufacture of coffee pulpers.

Simon Engineering Works, established outside the Moshi Industrial estate, is a general engineering workshop, with capacity to manufacture ox-carts. This company is presently installing a rather large manufacturing capacity for axes and hammers with Swedish assistance. The equipment includes second-hand forge hammers. The rated annual capacity is planned at some 120,000 pieces. Unfortunately we have $1 \mathrm{itt} l \mathrm{e}$ information about the present status of this project.

\subsubsection{MAFOTCO, Moshi}

This company was originally set up to forge component parts for other companies in the Moshi SIDO estate.

These were scissors, cutlery and hammers. MAFOTCO has recently started making plough shares. The production process includes cutting, forging, trimming, holepunching, grinding, heat-treatment, painting and packing. Plans are also made to forge axe-heads at MAFOTCO for one of the companies in the Moshi estate.

MAFOTCO has already made 7,000 ploughs shares and have a further 5,000 shares in progress. Without reducing their supply of component parts to other estate companies, MAFOTCO could manufacture 20,000 shares p.a. 
The raw material is high carbon steel, which is bought from Sweden. The forge hammers are rather strained by this production, which requires more force than the machines were originally designed for. They would need an extra forge hammer to increase their capacity for making plough-shares. The tool-room at MAFOTCO is well equipped.

Our conclusion is that MAFOTCO should be encouraged to continue plough share production but that the equipment needs should be evaluated, and some preventive measures be taken so that the forge hammer is not overloaded.

\subsubsection{Themi Farm Implements and Engineering Co Ltd}

This company, which is located in Arusha, was established in 1982 with financing from RIDEP (USAID funds) and with technical support from SIDO (and on the basis of a feasibility study prepared by SIDO). There are presently 7 active partners in Themi.

The company's main products are:

1) animal-drawn ploughs ("the Kabanyola tool-bar"), a multipurpose implement with a beam made from galvanized water pipes. The bottom-assembly is bought from UFI.

The plough is presently selling at TShs 2,050 (i.e., approximately 700 more than the UFI plough).

For more information, see Chapter 2.4,

2) metal components for ox-carts (axles, wheels, nuts and bolts) based on TAMTU/CAMARTEC designs as well as complete wheel-sets. Wheel-sets cost TShs 2,600 with iron wheels and TShs 3,000 with pneumatic tyres.

3) a push type hand planter.

In addition the company undertakes engineering jobbing.

Production of plough-shares has been discountinued.

During the first 9 months of 1983, Themi's production figures were as follows (with reference to targets): 


\begin{tabular}{lrr}
\hline & $\begin{array}{l}(8 \text { of target } \\
\text { i n SIDO study) }\end{array}$ \\
\hline wheelaxles & 561 & $75 \%$ \\
steel-wheels & 1,151 & $61 \%$ \\
plought+weeders & 486 & $86 \%$ \\
complete carts & 20 & $11 \%$ \\
\hline
\end{tabular}

Sales volume for the first 9 months was almost TSh 3.0 million, of which $65 \%$ refers to standard products and the rest to jobbing.

Themi has been given a special permit to sell to TFA and directly to village shops in addition to RTCs. RTCs have shown reluctance in dealing with Themi products.

Themi expansion requirements include a heavy duty power hack-saw, expansion of the foundry, arc-welding sets, a pillar drill, a shaping machine and wood working machines. At a later stage, Themi wants a new building with a forge hammer.

Our conclusion about Themi is that they have shown a commendable entrepreneurial and innovative talent, but we are not convinced that the product design development is complete as far as the animal-drawn plough is concerned. Themi's reliance on the TAMTU/CAMARTEC design of ox-carts is also an obstacle.

The profit level in the company indicates that they should be able to lower their plough-price to make it more in line with UFI's price.

We are of the opinion that no major investment should be made in this company until the right plough and cart-wheel design has been found. Themi may need technical advice from SIDO in this respect.

TRDB will apparentely continue to render raw material support t o Themi. 


\subsubsection{Other Small-Scale Industrial Units}

Apart from the SIDO-supported units discussed above, and the ox-cart manufacturing workshops discussed in Chapter 4.5, there are a number of small units operating on their own. We have not had the opportunity of identifying all these, but we have visited some which may be of interest.

Umoja Engineering Works in Arusha manufactures wheelbarrows and some hammer-mills. The operations are severly constrained by lack of funds and raw materials. The operation employs 15 people and has a turn-over of TShs 1.5 million per year. Wheel-barrows sel1 at TShs 2,200 .

Azimio Engineering Works outside Arusha primarily makes window frames and auto spare parts. But they are also making some wheel barrows for TFA selling at TShs 1,400 (small size) and TShs 1,800 (large size). Capacity is 100 wheel-barrows a month. The unit also undertakes a lot of repair work.

Tanzania Industries in Mwanza manufacturers nuts and bolts, but the steel supplied to them is of poor quality and thus the products are not very good. Considering the need for nuts and bolts (e.g., for oxploughs), the possibilities of up-grading this company should be studied.

\subsection{Medium Scale Production}

The title of this section is not entirely correct, as we are also going to discuss some units which by most standards would be described as small, and some of the SIDO-supported companies described in Chapter 5.1. may well be considered as medium scale in the Tanzanian context. However, the industries discussed below are generally not the result of SIDO or other government directed efforts, They are privately owned, mostly by people of Asian origin or nationality. Futhermore, they are members of the Metal Engineering Industries Deve- 
lopment Association (MEIDA) which was set up with Swedish assistance in 1979. MEIDA was formed to facilitate exchange of information and experience among metal engineering industries, and between them and government institutions. MEIDA is also assuming an advisory role of a problem-identifying nature.

The companies to be discussed can be grouped into two categories, those who can play a role in manufacturing farm implements in the future, and those who are presently manufacturing post-harvesting equipment.

\subsubsection{The MEIDA "capacity-identifying"exercise}

In November 1983, MEIDA submittted to the Ministry of Industries a paper entitled Capacities within MEIDA for the manufacturing of farm implements. This was the result of discussions in the Farm Implements Manufacture coordinating committee. It should be recognised that the demand for implements underlying the exercise are those provided by TISCO, and which we consider too high.

MEIDA identified 12 companies that between them could manufacture $1.3 \mathrm{million}$ hoes. These hoes are either rivetted or welded hoes, not the common forged hoes. Four companies were identified for matchet production, altogether 6 million pieces. Four companies could make 720,000 shovels p.a. between them, three companies 120,000 slashers, and four companies 80,000 rakes. Four companies were identified to have the capacity to manufacture ox-ploughs, harrows, cultivators and ridgers.

Of a 11 the identified companies only three are actually producing the items and another is about to start production. MEIDA is proposing that government should allocate foreign exchange to these companies for importation of raw materials and required tools and dies. MEIDA is also proposing to introduce a quality control standard, which MEIDA would supervise and guarantee by the issue of certain trade mark labels.

It should be noted that the exercise was merely aimed at identifying existing capacity in Tanzania, it does not discuss or evaluate if the production volumes proposed are realistic, nor the cost effectiveness (in 
terms of local and foreign funds) of manufacturing the mentioned items.

According to our opinon, the manufacture of hoes should continue to be concentrated to large-scale production units. We do not exclude, however, the possibility that a welded, rivetted or press-hardened hoe may be cheaper to produce, but we are not convinced that this is a given fact. In addition, we believe the market preferences should not be underestimated. Casements Africa has manufactured some welded hoes, which are of poor quality, and consequently we have found them lying in the RTC go-downs and unsaleable. The relatively small numbers to be produced at each unit $(200,000$ being the highest) makes the impact small. In particular, such low production must not be allowed to justify a higher price per hoe than what UFI is charging. If, however, the unit price can be lowered, an the saleability be demonstrated, this alternative production technology should be supported, but this does not exclude concentration of manufacture. Advanced plans for hoe production appear to exist in respect of one company, Simon Engineering Works in Moshi, but the equipment which is being installed is versatile enough for other production. MEIDA has already ordered steel for 200,000 hoes, but has not yet decided where to use it.

Matchets are not produced in Tanzania today. Trial production started in December at Cotex (see below). The identified total capacity (6.0 million matchets) is much too high for the national demand and we are strongly suggesting to restrict manufacture to one MEIDA unit.

One of the companies identified as capable of producing matchets as well as ploughs is the National Bicycles Company Ltd (NABICO) in Dar es Salaam. This company has presently ceased manufacturing bicycles, and only a small number of hinges and some window-frames a re presently produced there. We share the general feeling that this impressively equipped unit should not be standing idle, but we believe bicycles would have such an economic benefit (particularly in the rural areas) that it would be premature to restructure NABICO into a 
farm implements manufacturer as suggested by MEIDA. If no bicycle manufacturing partner can be found, a thorough investigation should be done at NABICO to judge the usefulness of the equipment for, e.g., plough manufacture. (Considering market forecasts and the available capacities at ZZK and UFI and other units, plough production will still have to be a rather small operation at NABICO, not exceeding 10,000 pieces per year for the next 4-5 years, and thereafter perhaps even less.)

Shovels can be manufactured at four companies, three of which already have the tooling required. The total capacity in our view far exceeds national demand, particularly if we consider the demand for shovels in agriculture. According to the TISCO market study from 1980, total demand in 1986 was forecast at almost 700,000 pieces. In the draft report to NDC on Mwanza farm implements factory, the demand based on present importation is reduced to 300,000 .

One of the proposed manufacturers is Hans Paul Dharam

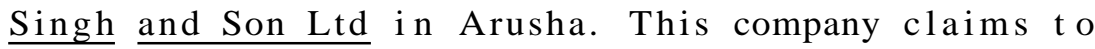
have a capacity to manufacture as many as 1,500 shovels per day, i.e., more than 300,000 per annum, which is the figure used by MEIDA, but the manager states that he would prefer to operate at $1 / 3$ of this capacity. There is a bottleneck in the manufacture of handles. The companyappearsto have all the equipment required. A problem for the manufacturer was that he had not been allowed to sell directly to the market (UFI is the confinee). Preferably he would sell not only to RTCs but to TFA as well. During our visit we were told that this matter had been positively resolved.

In addition to shovels, Hans Paul Dharam Singh and Sons is also manufacturing maize hullers and maize mills in limited numbers.

We were very impressed by the ingenuity of the entrepreneur. However, his premises were extremely small and we are doubtful whether they will allow the scale of production foreseen. The only requirement, since the 
marketing problem has been resolved, is foreign exchange for raw materials. A stock for 30,000 shovels was available.

Rakes and slashers are also identified as suitable for MEIDA production. We do not think that these implements find much use in agricultural activities, and prefer not to comment on plans for their manufacture. It should be noted, though, that UFI has decided to stop manufacture of slashers, which increases the opportunity for smaller scale operations. Competitiveness with imports must, however, be demonstrated. Axes and

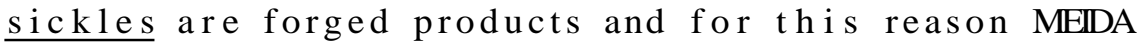
recommends that ZZK should manufacture those.

The only ox implement proposed for MEIDA companies is the plough, based on the wooden beam design. Plough bottom assembly and plough shares are to be bought from other manufacturers (UFI and MAFOTCO) as well as the cast iron drag wheel. In our discussions with MEIDA personnel, they expressed some apprehension that the demand for ploughs estimated by TISCO $(75,000)$ may be too high and thus the market will become flooded if all the four identified companies would commence manufacture. We share this apprehension, and we are furthermore advising against too high production of the wooden beam plough until it has been properly tested and evaluated on peasant farms in rural areas. We have visited one of the proposed MEIDA-member companies, Vitanda Manufacturing Company Ltd in Mwanza.

This company has a wide product range, including wooden furniture, which has even been exported, shoes, beds, travelling goods, and farm implements. The production equipment is largely self-made, but still it appears appropriate to the production.

Vitanda has started prototype production of ploughs, both wooden beam and hollow box steel beam. Shares are bought from MAFOTCO. Bottom assemblies have been promised from UFI but not yet received. The capacity is stated as 5,000 ploughs per year, if raw material is made availabe. Plans exist to make either shovels or hoes as well. 
The workforce is presently about 300 but was 700 before 1978. There are four Indian expatriates working in the company.

\subsubsection{Cotex Metals and Machinery Ltd}

Cotex, which is a member of the cotex group of companies, started operations in 1980. They have a number of product lines, including plastics, spare parts of various types, telecommunication equipment and pressed sheet metal products. Cotex also has a well equipped tool-room, which is considered to be one of the best in Tanzania.

The group is owned by two overseas-based shareholders, who also own industries in the UK.

The total investment in cotex is TShs 24.5 million, and turn-over in 1983 is going to be above TShs 20 million.

The company is managed by 6 directors, 5 of which are expatriates. 40 of the 150 workers are skilled.

The operations are severly hampered by lack of raw materials, particularly tool and die steel, as cotex has not received any foreign exchange allocation from the Bank of Tanzania for the last three years. Mr.

Ramathal, the Director in charge of operations, is convinced that cotex could provide tool-room services for a 11 the companies in the MEIDA group wich do not have adequate facilities themselves. They are presently negotiating with ZZK to make tools for plough-parts.

Cotex was chosen by the Swedish expert who helped MEIDA identify the most suitable company for matchet production. This expert from the Swedish steel company

Sandvik (previously also a matchet manufacturer) has advised on the requried tools and additional equipment. The total cost to cotex (including MEIDA commission of $10 \%$ ) for matchet production is TShs 1.14 million. (Mr Ramathal claims that Cotex itself would have been able to make the tools at a much lower price than the one Sandvik charged for some items.) Cotex is certainly now in a position to duplicate the matchettools. 
The specification for the straight 16" matchets to be manufactured by Cotex is based on the matchets imported from PRC. Raw materials are going to be imported from Sweden. The steel is already heat-treated. 100 tons have been ordered of which 40 tons have been received.

Cotex estimates to be able to produce 4,800 matchets per day, or up to 1.5 million a year (two shift production). With a conservative assessment, recognizing a bottleneck in handle production, we would put the capacity at 750,000 pieces per year.

Cotex should be able to manufacture matchets according to the MEIDA programme. Given raw materials they have the capacity to fulfill most of the national demand. However, costs to the consumers are going to be very much higher than at present if the Cotex costing is correct and accepted by the National Price Commissioner. We believe that the costs should be reduced, e.g., by allowing duty-free importation of steel and by writing-off the tooling over a longer period. But also other cost items should be possible to reduce to make the Cotex matchet competitive with UFI's imported matchet. In foreign exchange terms, there is a saving which is not negligible. (At an annual production of 1 million matchets it may be some 4 million TShs), thus the tooling is paid for in only a couple of months.

\subsubsection{Manufacture of Post-Harvesting Equipment}

Post-harvesting equipment refers to mills and dehullers for various types of produce. The use of hand-powered equipment is not common in Tanzania, although some attemps to introduce them has been made by Oxfam. The common types of mills or hammers are powered by diesel engines or electric motors, and their capacities are sufficient to supply entire villages. The dieselpowered maize hammer-mills are commonly seen all over Tanzania.

This type of equipment is primarily distributed by AISCO. TFA has previously sold mills but has lately had difficulties in obtaining supplies. AISCO is the 
importer for the prime movers, i.e., the motor or engine, and sub-contracts the mill manufacture to any of the companies mentioned below. Such manufacture is largely financed by TRDB. For the last few years TRDB has had access to USAID funds to finance the importation of raw materials. SIDO has also played an important role in the distribution of maize mills to villages by utilizing funds in the Rural Hire Purchase Fund, which is financed by Sweden.

A short description of the most important manufacturers of post-harvesting equipment is given below. Other production units, such as Hans Paul Dharam Singh and Son in Arusha (see above) and Umoja Engineering Works, also in Arusha, make a small number of maize mills, as do many other engineering workshops. Mangula Machine Tools in Ifakara is also active but their reputation in terms of quality is rather bad.

Manik Engineering Ltd in Arusha manufactures 4 different sizes of maize mills. The company has a capacity of $60 \mathrm{mills}$ per month, but due to raw material shortages they only manufacture 4-5 mills per month at present. (Production in 1981 was approximately 400 units and in 1982 only 140 units.)

The company was established in 1975 and moved to a new factory in 1980. The present number of employees is about 20 .

The company appeared to have a good production line but the factory was stocked with a large number of unfinished products. These products are delivered to AISCO for addition of the prime movers, but AISCO has been slow in placing orders,

If the present stock was completed, a large number of mills could be supplied to the market. Manik Engineering undoubtedly has a large capacity.

United Engineering Ltd, was started in 1966, and the Director, M Manik, claims to be the first maize mill manufacturer in Tanzania. The capacity is said to be 
$100 \mathrm{mills}$ per month. United Engineering has a contract with TRDB to manufacture 1,000 maize mills. TRDB is supplying the raw materials (and the bearings). The company also manufactures dehullers and oil expellers.

They have plans to start manufacture of straight matchets. The annual turn-over is about TShs 30 million. The work-force is 30 people.

\subsection{Large Scale Production}

Large-scale production of farm implements is presently carried out at two plants: Ubungo Farm Implements (UFI) in Dar es Salaam and Zana za Kilimo (zzK) in Mbeya. Mangula Mechanical and Machine Tools Company (MMT) in Ifakara along the Tazara railway is not primarily a farm implements manufacturer but has production of post-harvesting equipment. A fourth factory is planned t o be started in Mwanza.

The National Development Corporation (NDC) is the holding company for all these companies, and is also responsible for the planning and establishment of the Mwanza factory. A number of policy issues is thus discussed and decided by NDC. Sector co-ordination rests, however, finally with the Ministry of Industries.

The installed capacity for manufacturing hoes and ploughs at UFI and ZZK is as follows:

\begin{tabular}{lrrr}
\hline & UFI & ZZK \\
\hline Hoes & $2.0 \mathrm{~m}$ & $0.75 \mathrm{~m}$ \\
Ploughs (complete manufacture) & 25000 & 15000 \\
\hline
\end{tabular}

\subsubsection{Ubungo Farm Implements Company (UFI)}

UFI, located in Dar es Salaam, was commissioned in 1970. It has been financed by an interest-free loan from the Peoples Republic of China. The factory is 
built around three hot-forging lines, and it also has a small foundry. The second and third forging lines were installed in $1979 / 80$. The main products manufactured at UFI are round-eyes hoes and ox ploughs. UFI has also produced grass slashers and baling hoops, but this production was recently discontinued. As UFI is the sole importer of hand farm implements and ploughs, it also has an important trading function.

UFI has been the subject of several studies; recent ones include Rehabilitation proposal - Farm Implements (Stehagen - Arefalk) from July 1982 (referred to below as the "Stehagen report") and Farming implements (Kiherile and Hurtig, NDC) from May - June 1983 (referred to below as the "Hurtig report").

The Stehagen report is oriented towards the solution of the production problems which had hampered (and to a large extent still hamper) UFI's production. At the time of the report (June 1982), production was about half of the rated capacity. General problems, such as poor planning, coordination and collaboration throughout the industry and within NDC/UFI were quoted as basic. The production equipment at UFI was considered rather worn, and bottlenecks identified were the heat treatment section, the lack of conveyors and the friction elements of the screw presses. Another weakness was the purchasing function. The report is very critical of the top management of UFI, and the team recommended that SIDA should make any support to UFI conditional upon a declaration of collaboration from the Board of UFI.

The team proposed that UFI should maintain its production programme and stick to hoes and ploughs. More components should be bought, e.g., cast parts. No heavy investments were considered necessary but a number of smaller items needed replacement, The heat treatment section, however, needed to be completely replaced,

The Stehagen report thus proposed to retain the technology and rehabilitate the existing equipment and put emphasis on the strengthening of the management of UFI, 
The Hurtig Report argues strongly for concentrated production of hoes and ploughs, and attempts to demonstrate how UFI can fulfil total national demand for these implements. A number of suggestions were put forward to reduce UFI's production costs, including better energy usage by replacing the heat treatment section and reducing the work force. The report suggests replacement of the present Duplex-rolling machines identified as a main bottleneck, and installation of 3 edge-grinding machines and 17 conveyors. According to Hurtig this would result in a rated capacity at UFI of 3.5 million hoes annually. The cost estimate for this is TShs 26 million. A new heat treatment section was proposed. The report appears to be arguing against personnel support to UFI. The mentioned investment programme is aimed at increasing production according to present technology. However, UFI should also start planning for a change of technology, adopting rivetted hoes and not forged hoes as the main product at UFI.

These two reports are still basic to the analysis of the problems at UFI and their conclusions are used in a NDC board paper from November 1983 on the rehabilitation of UFI. A delegation from NDC visited Sweden in April and May 1983 to discuss with possible collaboration partners and clarify the requirements, but as yet no final conclusions have been arrived at. There has been some argument as to whether UFI should broaden its product range to include tanged hoes, matchets, spades and axes.

In the above-mentioned NDC board paper, the latest position of UFI is well summarized. UFI's capacity is stated as 2.0 million hoes and 25,000 ox-ploughs per year with $2-$ shift production, The producton achieved over the last years is as follows:

\section{0}

1981

1982

\begin{tabular}{lrrr}
\hline Hoes & 950,000 & $1,220,000$ & 890,000 \\
Ploughs & 11,583 & 4,845 & 11,057 \\
\hline
\end{tabular}


Production problems include some malfunctioning machines, particularly the Duplex machines, which in addition are extremely cumbersome to maintain and thus cause production losses, and lack of spare parts.

Material handling and quality control devices are inadequate. The latter has resulted in the poor performance in the heat treatment shop. The Duplex machines and the heat treatment unit have unnecessarily high running costs. NDC thus considers new heat treatment equipment absolutely necessary, and further believes that a conveyor system for handling of the blanks is required. Replacement of the Duplex machines along with Hurtig's proposal is also suggested. However, the NDC representative that we discussed with did not agree with the suggestion that UFI should adopt a different technology yet for a long time to come. Even if the machines are out-dated they are functional, and NDC/UFI cannot afford to write-off the investment. A change in technology must consequently be deferred.

The following should be noted about UFI's production machinery. It was imported from PRC and installed by Chinese technicians. A 2nd and 3 rd production line were added in 1979/80, but have never functioned properly. The agreement with the Chinese established performance rates and the product range but this has not been possible to achieve, not even with Chinese supervision. Some of the agreed products, e.g., matchets and axes, have never been produced. A delegation from RC visited UFI at the time of our visit, to try to rectify the machines. On our repeated questions at both the Ministry, UFI and NDC it was clearly stated that there were no plans to ask the Chinese to send any technical staff to assist in the production at UFI.

The Stehagen report also identified top management as a weakness at UFI. Several management changes have since taken place. In September 1983 a new General Manager for UFI, Mr B J Chambaka, took over. Mr Chambaka had previously been General Manager at Steel Rolling Mills in Tanga. The new General Manager has made a good effort in stepping up production, and the figures given to us show an impressing improvement. ( I t is noteworthy that UFI did not suffer its low capacity utilization as 
a result of lack of raw material, as most other companies in Tanzania, but from production bottlenecks.)

UFI sales of hoes (imported and manufactured) totalled 1.9 million for the period Jan. 1 - Nov. 8, 1983. For the period up to Sept. 30, sales were only 1.0 million, thus there was an increase in 2 months of 0.9 million. (It should be noted though, that this is the peak season.) UFI imports for 1983 are planned at 728,000 but we do not know if this whole amount has yet arrived. The Hurtig report states that production up to June 1983 was only 0.3 million hoes. Production for the last quarter of 1983 was 757,600 hoes, 23,800 plough beams, 17,000 bottom assemblies and 21,000 handles. Ploughs were most certainly partly made from semifinished stock. M Chambaka has introduced 3-shift operations to make up for the machines that are idle because of the Chines fault-finding programme. Achievement of the production target for 1983, 1.3 million hoes is thus almost secured. The target for 1984, which is set at 1.66 million hoes, will easily be achieved at this rate of production. It should be added, that $\mathbf{M}$ Chambaka in spite of his success in improving production, fully supports the NDC request for replacement investments.

Sales of ploughs up to Nov. 8, 1983 were 22,423.

(Stocks at the same date were 4,000.) The production target for 1984 is 20,000 ploughs. Plough spare parts to rehabilitate 40,000 ploughs, and bottom assemblies to other manufacturers will be manufactured in addition.

We were subsequently informed that the total production figures for 1983 were 1.45 million hoes and 23,252 complete ploughs.

UFI has a rather large stock of pick-axes and garden tools, which were purchased on the basis of demand overestimations. There is also a large stock of pick-axes with the various RTCs, and these have created a lot of tension between UFI and the RTCs. (As noted elsewhere in this report, many RTCs claim that they were sent 
these pick-axes without having ordered them, and are therefore refusing to pay for them.)

The pick-axe problem stems from that other activity of UFI's, viz trading. We are discussing this role in Chapter 6, Distribution. There has been strong criticis m of UFI that previous management overemphasized importation. It tended to hide the fact that manufacturing operations were running at a loss because of too low efficiency. To rectify this, NDC imposed on UFI the obligation to keep imports in a separate account. It should also be noted that UFI has decided itself what number of implements to manufacture and import respectively, on the basis of order forecasts from RTCs but with little or no coordination with the Ministry of Agriculture.

The shortfall in meeting demand will continue to be imported by UFI also in 1984. Apart from the traditional sources (India, PRC and UK), imports willalso be made from Zimbabwe and Zambia. The previous manager at UFI has ordered 30,000 welded hoes and 15,000 ploughs from Zambia. Our inspection showed that the quality of the Zambian products is very low and anyway the Zambian manufacturers will not be able to deliver the ploughs until the end of 1984. UFI has stopped sending the Zambian hoes to the RTCs because of their inferior quality. On the other hand, samples from Zimbabwe indicate that their quality is good.

The presently manufactured ox plough is based on an Indian design and components are imported from the company Cossul. This plough is the most popular in Tanzania (given the lack of alternatives) but it has some weaknesses (refer to Chapter 1.3.1) We discuss how to introduce more modern plough types into Tanzania in Chapter 2. However, we strongly recommend that UFI should try to improve on the present design to increase the durability and life time of the plough. One important area of improvement is the nuts and bolts. These are of no less than 9 different sizes, and thus a reduction of this number would be of advantage to both UFI when procuring stocks and to the farmer when he needs a replacement. Secondly, the nuts and bolts 
should be fitted with some locking device, which would prevent them from loosening and thus avoiding the commonly seen disintegration of the ploughs. At ploughing turns or during homestead-to-field transports the plough is often dragged on the ground skidding on the handle, which leads to heavy wear. A simple skidding device should be fitted onto the right handle.

A more profound design change, which is crucial, is to improve the steel beam, so that it can allow the use of other implements than the plough.

The team's conclusions from reviewing the reports on UFI and from our discussions in Dar es Salaam are the following.

There are no valid reasons for discontinuing production a t UFI. The cost comparisons indicate that hoe production locally can compete with importation and is a foreign exchange saving activity. In our opinion it would be premature to change technology until further experience has been gained from production and marketing of welded or rivetted hoes. We strongly suggest that UFI should concentrate on hoe and plough production, including spare parts for ploughs. (The next product to be considered should be axes, which is also a forged product, provided the cost efficiency is competitive to imports.) We believe that UFI, with a capacity of 2.0 million hoes and 25,000 ploughs, will be able to satisfy $65 \%$ of the hoe demand and at least $40 \%$ of the plough demand in Tanzania. Design modifications to the steel beam of the UFI plough are desirable.

Higher efficiency and a better utilization rate may allow UFI to trim its product prices, which we find unnecessarily high. To be able to fulfill its important role in the Tanzanian economy, UFI must be given support in the forms of funds for raw material importation, for replacement of some machines, for spare parts and for certain management reinforcements. We believe this is an area where donors can provide assistance. 
We feel strongly convinced that UFI should be relieved of its role as a trading company. Only for those items where UFI is the main manufacturer ( $r / e$ hoes, ploughs and possibly axes) should UFI maintain its role as importer.

On the other hand, UFI should continue to have the responsibility for selling to the regions in order to have a connection with the market. We see no need to introduce yet another middle-man (such as AISCO) in the present distribution chain. This also means that we consider the present arrangement concerning credits to RTCs as proper, although the credit volume has to be reduced.

We suggest an administrative coordination between UFI and $Z Z K$, and a strengthening of the two companies' production management through a management agreement with a suitable operating company.

\subsubsection{Zana Z a Kilimo Ltd, Mbeya (ZZK)}

The construction of this plant started in 1977 but commissioning was severely delayed. Trial production started in April 1982, and commercial production in September 1982. However, the equipment is still not complete due to lack of funds. The plant was originally financed with Indian government credits. SIDA has recently agreed to finance some of the missing tools and equipment.

The total investment in the plant up to October 1983 was TShs 85.5 million, including civil works. The machinery cost 36.5 million. A further investment of TShs 24.5 million is considered necessary before the plant is complete. The project finance has been provided through an Indian Government credit of approximately TShs 24.5 million, loans from TIB and TDFL of totally TShs 34.2 million and equity capital from NDC (financed by a grant from the Netherlands). Working capital is provided by NBC. The Dutch government has also financed a consignment of raw materials.

The plant was designed with the assistance of an Indian consulting firm but this company obviously lacked ade- 
quate experience. At present there is a team of Indian technical assistance personnel from a manufacturing company assisting in the management of ZZK. The team consists of 2 people. Three more Indians are training Tanzanian personnel in hand-forging techniques.

The plant was designed to produce:

Hoes

Matchets

Axes

Pick-axes

Shovels

Hand sprayers

Ox ploughs

Plough spares

Tractor drawn disc harrows,

disc ploughs and cultivators

$$
\begin{array}{rl}
750,000 & \text { annual1y } \\
900,000 " & " \\
250,000 " & " \\
20,000 & " \\
50,000 & " \\
20,000 & " \\
15,000 "
\end{array}
$$

$$
2,500
$$

Present production includes hoes, ox ploughs, some shovels and some hand-forged pick-axes. Production figures are as follows:

January 4 - September 30, 1983

Production at $\mathrm{ZZK}$

$\mathrm{r} / \mathrm{e}$ hoes

117,334

ploughs

1,064

shovels

2, 084

pick-axes 305

This represents less than $10 \%$ of the capacity of the plant,

For the 6-month period January to June 1984, ZZK is planning the following production:

$\%$ of rated capacity

\begin{tabular}{lrr}
\hline r/e hoes & 150,000 & 47 \\
Rungwe (tanged) hoes & 25,000 & \\
Mould board ploughs & 9,000 & 180 \\
Pick-axes & 12,000 & 120 \\
Shovels & 30,000 & 720 \\
Wheel-barrows & 1,800 & $2 \overline{4}$ \\
Hand axes & 30,000 & \\
\hline
\end{tabular}


Wheel-barrow production started already in 1983. Among the products originally planned for ZZK, matchets and sickles are not included in the programme, nor hand sprayers or tractor-drawn implements. During 1984, ZZK hopes that the production of hoes can reach 2,500 a day ( $2-$ shift operation), which is about double the present production. This corresponds to an annual production of 625,000. Another planned development is to start forging of plough shares, mould-boards and frogs. However, ZZK will have to purchase dies, as ZZK does not yet have enough skilled personnel in its machine shop. ZZK has asked UFI and cotex for quotes but these have been considered too high. Some other dies have been made by the SIDO Common Facility Workshop in Mbeya.

NDC and ZZK are still trying to identify a suitable collaboration partner for tractor implement manufacture.

Materials to cover hoe production for approximately 8 months are available (the remainder of a Dutch grant). For plough production there are no components in stock but materials may be made available from TRDB (USAID funds).

ZZK is presently selling hoes to RTCs. In the future ZZK hopes to sell also to TFA. A submission was made to the National Price Commissioner in October 1983 to get approval on proposed prices for sales from ZZK.

The equipment and machinery at ZZK is generally considered to be very good, although it is unbalanced and provided with too few tools. M T. Liljevik is of the opinion that the plant is over-equipped and suggests that certain machines should be disposed of. There are a few machines that he considers necessary to procure.

SIDA has recently agreed to finance TShs 7.0 million worth of the most needed items of spare parts, tools, die steel and raw materials. A further TShs 6 million appears to be available under an Indian state credit for spare parts and plough component purchases in India. 
NDC has prepared a proposal for "de-bottlenecking" investments as follows:

Tools and dies

Raw materials for spares

Balancing equipment

Spares

Accessories

Training

TOTAL

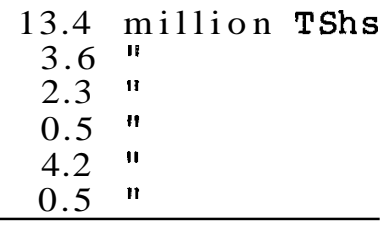

24.5 million TShs

It appears that this proposal does not take account of the above-mentioned SIDA grant, and the requirements ought thus be reduced by TShs 5.9 million, without taking into account the Indian credit, which, if taken up, will possibly go to the purchasing of plough components.

As far as the present production is concerned, ZZK is manufacturing a round-eyed hoe which is not easily sold in the Southern Highlands, where the Rungwe or Ufipa hoes (both tanged) are in demand. Most of the ZZK production has therefore been sold to Morogoro RTC.

However, the SIDA funds will be used to purchase tooling for Rungwe and Ufipa hoes.

The original plough was based on an Indian design, which did not sell at all. ZZK then changed to the wooden beam plough design. However, ZZK claims that they have been unable to sell the wooden beam plough, as the RTCs refuse to buy it, and ZZK has decided to replace the wooden beam with a similarly shaped (hollow box) steel beam which is now in production. The bottom assembly is bought from UFI. 750 stee 1 beam ploughs have been sold to Mbozi district, at a price of TShs 1,600 .

The team's observations as a result of the factory visit were that production was badly organised and a an unacceptably low level. The hoes showed signs of the tool being very badly worn. The operations in the plough assembly hall appeared to be without logic. Pick-axe hand-forging can hardly be regarded as suitable for large-scale factory production. 
NDC has recognised the man-power constraints at ZZK, and has suggested an intensified training programme. However, we must conclude that a new management is of fundamental importance to rectify the situation at zzK, and we do not believe that the present team has this capability.

In the present organisation there are 5 departments under the General Manager. The present General Manager M Mbena, is still called Project Manager as NDC is still regarding ZZK a s a development project and not a commercial enterprise. Three of the departments lack a manager. The technical department is headed by one of the Indian engineers. There are 4 sections under him, two of which lack incumbents. The technical manager is supported by two production engineers, one of whom is an Indian, and one maintenance engineer.

A couple of engineers are undergoing training overseas. The total workforce is 60 people, of which 21 have been for training in India for 3 to 6 months.

The Indian personnel is provided in connection with the previously mentioned technical assistance agreement. However, the personnel is employed by ZZK and has executive functions. The Indian company provides process drawings and back-up services. The agreement runs for five years but is subject to annual reviews and entitles the Indian company to certain remunerations plus a royalty based on production volume. The agreement is financed under an Indian state credit.

Our conclusion is that the Indian company is not providing the services that are necessary to put ZZK into proper operating shape. Clearly there are not enough Tanzanian managers, and the Indians are too few to manage the plant on their own. We therefore strongly recommend:

a) to transfer one or two more production technicians t o ZZK;

b) to replace the Indian team of technical personnel. We are convinced, though, that ZZK needs management support from a company with solid experience of forging operations. 
Our conclusions with respect to the present and planned production at ZZK are the following:

a) a 11 activities should be concentrated on achieving proper hoe production and a smooth production flow. An annual production surpassing the rated capacity of 0.75 million hoes per year should be possible to achieve from 1985 ;

b) hand-forging of pick-axes should be discontinued. These items are in low demand and there is a large unsold stock in the country. We do not think it is justified to retain this operation for training purposes only;

C) shovel production should only be continued after proper assessment of the market and of the production at other manufacturing units in Dar es Salaam and Arusha. Local demand may not justify mass production at ZZK;

d) the idle work-force, unless it can be discharged, should be employed in wheel-barrow production, but a proper production line must then be set up;

e) manufacture of the present type of plough (wooden design of a steel beam) should be reviewed. Plans should be made together with UFI to start parts manufacture for the UFI type of plough until either ZZK is properly organised for manufacture of complete UFI-type or other marketable types of ploughs for the southern regions, or a possible new plough design has been properly evaluated;

f) any plans for manufacturing tractor-drawn implements should be shelved until proper production of hand tools and ox equipment is organised.

We finally believe that the cost estimate submitted to the National Price Commissioner should be thoroughly and critically evaluated. It does not seem likely that such a wide difference in the direct material costs between UFI and ZZK is correct.

\subsubsection{Mwanza Farm Implements Factory}

Planning for the third large-scale farm implements factory, which is going to be located to Mwanza, is continuing. This plant will be established with Bulgarian assistance. Its concentration will be on tractordrawn implements and irrigation equipment, but production of hoes, matchets, axes and ox ploughs is also 
planned. Construction of this plant is at present projected to start in 1985 and be finalized in 1986, with commercial production commencing in 1988.

The Bulgarian supplier has not yet submitted an offer but the Bulgarian government has agreed to finance $85 \%$ of the delivery. The remainder will be paid through barter arrangements. The total cost of the equipment is estimated by TISCO, who has recently submitted a draft feasibility study for the plant to NDC, at around TShs 220 million. For further details regarding this planned project we refer to the TISCO study.

For the purposes of this study, we consider that as far as hand tool supply is concerned, the new plant is not necessary. Ox plough production will start too late to have an impact in the period of concern to us and demand can be met from other sources.

\subsubsection{Mangula Mechanical and Machine Tools Company (MMT)}

This company was built as a maintenance workshop for the Chinese-built Tanzania Zambia Railway. It has a very large production capacity, which is not utilized for the railway, and has therefore taken up series production of, among other things, various items of postharvesting equipment, such as maize mills, rice hullers and coffee pulpers, but also wheel-barrows. The quality of the MMT products is regarded as rather poor. MMT's importance is primarily as a repair workshop. The operations are carried out with the assistance of a team of 46 Chinese technicians.

We did not include MMT in our field trips. 


\section{CHAPTER SIX}

DISTRIBUTION OF FARM IMPLEMENTS I N TANZANIA

\subsection{The Distribution System}

Until recently the supply of farm implements (hand tools and ox-drawn equipment) has originated from two main sources: Imports and production at the Ubungu Farm Implements Factory (UFI). In addition some production and repair of implements is done by local blacksmiths and in workshops or small industries. Since 1972, UFI has also been the sole importer of farm implements, giving it a monopoly position in national supply. Until 1980 the distribution channels for farm implements were rather loosely defined providing opportunities for private, cooperative as well as government units to participate.

The increasing balance of payment problem has had a marked impact on the quantity and the structure of national imports. Farm implements were affected directly through cuts in imports of finished implements and indirectly through reductions in imports of raw materials, spare parts and fuel for production. UFI representatives claim that 1979 was the last year in which farm implements were amply supplied to the national market. 1

The increasing shortages of basic commoditions led to the introduction of confinement policies based on the Regulation of Trade Act (1980). The confinement included 31 lines of commodities, including some farm implements. The objective was to secure an equitable

1 A comparison of costs of importation to costs of production in Tanzania is given in Appendix 3. 
national distribution in a period of mounting supply problems. The policy also gave instructions on the use of distribution channels. However, the confinement directives were only partially adhered to. This led the National Executive Committee (NEC) of the Party, CCM, to appoint a task force to investigate the causes for the uneven and declining supply of farm implements. Its findings were that UFI, contrary to directives, chanelled substantial amounts of implements though both private and its own outlets. Hence the confinement was reinforced for the 1983/84 season. In April 1983, UFI was specifically instructed to route all implements through RTCs. RTCs were told to distribute solely through their own outlets or through cooperative or village shops. Farm implements were further to be denoted as specified items which means that they were not to be found in private shops. The confinement was expanded to include most implements imported or produced by UFI.

The types and quantities of farm implements to be distributed by UFI to various regions are determined by the National Allocation Committee (NAC). NAC makes decisions on allocations on the basis of requirements for each region as reported by regional authorities. The procedure is as follows. The Regional Agricultural Officers (RADO) compile the regional requirements on the basis of village data. They then consult with relevant regional authorities and the regional RTCs in the regional development committee. RTCs forward the regional figures to the Board of Internal Trade (BIT), the parent organization of RTC, which acts as secretary to the National Allocation Committee. BIT in addition collects information about likely supply, imports and production. Based on this, BIT makes a proposal for regional allocations, which is forwarded to the NAC for the final decision. The proposed allocations are regional percentages of total supply to the various regions. These percentages were worked out when confinement policies were introduced and they are adjusted annually if necessary. The NAC is not bound by the BIT proposal, but may make amendments. 
Once the NAC has reached its final decision on allocations, the results are conveyed to BIT, regional RTCs and UFI. The actual dispatches from UFI are supposed to correspond to orders from regional RTCs on the allocated amounts. Once the allocations reach the regions, the responsibility of BIT as overseer of the distribution process ceases. The regional distribution of implements follows from decisions of allocation committees at regional, district, and divisional levels.

\subsection{Distortions in the RTC Distribution System}

In our investigation of this distribution system based on confinement and allocations, various distortions were identified. The major ones are:

Inflated regional requirements: This is a response to the fact that farm implements have become increasingly scarce and that allocations are made on the basis of reported requirements. An inflated requirement is thus hoped to give some assurance for a favourable allocation.

In order to assess the validity of this claim, let us look at how requirements are built up and whether possible control or adjustment mechanisms exist. The process of data compilaton starts at the village level, Village secretaries fill in forms about the type and quantities of various implements required. It has been difficult to verify whether there is a standard method for collection of data on village level. The quality of the data will depend upon the ability of the collectors, their attitudes and relations to peasants. It is, however, likely that village officials try to secure the best possible supply of implements for their respective villages. Hence there is a tendency for inflated village requirement figures. In our opinion the major causes for inflation of requirements are found at this level.

The RADOs compile the district requirements submitted by the DADOs (District Agricultural Officer). There are 
several indications that requirements at least for some types of implements are scaled down at the regional level. This is seen mainly to be done by the RADOs in consultation with the RTC regional manager. The RADOs, given their central mediating role in the regions, are seen to be more inclined to provide correct rather than inflated figures. The RTC managers' perspective on requirements is more based on the expected likely effective demand rather than on perceived needs. BIT also scrutinizes regional requirements. If the figures are thought to be unreasonably low or high in relation to population and agricultural practices, etc., BIT may amend them or notify NAC about the suspicion. In spite of some scaling down of village requirements on regional or possibly national level, they are, in our opinion, frequently inflated. The degree may vary between regions and it is impossible to make a wellfounded estimate on the national scale of inflation of figures.

\section{Amendments made by the National Allocation Committe}

(NAC): In our interviews we are informed about two possible types of NAC amendments of regional requirements. The first, more corrective than distortive, happens when the gap between reported requirement and the BIT proposed allocation is excessive. NAC will then raise the final allocation to a perceived reasonable level. A second type, more distortive in character, is motivated by economic or political reasons. For instance, the NAC may give preference in allocations to export crop growing regions due to the balance of payment situation, and low priority to non-export crop growing areas. Amendments may also stem from the view that some regions have more political weight than others. For the $1983 / 84$ season in particular Mwanza region seems to have been given favourable allocations which may be based on both export crop orientation and political importance. In addition Arusha, Kilimanjaro, Iring, Mbeya, Rukwa, Ruvuma and Mara regions are seen to be favoured.

UFI deliveries do not correspond to RTC orders: Lack of correspondence between RTC orders and UFI deliveries and leakages of implements to private traders led the 
NBC to appoint a probe committee into UFI activities. Its findings led-in April 1983 to the sacking of the general manager and the marketing manager of UFI and reinforced confinement. However, even in the months to come large discrepancies occured between UFI deliveries and RTC orders. (For those cases where RTC orders were not submitted, discrepancies occured between deliveries and allocations.) In August 1983 the Ministry of Industries found it necessary to repeat the instructions to UFI to dispatch according to orders or allocations. In September a new General Manager was appointed. Hence, it is likely that the distribution system has operated according to expectations only for a few months. This makes evaluation of the system as such rather difficult. Maybe the focus should be put on explaning why its implementation was so severely obstructed.

Untimely deliveries from UFI: There are many examples of late deliveries from UFI, i.e., implements do not arrive in time at regional RTCs to be distributed to village shops. The demand for implements increases rapidly at the beginning of the agricultural season, being very low in the off-season. This seasonal demand pattern requires that implements are dispatched from UFI during the off-season in order for timely arrival at retail outlets. There are several reasons for the numerous delays registered and they operate at different levels. Delays, may result from production problems or patterns of UFI, from delays in the reporting and allocation system and from transport problems.

Credit and financial problems: The seasonal demand pattern for farm implements requires build-up of stocks in RTCs in the off-season. As RTCs are short of funds in this period, RTCs require credit from UFI in order to assure a timely flow of implements to the regions. This has caused serious problems for UFI due to continuous accumulation of RTC debts.

The credit problem is also linked to intra-regional deliveries. The re-inforced confinement made RTC sell only through its own outlets or village shops. However, due to poor payment performance of village shops, RTCs 
have refused to sell on credit. Village shops now have to pay cash on delivery. Allocated stocks may thus pile up in RTCs on district or regional levels and hence not reach the consumers. The establishment of divisional cooperative shops (Muungano shops) in some regions may ease this problem because RTCs have shown willingness to extend credit and train their personnel.

Lack of customer orientation of RTCS: The confinement policies made RTCs' role in national distribution even more paramount. It implied expansion of rules and regulations which made management tasks more cumbersome. Claims that RTCs lack customer orientation are seen to be based partly on an increasing workload unmatched by improvements on the personnel side. However, several observations indicate that RTCs could operate more efficiently and with more customer orientation than at present even at the existing level of resource availability. The tremendous range of commodities handled by RTCs undoubtdely gives limited possibility to pay proper attention to procurement and marketing of all lines of products. The goods are not displayed at RTC shops, they lie in stock in central godowns, some of them incomplete and rusting.

\subsection{Stock Position in October 1983}

One way of assessing the system for regional distribution of farm implements is to look at the level of stocks in regional RTC central godowns. An efficient distribution system would imply low stocks of implements at this level due to the immediate onset of the agricultural season. Implements should hence be available at retail outlets at district, division and village levels. The stock position in regional RTC central godowns for 5 regions visited was the following in October 1983: 
Table 6.1 RTC Stock Position, Central Regional Godowns, October 1983 (units)

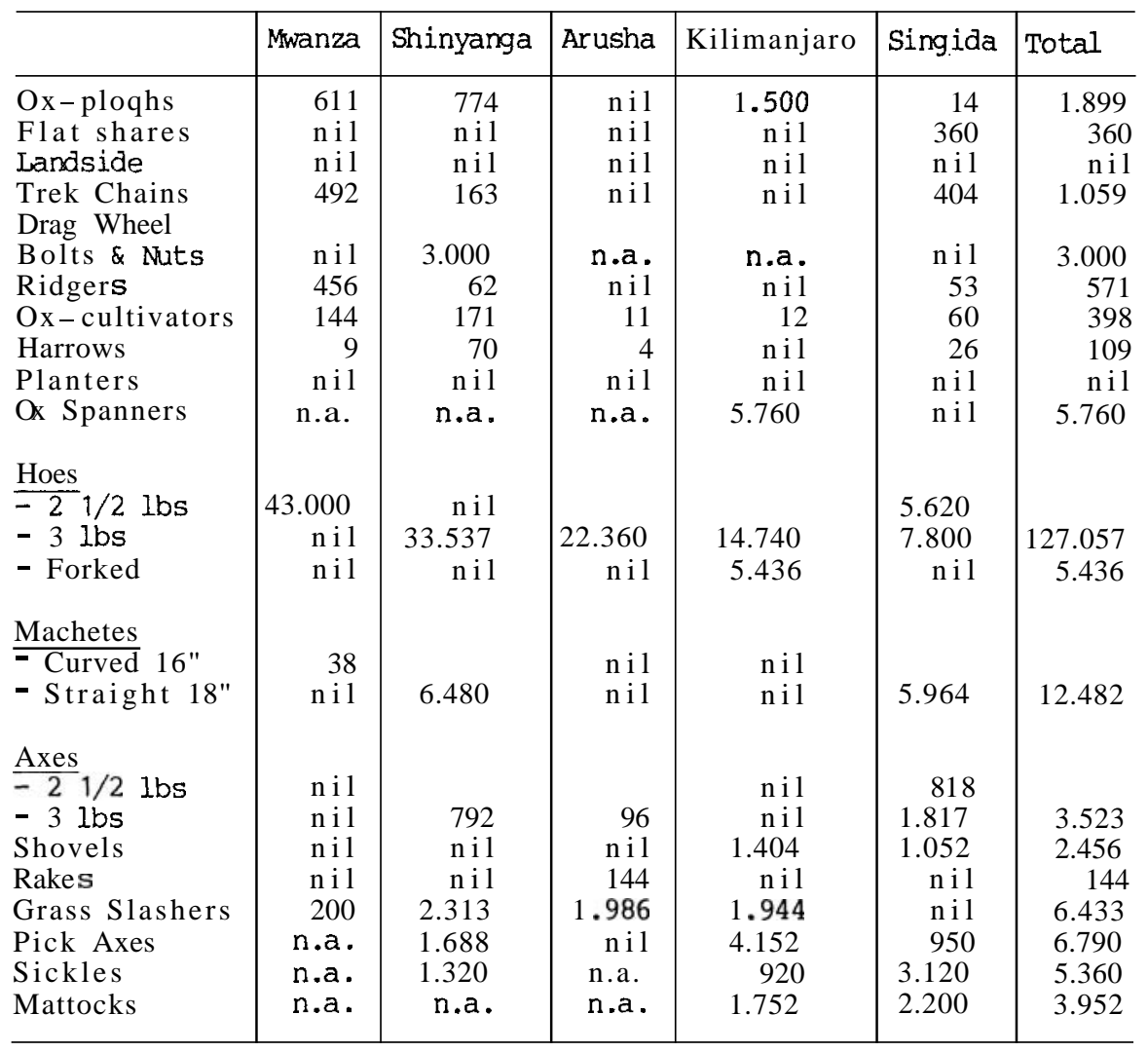

Sources: Visits to regional RTC, Oct. 1983

Note: $\quad$ n.a. $=$ no account

In a few regions we also physically inspected regional RTC stocks. In our opinion there seemed to be fairly good correspondence between reported figures and actual stocks.

Regarding animal-drawn equipment RTC stocks are generally at a low level, however the figures indicate a few misallocations. The stock of ploughs in four of the regions is very low compared to total allocations. Kilimanjaro is an exception as the stock is about three times the allocation. Evidently Kilimanjaro is unable to distribute its allocation, which implies that it is 
too high. Flat shares, trek chains and landsides are in high demand among ox-cultivators. The low stocks

reflect both extremely low supplies from UFI as well as efficient distribution by RTCs of whatever is received. Drag wheels, also in high demand, are not in stock except for Shinyanga. The large stock here is a recent arrival which has not yet been distributed. The general stock position regarding drag wheels clearly shows a low supply situation. For ridgers, cultivators and harrows the stocks are more evenly distributed, but at a relatively low level. RTCs have informed us that these items are slow-moving and they are mainly kept at central regional godowns. RTCs emphasise that many of these items are delivered by UFI without allocation or order. For RTCs they tie up capital and some of them have taken initiatives to return them to UFI or other regions where demand may exist. Agricultural extension people in the field indicate, however, that there would be a limited market for theseitemsif RTCs distributed them to district and divisional levels. For ox planters there are no stocks, hardly any demand and no supplies. Ox spanners are only in stock in Kilimanjaro. The quantity indicates an additional misallocation to this region.

A 11 regions have some stocks of hoes, but information obtained shows that this is mainly due to recent arrivals except for Mwanza's stock of $21 / 2$ lb hoes. As soon as transport is available distribution to district, division and village shops (if funds are available) will occur. The stocks are not seen to reflect inefficiences on the part of RTCs. Forked hoes are mainly utilized in Kilimanjaro, which explains the stock position in other regions.

There are very uneven stocks of matchets; none in three regions and about 6000 in Shinyanga and Singida. In Singida a misallocation is likely to have occured as people in this region prefer to use the long-handled bill-hook (hengo), locally made by blacksmiths. The stocks of axes are low for a 11 regions except Singida. Here the hengo may also supplement the axe in tree cutting. For grass slashers, pickaxes, sickles and 
mattocks stocks are uneven but relatively high. Our information indicates that most of these items are wrongly allocated. They are slow-moving and hence tie up capital for RTCs.

Altogether the October 1983 stock position indicates that RTCs are distributing implements received fairly efficiently. The stocks of fast-moving items like ploughs and hoes are relatively low and most items are in the process of being distributed. For some animaldrawn equipment the RTCs could have done a better job of promotion. The slow movement of ridgers, cultivators and harrows may be conditioned either by inappropriate designs (cultivators and harrows), high prices (harrows) or incomplete deliveries (all three types). Some of the hand tools are wrongly allocated and RTC cannot be blamed for relatively high stocks of these items. Thus it is our conclusion that RTCs do not represent at present a major bottleneck in the distribution system. However, an effective constraint on distribution from RTCs out to the rural areas is the very poor managerial and financial position of village and Muungano shops.

\subsection{The Tanganyika Farmer's Association (TFA)}

The only farm implements distribution system of some importance in addition to RTCs is the Tanganyika Farmers' Association (TFA).1 TFA was established as a

1) AISCO, another company under the BIT umbrella, also has a role in supply to the agricultural sector. The company, which presently has only three outlets, in Irinya, Mwanza and Tanga, has mainly been dealing with supply of fertilizers, chemicals, tractors, tractor-drawn equipment, and post-harvesting equipment. In regions without AISCO branches, RTC operates AISCO's activities, For the season 1983/84 AISCO has, however, also started to sell hand tools and ox equipment. AISCO mainly buys at sub-wholesale price from RTC and sells at fixed retail price.

AESCO is a t liberty to buy from any source, including producers $1 \mathrm{ike}$ UFI and $2 \mathrm{ZR}$. AISCO's distribution of hand tools and ox equipment is quite limited and mainly an appendage to the RTC system in a few regions, 
separate entity in 1955 when branching off from the Kenya Farmers' Association. TFA is a shareholder cooperative based on its members, today about 3000, but their number is increasing fast. Prior to 1980 membership was limited fo farmers possessing farms of more than 50 acres. Since then this has been reduced to 5 acres. Each member is obliged to buy $10 \mathrm{shares,} \mathrm{each}$ costing TShs 5. This gives no room for influencing the organization through share holding. Membership is also open to villages, but only a few have yet become members.

Today, TFA is organized in a northern and southern zone. The headquarters is located in Arusha and northern branches include Moshi and depots in Karatu and Oldeani. The southern zone has outlets in Iringa, Mbeya, Njombe, Tukuyu and Mafinga (opened late 1983). In Dodoma a branch will be established during 1984 following a Presidential directive.

TFA units function as retail outlets open to anybody. However, when commodities are in short supply, members are given priority. At the end of each financial year, the profit is distributed to members according to purchases ( $10 \%$ of purchases up to 1981, since then $15 \%$ ). Members are allowed to purchase on 30 days credit while non-members must pay cash. Previously TFA also awarded a substantial amount of long-term credits to its members. This loan fund has, however, diminished considerably due to financial pressures.

TFA handles a wide range of agricultural inputs and implements, like chemicals (obtained both from national producers and imports), farm implements (hoes and ploughs from UFI and ZZK, ploughs, shares and ox-cart wheel sets from Themi, shares from MAFOTCO, trek chains, etc.) and various commodities fom SIDO estates, NMC (animal feed) and BEHESCO (wire). Considerable amounts of the commodities handled were previously imported directly by TFA. For instance, spares for tractors were supplied through such arrangements.

During recent years, however, a 11 TFA applications for import licenses have been turned down. The last import 
credit line enjoyed was a loan valued TShs 2.8 million from IBRD for imports of chemicals and spares in 1980.

TFA states that the deterioration in supply of farm implements began to be seriously felt already in 1981. During 1983 TFA experienced further problems of procurement from national producers due to the confinement policy. TFA was affected because it was considered a private unit. By August 1983, TFA had made advance payments worth TShs 5.7 million to several parastatals (UFI, NMC and BEHESCO) but goods were only slowly or partially supplied. From UFI no goods were received throughout 1983. A government directive issued in late 1983 exempts, however, TFA from the confinement regulations of UFI products, which may improve the supply situation in 1984 .

Total turn-over for TFA is abut TShs 120 million annually. The main bulk of sales is related to various agricultural inputs, chemicals and pesticides. The value of sales of farm implements totalled TShs 8.4 million in $1981 / 82$ and was expected to be at the same level for 1982/83 in spite of the mounting supply problems. Volume reductions are, however, compensated for by retail price increases which are generously awarded by the NationalPrice Commission. TFA is efficiently run and consequently still enjoys relatively large profits, which are partly passed on to the members.

In our opinion TFA plays a useful role both as a complement and competitor to the RTC distribution system. It is of vital importance to encourage at least a limited number of distribution channels in order to increase efficiency and accordingly the availability of commodities at reasonable prices to the farmers.

\subsection{Credit and Prices}

Credits for hand tools and ox-equipment are hardly available to farmers in Tanzania except for Iringa and to a lesser extent Arusha region. In Iringa, EEC has channelled credit through TRDB to villages for ox- 
equipment, ploughs, ridgers, cultivators and harrows. Credit for ox-carts has been approved but is not yet distributed. In the period June 1982 to November 1983, loans of about TShs 1.4 million had been given to 45 villages in the region (excluding credit for oxcarts). No down-payment was required and repayment was to take three years a $8.5 \%$ interest and a three-months period of grace. The credit scheme has led to the distribution of 1008 ploughs, 148 ridgers, 197 cultivators and 87 harrows in the above-mentioned period. Credits schemes have also existed for seasonal inputs administered by TRDB. TRDB/USAID has also established a credit line to villages for the purchases of maize mills in a number of regions.

In Iringa region the repayment rates for the ox-equipment loans are satisfactory and much better than for those related to loans for seasonal input. By April 1983 the loan-receiving villages of Njombe district were even well ahead of the repayment schedule while those in Mufindi and Iringa district had reached about $40 \%$. By the end of the loan period (December 1983) TRDB expected the rate to increase to about $75 \%$ for the latter two districts. The experience from Iringa may indicate that provision of credit for purchase of oxequipment will yield satisfactory rates of repayment.

However, as stated by the well-informed Regional Oxenization Officer: "It is very easy for the farmers to accept implements on credit". Very few cultivators and virtually no harrows have been sold by the Oxenization project on cash terms, even though the cultivators were cheap. There is a danger that credit extension of full packages of ox-equipment - some of which is of poor design, inappropriate, of limited utility or unable to ensure economic returns on the real investment made may force the farmers into long-term indebtedness. This has been the result of similar schemes in a number of West African countries, notably the Gambia and Upper Volta.

The prices of farm implements, ex-factory, sub-wholesale and retail, are fixed by the National Price Commission. In 1983 the retail price increases for 
common farm implements were, on average, higher than the official rate of inflation of about $30 \%$, but for ridgers, cultivators and harrows the price increase was $200 \%$. Such a price policy tends to jeopardize the government objective of increasing the availability of farm implements in rural areas. These price increases for common farm implements may stem from higher production costs and from upward movements in import prices. The National Price Commission is and has been generous to producers by fixing sales prices so that the least efficient production unit is able to cover total production cost. Through such price setting, inefficiencies in management and production and the concomittant cost increases are passed on to the consumers, the farmers. There is accordingly a need to revise policies in order to improve consistency. Regarding import of improved ox-drawn implements, we do not believe that the increases in retail prices reflect higher import prices.

\section{6 Future Distribution system}

During our study we were unable to collect much information on distribution outside the regulated system consisting of RTCs and TFA. We have observed that private shops offer hand tools, hoes and matchets at prices which are TShs $10-20$ above official prices. Excessive black market prices for hand tools are not the order of the day since the March 1983 crackdown, partly because of an improved supply situation. This supports our previous conclusion that the shortage of hand tools is not as desperate as the official demand figures indicate. For ox-equipment, ploughs, shares and other plough spares as well as trek chains, the black market prices are considerably higher than the official prices. This confirms that shortages are more severe for these categories of implements.

Based on the supply of agricultural implements and stocks in the distribution system, our conclusion is that the system appears to function acceptably well for the 1983/84 agricultural season. There is a lot of uncertainty, however, about the future. 
It is clearly stated, both in the Agricultural Development Policy and in the Co-operative Societies' Act, that distribution on the local level of farm inputs, such as implements, shall be handled by the co-operative societies in the future. As soon as the primary societies are functional they will take over the role of the village shops in this area. It appears also to be the long-term policy that co-operative unions will be the regional distributors.

It is not possible for the team to express any opinion on the time-horizon for such transfer of responsibilities. We do, however, foresee a lot of discussion before the matter of regional distributon has been resolved.

The Agricultural Policy states that the Ministry of Agriculture intends to supervise a single body, which will be responsible for national distribution. It has been suggested that a new trading organization should be set up for this purpose. It was not possible for us to ascertain the status of this suggestion, but it appears that for the moment it has been shelved.

BIT appears to work under the assumption that for years to come, RTCs will maintain their role at least in some regions. BIT is also planning to insert AISCO as an intermediatry between UFI and RTCs. AISCO's function would be to finance stocks (there has been some difficulty for UFI to obtain payment from RTCs, but this matter has recently been resolved by $N B C$ extending further credit to UFI), and to arrange transportation to the regions. There is one merit in this proposal (which is presently submitted to the cabinet) as it would involve ZZK's production in the allocation system, which does not seem to be the case at present. On the other hand, adding AISCO in the distribution chain is likely to lead to additional over-head costs charged to the end consumer.

Many studies and official statements (such as the Agricultural Development Policy) point to the efficiency of TFA as a model for the distribution of implements. TFA 
is, however, only established in four regions having only few district outlet. But its advantage is that it is much more consumer-oriented in its sales policies than other organisations. Our discussions also indicated that it is quite possible that certain exceptions may be allowed in the confinement of RTCs, i.e. to enable other organization like RIDEP's to handle certain farm implements.

Our general conclusion as far as distribution is concerned, is that the distribution chain should be as short as possible. We find the confinement system to have limited advantages when shortages are not critical and we are of the opinion that if manufacturers are able to finance distribution, they should be allowed to trade freely with any outlet that provides acceptable service to the consumers. On the other hand, donors should refrain from imposing conditions which introduce specific distribution channels. RIDEPs should be given preferential status to the extent that they are able to get unproportionately large quantities for certain regions. There is an adequate distribution network at present, which should be allowed to develop on the basis of competition between RTCs, TFA and, in the future, the cooperative unions. Such a system has as a natural corrolary, proper market assessments for the most efficient distribution. 


\section{LISTOFREFERENCES}

A. Government of Tanzania Documents

URT/Ministry of Agriculture:

- (1982) Tanzania National Food Strategy. Main report. National Food Strategy project, DSM, June 1982 second draft (Restricted circulation).

- (1983) The Agricultural Policy of Tanzania.

- (1984) Ministry of Agriculture (Kilimo) (1984). Local Manufacture and Availability of Ox-drawn Implements and Improved Hand Tools including other Farm Machinery and Equipment. Screening 1ist. DSM.

URT/Ministry of Industries:

- (1982) Centre for Agricultural Mechanization and Rural Technology (CAMARTEC). Functional Role and Operational Policy, DSM.

URT/Ministry of Culture and Youth:

- (1976) Jembe ni Mali - Kuza Ufundi wa jadi, endeleza nchi yetu, Tanzania Publishing house, DSM.

B. Tanzanian Institutions

SIDO (1983), Project proposals for manufacture of Farm Implements in Singida, DSM.

MEIDA (1983), Capacities within MEIDA for the manufacturing of farm implements ( $4 \mathrm{th}$ November, 1983), DSM.

CAMARTEC (1983), Public Relations brochure, Arusha.

UAC (1982), Uyole Agricultural Centre Agricultural Engineering Research Department, progress report $1981 / 82$, Mbeya.

RDD Survey (1976), Ripoti ya kamati ya uchunguzi wa mahitaji ya Zana za Kilimo, DSM.

C, Consultants' Reports

TISCO (1980), Market Survey of Agricultural Implements i n Tanzania, DSM. Made for NDC. 
TISCO (1983), Farm Implements Plant Mwanza, DSM (Draft report). Made for NDC.

The National Industrial Development Corporation Ltd, India (1979-1980). Ubungo Farm Implements Ltd. Product up-grading study. Made for NDC.

Stehagen - Arefalk (1982), Rehabilitation proposal Farm Implements Tanzania. Made for SIDA.

Kiherile - Hurtig (NDC) (1983), Farming Implements. Made for NDC.

Merryman - Weiler (1982), Input Marketing Study of the Mbeya Region. Mbeya RIDEP Report No 39.

Whitcombe - Miles (1981), The establishment of the Centre for Agricultural Mechanization and Rural Techno$\log \mathrm{y} \cdot$

Croon (1982), Some selected issues in Agricultural Development in Mbeya Region. Mbeya RIDEP Report No 46.

Dagg (1978), FAO/Kilimo Agro-Mechanization Surveyr 1976-78. Made for the Ministry of Agriculture, DSM.

Agrar und Hydrotechnik (1980), Agricultural Development Project. Iringa Region Phase II, 1981-85. Project Dossier, EDF/URT.

Phillips and Zachariah (1980), Strategy and Programme for Developing the Agricultural and Small Industrial Equipment Sectors in Rural Tanzania. Commonwealth Fund for Technical Cooperation, Londoq.

SIDA (1976), Development of Small Industries in Tanzania. Report and programme proposal by a Swedish consultancy team.

UNIDO (1983), Evaluation of Project US/URT/77/03:

"Consolidation of Village Production of Agricultural Implements by Local Blacksmiths". Report from Consultant Mission 21. March to 18 April 1983.

\section{Other Reports}

Mariki (NDC) (1983): Rehabilitation of UFI, DSM 1983. SIDA - Ministry of Industries (1983): Report from the Seventh Annual Joint Industry Sector Review, February $14-28,1983$. 
Wortman (1983), Extension and Training Activities for the 1983/84 season. PMO/RIDEP, Shinyanga.

IFAD (1983): Report of the General Identification Mission to the United Republic of Tanzania (December 1983). (Draft - limited distribution).

FAO (1969): Farm Implements for Arid and Tropical Regions, Rome.

Mäller (1977), Promotion of Rural Implement Manufacture i n Tanzania. UNIDO, Vienna.

College of Agricultural Engineering, Punjab Agricultural University (1983), Briefs on human-powered and animal drawn improved farm equipment. Ludhiana, India.

Kjærby (1983, b), "The Farm Implements Sector for Animal Draught Power in Tanzania". Centre for Development Research Project Papers D.83.15, Copenhagen.

(Draft, limited circulation).

Kienbaum Beratungen (1976), Demonstration Manufacturing Plant Report. UNIDO project TF/RAF/74/009.

Rao (1975), Report on Agricultural Implements and Machinery Production and Maintenance. FAO/UNIDO project URT/74/006/A/OL/12, DSM.

\section{E. Research reports and books}

Chambers (1980), Rapid Rural Appraisal: Rationale and Repertoire. Development Paper No 155, IDS, Sussex.

Collinson (1977), "Diagnosing the need for new technology". In Commonwealth Secretariat (1977): Rural Technology Meet for East, Central and Southern Africa, London.

Dumont (1980), I'Afrique Etranglee, Seuil, Paris.

Havnevik (1980), Economy and Organization in Rufiji District. The Case of Crafts and Extractive Activities. BRALUP Research Paper No 65. University of Dar es $\overline{\text { Salaam. }}$.

Hydén (1980), Beyond Ujamaa in Tanzania, Heinemann, London.

Kiyenze (1981), "Traditional Handicrafts and the Process of Small-Scale Industrialization in Western Bagamoyo", in Jipemoyo. Development and Culture Research 4, 1981. Publication of the Finnish National Commission for UNESCO No 18. 
Kjærby (1983, 1) Problems and Contradictions in the Development of $\mathrm{Ox}-$ cultivation in Tanzania. Research Report No 66, Scandinavian Institute of A frican Studies, Uppsala.

Livingstone (1970), Results of a Rural Survey: The Ownership of Durable Goods in Tanzanian Rural Households and some Implications for Rural Industry. ERB Paper 70.1, University of Dar es Salaam.

MacPherson (1975), First Steps in Village Mechanization. Tanzanian Publishing House, Dar es Salaam.

Miller (1980), Liquidation or Consolidation of Indigenous Technology. Development Reserach Series No 1. Aalborg University Press.

Perkins (1978), Small Scale Industry in Rukwa Region: Survey, Analysis and Recommendations. Bralup Research Report No 28. University of Dar es Salaam.

Starkey (1981), Farming with Work Oxen in Sierra Leone. Ministry of Agriculture \& Forestry, Government Printing Department, Freetown.

Williams (1981), The World Bank and the Peasant Problem. In Heyer, Roberts \& Williams (eds) (1981): Rural Development in Tropical Africa. MacMillan, London. 
The following are the statements in the Agricultural Policy, which apply to this study:

The policy states (p. 8) that the dominant mode of agriculture in Tanzania is individual peasant production. But, "Farming in the villages needs modernization; in the majority of cases it is still carried on according to traditional practices, without taking advantage of modern knowledge or modern tools. The jembe, the panga, and the shoka - all hand tools still dominate production methods now". The policy goes on to state; (p. 11): "Increasing the output and the efficiency of agricultural production in the villages is central to increased national output".

The strategies adopted to achieve this are formulated on p. 18 and include: "a) Increased production of both staple food crops and appropriate market crops by expanded acreage where this is feasible with existing or available tools, and by increased yields through the adoption of modern methods of crop or animal husbandry. The move from hand tools to more advanced animal-drawn implements must be phased in with any expanded acreage".

"c) The Introduction of improved agricultural tools and implements for use on the Village and the Block and Homestead farms, with special reference to the use of animal-drawn implements, and a move to the tractor or other mechanisation after management care, and servicing problems have been planned for".

On Crop Production the following is stated (p. 33):

"The immediate objectives will be the achievement of national food self-sufficency, as well as sufficient agricultural output to meet the expanding needs of our industrial sector, and to provide increased earnings from export crops". ..." But nothing can alter the fact that the major task is to move the peasant farmers from reliance on hand tools to the use of animal or mechanically assisted implements and at the same time to convince them that settled agriculture (as distinct from the pre-villagisation pattern of shifting agriculture) demands improved husbandry practices".

A further reason for shifting from hand tools is given in p. 38: "it is to reduce the back-breaking labour 
involved in dependence on the hand-hoe that the Government intends to put so much emphasis on the use of animal or other power assisted implements".

The Agricultural policy goes on to state Government's support for Agricultural Research Activities, as well as for extension activities, to enable extension workers opportunity to "give or arrange training in the use of new techniques and improved implements".

Central to the present study are the statements made under the heading Agricultural Mechanisation:

"52. Agricultural. machinery and equipment will be imported only on the basis of technical evaluation and testing done under the close supervision of the Ministry of Agriculture. Local manufacture, especially of hand tools and animal powered implements, will be stepped up". ... "The testing of locally-made prototypes and of manufactured items, will, however, revert to the control of the Ministry of Agriculture.

53. The demand for improved hand tools and animal-drawn implements is currently growing very fast, and the Government intends to make every effort to expand production of such goods. In addition to the national factories in Dar es Salaam and Mbeya (an possibily others later), SIDO will be urged to be more active in helping the establishment of local manufacturing.

District Development Corporations will be urged to participate in this work, and co-operative and small private producers also have a role to play. The objective is to have a 11 these production items easily available for purchase by villages and peasants and to develop repair facilities in the villages themselves.

54. Where cattle and/or donkeys are available, the use of animals for agricultural work will be encouraged and ox or donkey carts for internal village and for local transportation will also be emphasized. Furher, it is intended gradually to introduce these animals into new parts of the country, together with the appropriate technical packages which will enable villages to look after them and get maximum benefit from them, Thus, while the production of animal ploughs will be increas ed and their use promoted, it is also intended to extend the range of animal-drawn agricultural implements to cover the work of harrowing, planting, and weeding, Ox and donkey carts will be promoted to deal with problems of collecting and transporting manure to the fields, of collecting firewood, of moving crops from the fields to the village stores, etc. Such carts will reduce the physical burdens of peasants and 
village workers, and also make possible operations necessary for good husbandry which are not practicable while a 11 goods are carried on the heads or backs of women and men. Animal transportation within the village is also more economic than dependence on lorries or tractors, quite apart from the frequent shortage of diesel fuel".

A pivotal aspect in trying to assist farmers in improving their production is the Farm Input Supply and Delivery System. In this regard the agricultural policy states:

"75. Thedelivery of agricultural inputs and equipment at the right time, in the required quantities, and at lowest possible costs, is an essential element in any plan to increase output. The following are among the measures which will be taken as rapidly as possible to ensure that these goods are available when the farmer needs them:

a) On the basis of information collected from the users, the Ministry of Agriculture will annually produce a calendar showing the type and quantity of inputs needed in the different regions, and giving a distribution delivery time-table for a 11 levels. The Ministry will also co-ordinate and monitor the supply and distribution of agricultural inputs, and of agricultural implements of a 11 types.

b) A single body under the supervision of the Ministry of Agriculture will have the responsibility for seeing that all agricultural inputs are made available to the farmers at convenient places. It will deal with plant and crop protection chemicals, seeds, irrigation pumps, fencing wires, fertilizers, animal-powered implements and carts, hand tools, and all other forms of goods required by the farmer in the course of efficient production. T.F.A. will be taken as a model. The new body will have zonal depots which will link up with Cooperative Unions, as well as with the Farmers' Service Centres which the Company will itself be responsible for opening and running at strategic centres.

c) Tanzanian manufacturers and/or suppliers (e.g., TANSEED) of agricultural inputs will be responsible for financing the distribution of the goods to regional level. They may sell through the new Agricultural Supplies Company or direct to Co-operative Unions and large commercial farms.

d) Co-operative unions will be responsible for distribution downwards from the regional level and for 
delivering the inputs to the peasants and small farmers through Primary Co-operative Societies and/or village shops.

e) The work of distributing and financing agricultural inputs will be separated". 
After a short introductory visit to the Regional Development Director (RDD, now Regional Executive Director, RED) discussions were held with the Regional Agricultural Development Officer (RADO), often with his staff present, e.g., District Agricultural Development Of $f_{-}-$ cers (DADO's and Regional or District Mechanization Officers (RMO's or DMO's). It was often found advantageous first to interview managers of Regional Trading Companies (RTC's) and Tanganynika Farmers Association (TFA) to record marketing statistics, visit the godowns for inspection of implements and to discuss users' preferences, regional requirements and demand for farm implements. Similar discussions were held with RADO and DADO staff, and general information was obtained on soil conditions, lifespan and wear \& tear of implements, household requirements, crop or local specific tools, usage pattern, etc. Recent census statistics on ox-equipment were recorded and efforts to introduce improved implements were discussed. Regional SIDO offices were visited to discuss small-scale industries and rural blacksmiths, including identifying villages with blacksmiths.

As regards the selection of districts and villages for the survey, we were constrained by shortage of petrol and time, but we did manage to get off the main roads and into oytlying areas and districts in Mwanza, Arusha, Iringa and Mbeya, and to some extent also in Singida. Still there is, we believe, an upward bias in the selection of villages in the sense that probably as many as $50 \%$ of these were near main roads, near Divisional administrative centres or had rural blacksmiths - since we had to combine visits to blacksmiths with interviewing farmers. Considering these factors, including relatively favourable transport opportunities for road-side villages, the conditions of the recorded tool inventories, both in qualitative and quantitative terms, was no doubt above average.

If sufficient time and fuel is available, a more appropriate method of selection would be random selection of districts and of district villages. Short of this time-consuming method, somebody with a "free hand" could point out villages on a map with shaded eyes, rather than being guided by people or officials with local knowledge, which by its very nature tends to be biased. 
A RADO, DADO or Planning Office member of staff accompanied us to guide us and introduce us to the village leadership. In some cases divisional and ward officials were called on as well. Another expected bias cropped up when households were selected. Although we took time and effort to explainthat we wanted to interview

average farmers, village leaders had a tendency to find above average farmers, sometimes to such an extent that we declined to interview them. And sometimes it did not help even when we pointed out, that above average farmers would tend to show tool inventories in a better condition, which would make us conclude that there was no problem in terms of farm implements, and that there was consequently no need for support to increased production and supply.

The bias was also made worse by our own need for interviewing plough-owning households. On the other hand, there is often a higher intensity in the use of farm implements in households with larger averages, so that the rate of wearing is increased. However, during almost all interviews, a number of neighbouring farmers were present, and consensus was sought on average tool inventory, usage pattern, life span and household requirements.

Some village leaders did, however, accept our selection criteria and in Rufiji, Singida, Nzega, Hanang, Moshi Rural, Njombe and Tukuyu districts we did get average and a few below average household interviews - which helps to get an idea of the range of inventoriers between above and below average household. At a 11 levels of our visits and at all household interviews, the purpose of the study was explained in detail. The interviews were conducted without an interpreter in

Swahili. In some cases the wives were interviewed and in several cases they were present and were either asked questions on their views, or they joined in the discussions themselves.

After the obligatory, introductory explanation, we asked for all tools and implements to be brought out for inspection, even old and unused ones - which in some instances prompted neighbours to bring theirs as well. We then started out with the biggest or newest hoe, checked its brand name, weight and make (whether round-eyed, tanged or blacksmith-made), its age or when it was bought, for how much and where. The order of the questions asked is important here, and the prices were used as a check against age or the place of purchase, whether an RTC village shop (official price) or a private shop (free or black market price). Year, reason for, place and cost or repairs were asked. The state of wear and tear was either measured with tape or assessed. It is an advantage to know the length and width of 
various implements beforehand. Finally, questions were asked about who used it in the household, when it was passed over to a more junior member, and for which farm activities is was used.

The whole procedure, which takes about 5 minutes for one implement, was repeated for a 11 implements, although very old tools were recorded in less detail. We believe that we did not see all harvesting knives found in the household. The farmers generally have very sharp memory on age of tools, purchase prices, etc. As regards ploughs we also asked about whether and when various parts had been replaced.

Finally, average crops grown, cultivation rate per plough and the number of wives in the household were recorded. It would be even better to record the number of adult ablebodied persons. The whole interview generally took $1-1.5$ hours, depending on the group discussion - to which should be added walking and

transport time.

Six rural blacksmith sites, worked by groups or individual smiths were visited. Their tool inventories were inspected and recorded as well, including implements undergoing manufacturing or repair work. Questions were asked about origin of material used, price, whether the tools were self-made or purchased, number of craftsmen and apprentices active at the site, time used to obtain raw material to produce common implements and to market the products, including their price.

The main constraint in the trade was neither marketing nor the tool inventory, with the exception of files. The most severe problem was the increasing difficulty in finding raw material. An attempt was made to assess prices at which the blacksmiths would be prepared to purchase suitable pieces of raw material, and whether such a process of production would be economical. However, these are hypothetical questions - especially for old blacksmiths - and the answers given cannot always be taken at face value, although many of them did seem realistic.

Three Divisional RTC outlets, 5 village shops, 4 private shops and 7 regional or divisional market places were visited to check out on the formal and informal marketing of farm implements, consumer preferences, prices, shortages, etc. In most villages questions on this were also addressed to farmers and village secretaries. As regards RTC outlets and villages shops, stocks or the lack of them were checked, and shop purchases, sales, prices, margin and liquidity position was recorded. The position of village shops in terms of farm implements distribution is generally very poor and a constraint on supply to the villages. 
As we are concerned in this report with supplying Tanzanian peasants with their requirements of farm implements at the lowest possible cost, we must also consider importation as an alternative to local production.

Before the establishment of UFI all farm implements, with some few exceptions (e.g., maize mills) and excluding blacksmith-produced implements, were imported. Importation had a negative effect on the volumes produced by blacksmiths.

The establishment of local production units was based more on the policy of self-reliance, than on proper evaluation of the cost-effectiveness of such production in comparison to imports. This resulted, as reported by Phillips and Zachariah and IFAD, in manufacture running at a loss. UFI's profit margin on imported products subsidized local manufacture. Phillips and Zachariah concluded that comparative advantages were to be found in the manufacture of bulky items, such as grain mills, and in assembly of semi-finished products (e.g., ploughs) rather than in mass-production of items like hoes, axes and matchets. At the achieved production levels at UFI, Phillips and Zachariah did not consider local production justified even if shadow prices were used. IFAD, applying the conventional 15\% local preference margin, came to the same conclusion.

These two reports base their conclusions on the following 1978 figures:

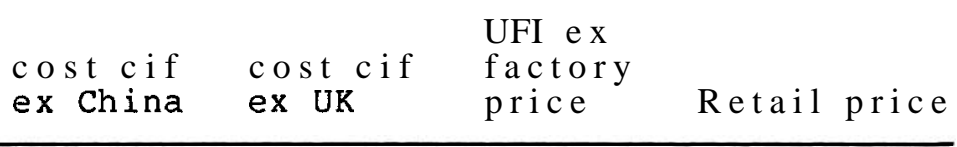

$31 b$

r/e hoe TShs 15.39 TShs 18.49 TShs 19.25 TShs 25.10

For comparative purposes, we show below the 1983

figures for the same item: 


\begin{tabular}{lllllll} 
& & & & ZZK & Ex \\
cost cif cost cif & $\begin{array}{l}\text { UFI } \\
\text { factory } \\
\text { ex India ex UK }\end{array}$ & $\begin{array}{l}\text { turing } \\
\text { cost }\end{array}$ & $\begin{array}{l}\text { fac- } \\
\text { tory } \\
\text { price }\end{array}$ & $\begin{array}{l}\text { Retail } \\
\text { price }\end{array}$ \\
\hline $\begin{array}{l}3 \mathrm{lb} \\
\mathrm{r} / \mathrm{e} \text { hoe }\end{array}$ & TShs & TShs & TShs & TShs & TShs & TShs \\
\end{tabular}

(We do not have access to a recent quote from PRC, but it can be assumed that it will be slightly less (1-2 TShs) than the Indian price.)

We have based the comparison on costings provided to us by UFI and ZZK. (As far as UFI is concerned, the figure is in line also with the Stehagen report.)

We can thus conclude that as far as this particular item is concerned, UFI is still not competitive with world market prices, and that a margin of $25 \%$ has to be accorded to make it competitive. However, it must be recognized that the costs to UFI, and in much higher degree to ZZK, are based on low capacity utilization levels, and furthermore that the overvalued Tanzanian currency works against local production in such a comparison. (This would affect a shadow price computation.)

A higher rate of capacity utilization would in our view justify a decision to continue local production of hoes.

We do not have comparative figures for axes, the import cost (cif) of which is presently TShs 36, compared to a maximum ex. factory price of TShs 65.58 .

The import cost comparison made for matchets indicated that Cotex costs (as submitted to the national Price Commissioner) were $189 \%$ above the quoted cif price. A sizeable reduction in costs would thus be necessary to make cotex competitive with imports.

On the other hand, if raw materials are assumed to be the main foreign currency cost (equipment etc being regarded as "sunk" costs), we find that local manufacture represents a considerable foreign exchange saving:

\begin{tabular}{lllll} 
& import & raw material costs & \\
& cif & UFI & ZZK & Cotex \\
\hline 3 lb & & & & \\
r/e hoe & 28 & 14.90 & 22.48
\end{tabular}

$16 "$ matchet 14.62

10.30 
Ploughs are a slightly different matter. It has been stated to us by NDC and UFI that it is cheaper to import semi-finished ploughs from India, than to manufacture the ploughs from raw materials as the Indian government subsidizes Indian manufacturers. The cost comparison, based on UFI December 1983 figures, does not bear this statement out. Locally manufactured ploughs would be $18 \%$ cheaper in raw materials, and $19 \%$ more expensive in manufacturing cost giving total direct costs which are the same (within Tshs 3 ) for the two ploughs. It appears to us that this may be a shifting of manufacturing charges to the semi-finished plough.

The following figures have been collected on the volumes of importation. The 1979 figures are quoted from the TISCO market survey 1980, the remaining figures are provided by UFI. The 1983 figure is a planned figure with deductions made in respect of certain orders that will not be fulfilled.

Importation Volumes (thousand pcs) $\begin{array}{lllll}1979 & 1980 & 1981 & 1982 & 1983\end{array}$

\begin{tabular}{lrcrcc}
\hline Hoes & 2231 & 959 & 195 & 2019 & 728 \\
Axes & 292 & 106 & 36 & 82 & - \\
Matchets & 1226 & 715 & 175 & 668 & - \\
Ploughs & - & 3.6 & - & 20.7 & 35.51 \\
Plough shares & n/a & - & - & 30 & 130
\end{tabular}

1) finished + semi-finished

Until UFI and ZZK have been able to rehabilitate their operations to the output levels suggested, which may take 1 to 2 years, there is a demand gap, which will have to be met by imports of hoes, ploughs and plough spare parts.

Whether local manufacture of axes, shovels, rakes, etc., is justified from cost efficiency and saving foreign exchange points of view remains to be demonstrated, and should in each case be demonstrated before funds are expended for equipment and raw materials for such production. 
This book deals with major issues related to hand- and ox-drawn farm implements for different farming systems and ecological areas in Tanzania, It is based on field visits in some ten Tanzanian regions during the second half of 1983, the most intense crisis period in Tanzania. Hence the study may shed some light on the relative importance of problems related to production and distribution of basic farm implements as an element of the crisis.

The study includes a survey of the types of farm implements used and preferred by Tanzanian peasants. The structure and conditions of the different levels of production and repair of farm implements in Tanzania, village blacksmiths, small-, mediumand large scale production, are investigated.

Introduction and development of new farm implements are analysed through the different existing approaches to technology dissemination examplified by case studies of among other institutions, CAMARTEC, Uyole Agricultural Centre and the Regional Oxenisation Project in Iringa. It is found that most technology development is rather irrelevant to peasant needs. The argument is raised that such development must be conditioned on a close relation between the users and the assisting bodies. Ideas are put forward as to how to improve relevant technology development for small scale farmers.

The field survey undertaken also provides the basis for establishing demand estimates for most hand- and ox-drawn implements in Tanzania for 1983184 and the years ahead. The structure and functioning of the distribution system for farm implements are also analysed.

The study is concerned about ways and means to assist and improve critical activities of peasant fanning in Tanzania, including supply of relevant implements, raw materials for local village production and repair of implements, and how to improve village connected transport through increased production of good quality ox-carts.

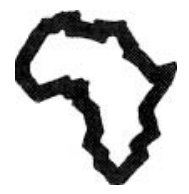

Published by

Scandinavian Institute of African Studies

P O Box 1703

S-751 47 UPPSALA, Sweden

ISBN 91-7106-290. 